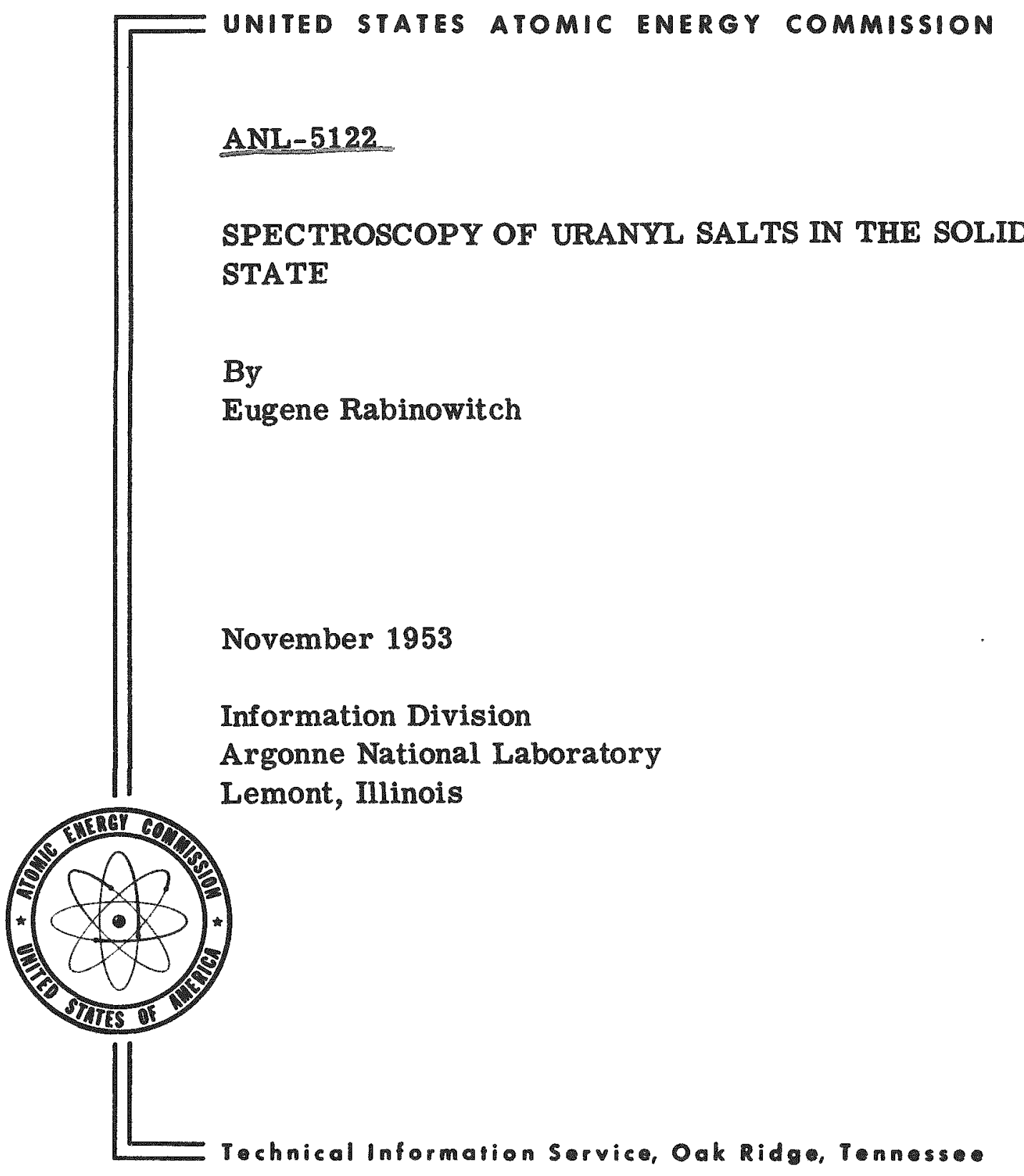

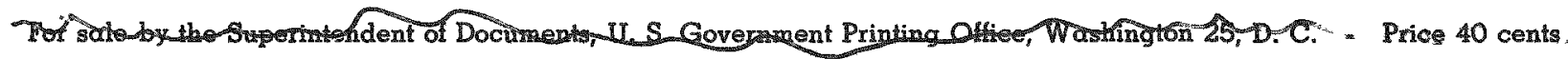




\section{DISCLAIMER}

This report was prepared as an account of work sponsored by an agency of the United States Government. Neither the United States Government nor any agency Thereof, nor any of their employees, makes any warranty, express or implied, or assumes any legal liability or responsibility for the accuracy, completeness, or usefulness of any information, apparatus, product, or process disclosed, or represents that its use would not infringe privately owned rights. Reference herein to any specific commercial product, process, or service by trade name, trademark, manufacturer, or otherwise does not necessarily constitute or imply its endorsement, recommendation, or favoring by the United States Government or any agency thereof. The views and opinions of authors expressed herein do not necessarily state or reflect those of the United States Government or any agency thereof. 


\section{DISCLAIMER}

Portions of this document may be illegible in electronic image products. Images are produced from the best available original document. 
Sub ject Category, CHEMISTIRY.

Operated by the University of Chicago for the U. S. Atomic Jhergy Comission under Contract No. W-31-109-eng-38.

The Atomic Energy Commission makes no representation or warranty as to the accuracy or usefulness of the information or statements contained in this report, or that the use of any information, apparatus, method or process disclosed in this report may not infringe privately-owned rights. The Commission assumes no liability with respect to the use of, or for damages resulting from the use of any information, apparatus, method or process disclosed in this report.

This report has been reproduced directly fram the best avallablo copy.

Reproduction of this information is encoureged by the United States Atomic Bnergy Commission. Arrangements for your republication of this document in whole or in part should be made with the author and the organization he represents.

Issuance of this document does not constitute authority for declassification of classifled material of the same or similar content and title by the same authors. 


\section{TABLE OF CONTENTS}

Page

1. Introduction. Qualitative Interpretation of the

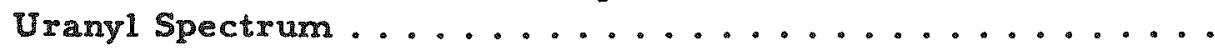

2. Studies of Fluorescence and Absorption Spectra of Solid Uranyl Salts (except those of Dieke and Duncan) .........

2.1 Band Measurements and Empirical Classification ......

2.2 Term Analysis ......................... 14

2.3 Fluorescence Spectrum in Relation to Exciting Light.... 16

3. Infrared Spectrum of Uranyl Salt Crystals ........... 18

4. Analysis of Uranyl Spectrum by Dieke and co-workers . . . . 26

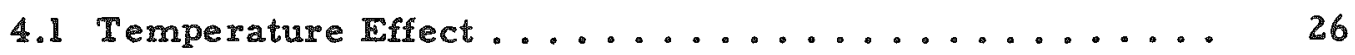

4.2 Analysis of Uranyl Spectrum: Electronic States . . . . . 29

4.3 Analysis of Uranyl Spectrum: Dichroism, the "Yellow" and the "White" Absorption Spectrum ........... 29

4.4 Analysis of Uranyl Spectrum: Vibrational Fequencies

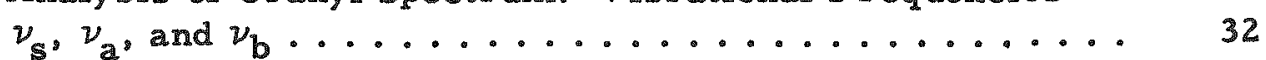

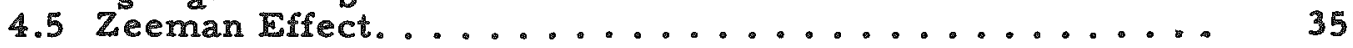

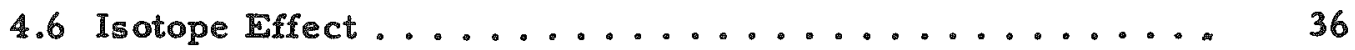

4.7 Intensity Studies: Life Time of Excited States ....... 39

5. Additional Spectroscopic Data on Some Uranyl Salts....... 41

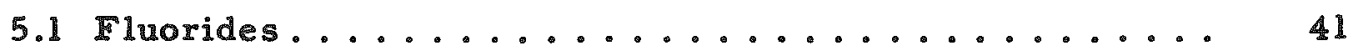

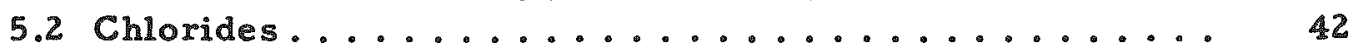

5.3 Uranyl Nitrate and Double Nitrates............. 45

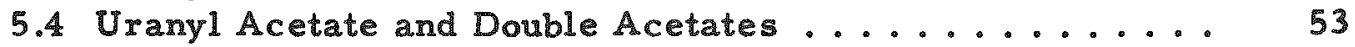

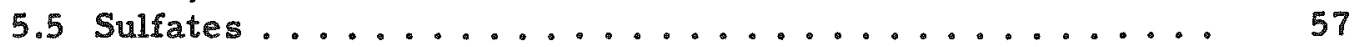

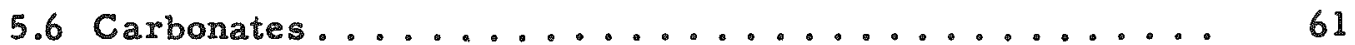

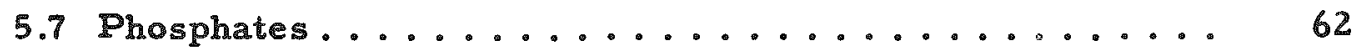

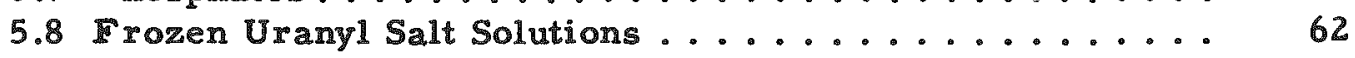

5.9 Miscellaneous Observations.................. 71 


\title{
SPECTROSCOPY OF URANYL SALTS IN THE SOLID STATE
}

by

\author{
Eugene Rabinowitch
}

\section{INTRODUCTION. QUALITATIVE INTERPRETATION OF THE URANYL SPECTRUM}

The divalent uranyl ion, $\mathrm{UO}_{2}^{++}$, can be considered as an intermediate product of hydrolysis of the ion $\mathrm{U}^{+6}: \mathrm{U}^{+6}+4 \mathrm{OH}^{-}-\mathrm{UO}_{2}^{++}+2 \mathrm{H}_{2} \mathrm{O}$; an intermediate, however, that possesses a remarkably wide range of stability. The absorption and fluorescence bands of most solid or dissolved uranyl salts in the visible and near ultraviolet belong to this ion, and are therefore similar in their general pattern, except for minor changes in position, width, and intensity of the individual bands caused by the electrical fields of the surrounding anions (in crystals or ionic complexes), or water dipoles (in crystal hydrates, or aqueous solutions).

In addition to the absorption and emission bands due to electronic excitation within the uranyl ion, uranyl compounds could have also spectral bands due to excitation of the associated anions (or molecules), or to the transfer of electrons from these anions or molecules to the uranyl ions ("electron affinity," or - more correctly - "electron transfer" spectra). With the exception of salts of colored anions (such as chromate), the electronic bands of the last-named types lie, however, at much shorter waves than the absorption bands due to excitation of low-lying electronic levels within the uranyl ion itself.

In absorption, most solid or dissolved uranyl salts show a regular sequence of broad bands (or rather, band groups, as revealed by their resolution into narrow bands or "lines" at low temperatures) covering the blue, violet, and near-ultraviolet region; in fluorescence, a similar sequence extends from the blue into the green and yellow part of the spectrum.

$X-r a y$ and electron diffraction studies indicate that in solid uranyl salts, the uranyl ion is linear and symmetric, with a U-O distance of about 1.9 A (cf., Dieke and Duncan, 1949, Chap. 2). Such a linear group has three fundamental vibrations:

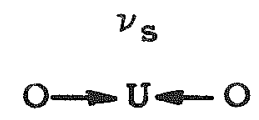

Symmetric bond vibration

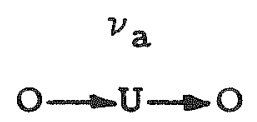

Antisymmetric bond vibration

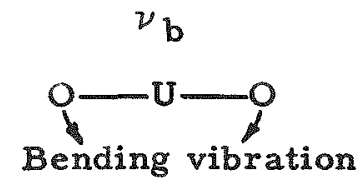


The bending vibration, $\nu_{b}$, is degenerate (since it can occur in two mutually perpendicular planes): it should therefore split into two components when the ion is placed into an external field of force (except when this field is directed along the $\mathrm{O}-\mathrm{U}-\mathrm{O}$ axis). The excitation of the symmetric vibration, $\nu_{\mathrm{g}}$, has no dipole moment change associated with it, and should therefore be absent from the infrared absorption spectrum. In the Raman spectrum, inversely, only the symmetric vibration, $\nu_{s}$, should occur. All three vibram tions are permitted in combination with changes in electronic structure, i.e., in visible and ultraviolet absorption and emission bands.

These expectations are not confirmed by experience: the frequency $860 \mathrm{~cm}^{-1}$, which should be $\nu_{\mathrm{s}}$ in the linear model (cf., p.32), is represented albeit weakly - in the infrared absorption spectrum, and the frequency $210 \mathrm{~cm}^{-1}$, corresponding to $\nu_{\mathrm{b}}$ in the linear model, is present, with moderate intensity, in the Raman spectrum of uranyl salt solution.

The exclusion rules for the infrared and Raman spectrum are, however, strictly valid only for free molecules (or molecular jons) while what is observed in practice are the spectra of uranyl ions in the electric field of anions or solvent dipoles. Under these conditions, "prohibited" transitions are not impossible, although they remain comparatively improbable and can be expected to give rise to lines which are weaker than those due to permitted transitions.

An alternative explanation - that the ion $\mathrm{UO}_{2}^{+}$is angular - has been advanced, specifically in application to solutions (to avoid contradiction with $X-r a y$ data which definitely indicate linear structure in crystals). However, at present it seems most likely that the ion UOt remains lineax in the solvated state, but that solvation weakens the exclusion rules for the Raman spectrum so as to bring out the $\nu_{b}$ frequency.

If the three vibrations are assumed to be harmonic, with the elastic force constants $f$ (in the direction of the $U-O$ bond) and $d$ (in the direction perpendicular to this bond), their frequencies must be:

$$
\begin{aligned}
\nu_{\mathrm{s}}(\text { symmetric }) & =\sqrt{\frac{f}{m_{0}}} \\
\nu_{\mathrm{a}}(\text { antisymmetric }) & =\sqrt{\frac{f}{m_{0}}\left(1+\frac{2 m_{0}}{m_{u}}\right)}=\nu_{s} \sqrt{1+\frac{2 m_{0}}{m_{u}}} \\
\nu_{b}(\text { bending }) & =\sqrt{\frac{2 d}{f}\left(1+\frac{2 m_{0}}{m_{u}}\right)}=\nu_{a} \frac{\sqrt{\frac{2 d}{f}}}{}
\end{aligned}
$$

where $m_{0}$ and $m_{u}$ are the masses of the atoms of oxygen and uranium, respectively. 
Since $m_{u} \approx 15 \mathrm{~m}_{0}$, the antisymmetric vibration frequency must be about $6 \%$ higher than the symmetric one. The bending frequency, on the other hand, can be expected to be considerably lower than the other two fundamental frequencies (because of the relation $\mathrm{d}<<\mathrm{f}$ ). We will see below that the values of $\nu_{\mathrm{s}}$ and $\nu_{\mathrm{a}}$ for uranyl salts (in the stable electronic state) are about 880 and $920 \mathrm{~cm}^{-1}$ respectively, while $\nu_{b}$ appears to be of the order of $200 \mathrm{~cm}^{-1}$ (although the identification of this vibration is not yet quite certain).

The existence of two fundamental frequencies, $\nu_{\mathrm{s}}$ and $\nu_{\mathrm{a}}$, of approximately equal magnitude, could lead to a spectrum of considerable complexity; instead, the absorption spectra (and to an even greater extent the fluorescence spectra) of uranyl compounds appear to be rather simple, consisting of a single series of approximately equidistant band groups. This indicates that only one type of vibration is so strongly coupled with the electronic transition that several quanta of this vibration (up to 8 , as indicated by the number of band groups in the spectrum) can be excited in conjunction with this transition. We will see below that this is the symmetric bond vibration. Of the antisymmetric and the bending vibration, on the other hand, apparently not more than one quantum can be excited in conjunction with the transition from the lowest excited electronic state to the ground state (which gives rise to the fluorescence spectrum at low temperatures). In the reverse transition - from the ground electronic state to the excited electronic state - one or two quanta of the vibrations $\nu_{a}^{*}$ and $\nu_{b}^{*}$ can be excited (astexisks denote the excited electronic state). A further complication arises in the absorption spectrum from the fact that apparently not one but several electronic states of the $\mathrm{UO}_{2}^{++}$ion can be reached by the absorption of visible or near-ultraviolet light, while only the lowest one of these states contributes to fluorescence.

That the one vibration strongly coupled with the electronic transition, must be the symmetric bond vibration, $\nu_{\mathrm{s}}$, follows from the Franck-Condon principle. According to the latter, the electronic transition is so fast that it leaves the nuclei in the positions and with the velocities close to those they had before the transition; if the molecule in the new electronic state cannot have these co-ordinates without a change in the number of vibrational quanta, the acquisition (or loss) of the se quanta will follow the electronic transition. In the case of the symmetric bond vibration in the linear $\mathrm{O}-\mathrm{U}-\mathrm{O}$ system, such a change is to be expected, because electronic excitation changes the strength of the $\mathrm{U}-\mathrm{O}$ bond, and thus also the $\mathrm{U}-\mathrm{O}$ distance of minimum potential energy.

If, as is likely, the equilibrium distance is wider in the electronically excited state than in the ground state, the oxygen atoms will find themselves, after the emission of a quantum of fluorescent light, too far apart and the system will begin to vibrate like a stretched and released spring.

At first one may think that the same consideration should apply also to the antisymmetric vibration; but while in the case of the symmetric bond 
vibration, the excess potential energy of the stretched $0.0-0$ system is decreased when two oxygen atoms move simultaneously towards the $U$ atom, no similar approach to equilibrium is possible by the excitation of the antisymmetric vibration, since in it the two oxygen atoms move in the same direction = one toward the uranium atom, and the other away from it. Therefore, in the first approximation (i.e., assuming an elastic force), antisymmetric vibrations should not be excited at all as a consequence of electronic transition; the actually observed excitation of a single quantum of this vibration in fluorescence must be attributed to deviation of the bond from elasticity. This deviation appears to be stronger in the excited electronic state, since two quanta of antisymmetric vibration can be acquired in absorption.

The bending vibration, $\nu_{b}$, is also relatively little affected by the excitation of one of the bonding electrons in the $\mathrm{O}-\mathrm{U}-\mathrm{O}$ system. A much stronger excitation of this vibration could be expected if the uranyl ion were non-linear in the excited electronic state.

To sum up, the (low-temperature) fluorescence spectrum of the uranyl ion can be represented by the equation:

$$
\nu_{\mathbf{f} 1}=\nu_{\mathbf{F}}-\mathbf{n}_{\mathbf{s}} \nu_{\mathbf{s}}-\mathbf{n}_{\mathbf{a}} \nu_{\mathbf{a}}-\mathbf{n}_{\mathbf{b}} \nu_{\mathbf{b}}-\Sigma \mathbf{n}_{\mathbf{i}} \nu_{\mathbf{i}}
$$

where $\nu_{F}$ is the pure electronic transition ("resonance transition"), and $\mathrm{n}_{\mathrm{s}}(=0$ to 8$)$ the number of quanta of the symmetric vibration excited simultaneously with the loss of the electronic quantum, $h \nu_{f}$. The coefficients $n_{a}$ and $n_{b}$ are either 0 or 1 . The term $\Sigma n_{i} \nu$ refers to vibrations of the as sociated anions ( $\operatorname{such}$ as $\mathrm{NO}_{3}^{-}$), water molecules, or the crystal as a whole, which too can be coupled with the electronic transition - either directly, or more likely, through the intermediary of the fundamental vibrations in the O-U $-O$ system. The low-temperature absorption spectrum of the uranyl ion can be similarly represented by the equation:

$$
\nu_{a b s}=\nu_{E}+n_{s} \nu_{s}^{*}+n_{a} \nu_{a}^{*}+n_{b} \nu_{b}^{*}+\Sigma n_{i} \nu_{i}
$$

where $\nu_{\mathrm{E}}$ can be equal either to $\nu_{\mathrm{F}}$ or to the excitation frequency of some higher electronic term of the $\mathrm{UO}_{2}^{++}$ion. In this case, too, $\mathbf{n}_{\mathfrak{s}}=0$ to 8 , and $n_{a}$ and $n_{b}$ can have the values 0,1 or 2 .

Figures $1 \mathrm{~A}$ and $\mathrm{B}$ are simplified term schemes of the low-temperature fluorescence and absorption spectra of the uranyl ion, respectively. Each arrow corresponds to a band group with a common value of $n_{\mathrm{s}}$. A second electronic level, $M$, is indicated in Figure $1 B$, in addition to the lowest level, $F$, in which the low temperature fluorescence spectrum originates.

The sub-levels due to the vibrational frequencies $\nu_{a}$ and $\nu_{b}$ are not

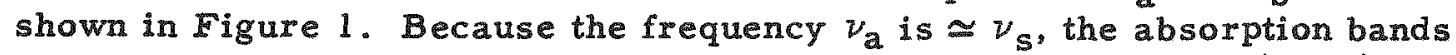
$\nu_{E}+n \nu_{s}+\nu_{a}$ will be located among the bands of the group $\nu_{E}+(n+1) \nu_{s}$; 


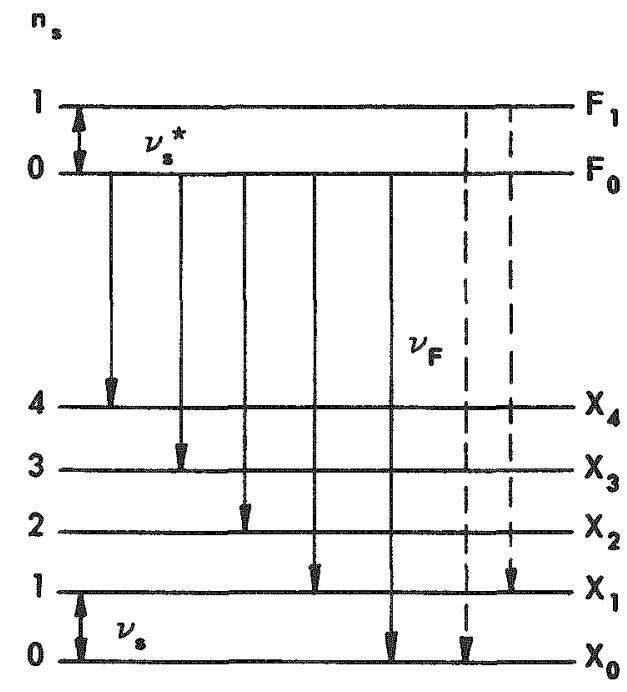

Fluorescence Spectrum

A

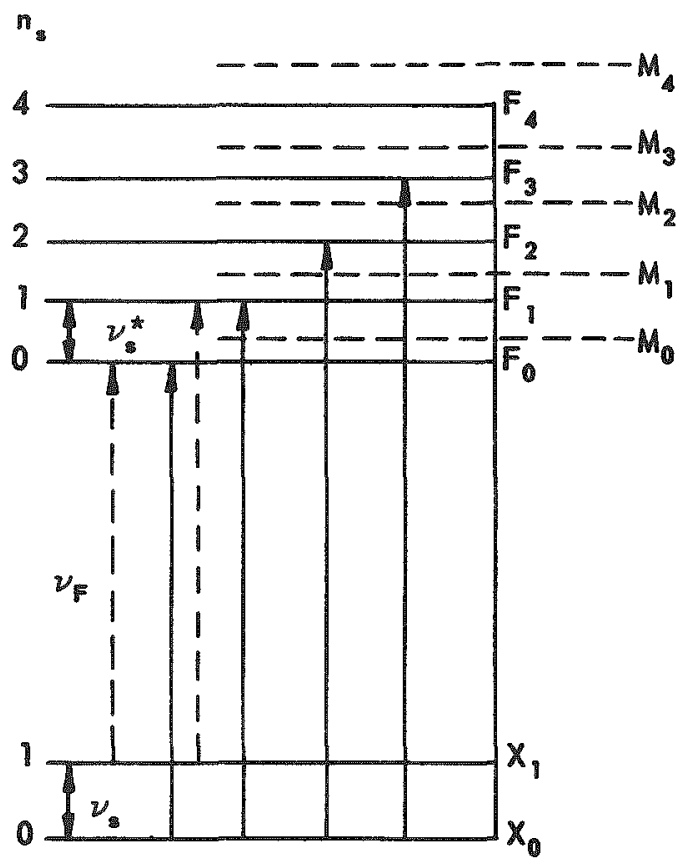

Absorption Spectrum B

Figure I

TERM SCHEMAS OF FLUORESCENCE AND ABSORPTION.

$\nu_{F}$ IS THE RESONANCE FREQUENCY.

DOTTED ARROWS INDICATE ANTI-STOKES BANDS. 
the fluorescence bands among those of the group $\nu_{F}-(n+1) \nu_{s}$. Thus, the empirical definition of a band group as comprising bands situated close together (and fusing into a single, broad band at higher temperatures), does not quite correspond to the theoretical definition, based on equations (4) and (5), according to which a band group is formed by bands having a common value of $\mathrm{n}_{\mathrm{g}}$. Instead, one (or several) components of each theoretical group must be sought within the neighboring empirical group (on the red edge of the main group in fluorescence, and near the violet edge of this group in absorption).

At low temperatures only the band group $x_{0}=F_{0}$, and at very low temperatures only one component of this group, the "resonance" line (involving transition between two levels in which all vibrational quantum numbers are zero), can appear in both absorption and fluorescence. At higher temperatures when the strongest "anti-Stokes" band groups $\left(F_{1} \rightleftharpoons X_{1}, F_{1} \rightarrow X_{0}\right.$ and $\mathrm{X}_{1}-F_{0}$ in Figure 1) have made their appeaxance in the spectrum, as many as four band groups of the absorption spectrum can overlap with groups of the fluorescence spectrum (cf., Figure 2). However, since the difference between $\nu_{\mathrm{s}}$ and $\nu_{\mathrm{g}}$ is small, the band $\mathrm{groups} \mathrm{F}_{0} \rightarrow \mathrm{X}_{0}$ and $F_{1} \rightarrow \mathrm{X}_{1}$ may appear as a single group; superficial observation will then suggest that the absorption spectrum and the fluorescence spectrum have three bands in common (ci., Table 1 ).

Higher electronic levels, such as M (Figure 1), could also contribute "anti-Stokes" components to the fluorescence spectrum.

At very low temperatures many uranyl bands are as sharp as lines in the iron arc spectrum (cf., Figures 6 and 7 ). This shows that in the uranyl ion, similarly to the ions of the rare earths, electronic transitions are so effectively "shielded" that no low-frequency vibrations (in the solvation sphere, or in the crystalline lattice as a whole) are excited (or lost) when the ion changes its electronic state. Because of the triatomic structure of the group [OUO] $]^{+t}$, the spectrum of the uranyl ion differs from those of the rare earth ions by the possible co-excitation (or loss) of vibrational quanta in this group; and the complication caused by these quanta becomes greater with increasing temperature, when vibrating $\mathrm{UO}_{2}^{++}$ions appear in thermal equilibrium with the non-vibrating ones.

However, the broadening of the sharp low-temperature bands of $\mathrm{UO}_{2}$, and their fusion into broad bands, is observed much earlier and is much more extensive (cf., Figures 6 and 7 ) than could be explained by mere superposition, upon the electronic transition, of the vibrational frequencies of the ion $\mathrm{UO}_{2}^{++}$. The probable reason is that the electronic transition is coupled also with low-frequency vibrations in the solvation sphere, or intra-ionic vibrations in the salt crystal. In the case of polyatomic anions such as $\mathrm{NO}_{3}^{-}$, a coupling occurs also with vibrations within these anions. All these modes of vibration are included in the terms $\Sigma n_{j} \nu_{j}$ in equations (4) and (5). 


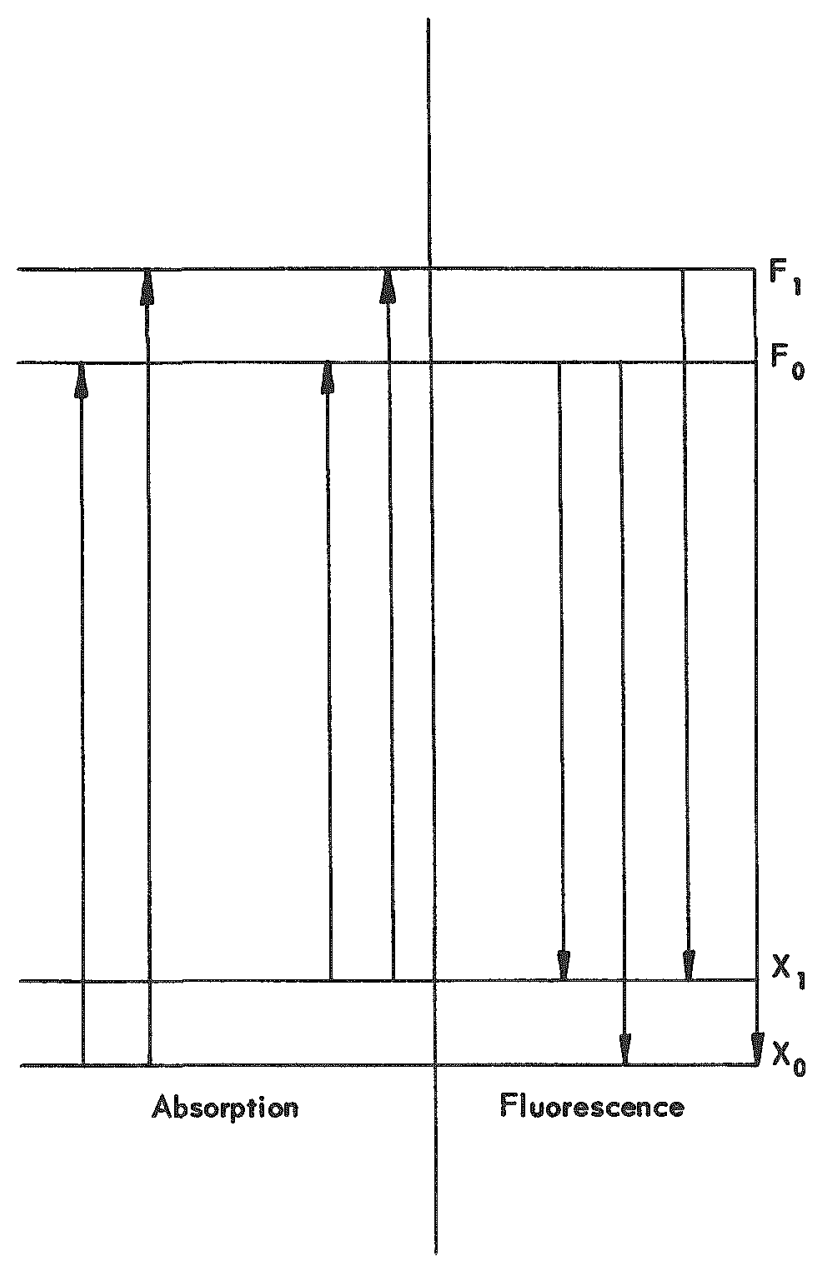

Figure 2

RESONANCE BANDS AT HIGHER TEMPERATURES 
Because of the co-excitation of low-frequency vibrations of the medium, the analysis of the uranyl spectrum (i.e., the determination of the electronic terms and of the fundanental vibrations) must be based on observations at the lowest conveniently obtainable temperature, such as $20^{\circ} \mathrm{K}$ (liquid hydrogen bath). Even at $77^{\circ} \mathrm{K}$ (liquid nitrogen bath), the bands are blurred and displaced. At room temperature the peaks of the broad absorption bands often do not indicate, even approximately, the number and position of the strongest individual bands, and therefore do not permit the determination of vibration frequencies with any degree of precision (Figures 7 and 8 ).

As usual, the vibrational frequencies of the ground electronic state must be derived from the fluorescence spectrum (Figure 1A), and those of the excited electronic state, from the absorption spectrum (Iigure 1B).

The interpretation of the fluorescence and absorption spectrum of the uranyl ion, indicated in this introduction, is based on the spectroscopic work of Nichols, Howes and co-workers $(1914-1919)$, Dieke and van Heel (1925), Moerman and Kraak (1939), and Feymann and co-workers (19461948); on infrared studies (cf., Section 3 below) and Raman spectra; but most of all, on the work of Dieke, Duncan, and co-workers, carried out in 1943-1944 under the Manhattan District program. In the course of these studies experimental data far superior in precision and detail to the previously available material have been assembled and at least in part inter preted in terms of the theory of crystal spectra. These experimental and theoretical results are described in detail in Volume 2 of Division III of the National Nuclear Energy Series (Dieke and Duncan, 1949). In the present chapter we will review briefly the earlier investigations in the field of uranyl salt and spectroscopy and give a somewhat more detailed summary of the results of Nichols and Howes and, particularly, of Dieke and co-workers.

The interpretation of the $210 \mathrm{~cm}^{-1}$ frequency as that of the bending vibration $\nu_{b}$ was contested by Sevchenko and comworkers (1951), mainly on the grounds of its excessive multiplicity (seven components in $\mathrm{UO}_{2} \mathrm{Cs}\left(\mathrm{NO}_{3}\right)_{3}$ !), and its dependence on crystal structure (in $\mathrm{CsUO}_{2} \mathrm{Cl}_{4}$, Dieke and Duncan interpret as $\nu_{\mathrm{b}}$ the frequencies 109 and $118 \mathrm{~cm}^{-1}$ instead of the usual $210 \mathrm{~cm}^{-1} \mathrm{l}$ ). Sevchenko also argued that $\nu_{\mathbf{b}}$ should exhibit as many overtones as $\nu_{\mathbf{s}}$. Furthermore, the $210 \mathrm{~cm}^{-1}$ frequency shows no oxygen-isotope effect, and the polarization of the lines in which this vibration is excited depends on crystal structure. All these characteristics point, according to Sevchenko, to a crystal lattice vibration, rather than to an internal vibration frequency of the $\mathrm{UO}_{2}^{++}$ion. However, this interpretation is inconsistent with the lack of influence on the $210 \mathrm{~cm}^{-1}$ vibration of the number of water molecules in the series $\mathrm{UO}_{2}\left(\mathrm{NO}_{3}\right)_{2} \cdot \mathrm{nH}_{2} \mathrm{O}(\mathrm{n}=1,2,3,6)$ (cf.s Section 5). 


\section{STUDIES OF FLUORESCENCE AND ABSORPTION SPECTRA OF SOLID URANYL SALTS (EXCEPT THOSE OF DIEKE AND DUNCAN)}

2.1 Band Measurements and Empirical Classification - Brewster (1833) was probably the first to observe the green fluorescence of uranyl ions (in so-called Canary glass); Stokes $(1852,1853)$ the first to systematically study the fluorescence and absorption spectra of uranium compounds. In illumi= nating a crystal of uranyl nitrate with a beam of blue light (white light filtered through a copper salt solution) and observing in a spectroscope the light emerging from the crystal, Stokes noted "a most remarkable spectrum," consisting of "nothing but bands, arranged at regular intervals." He saw that the bands formed two distinct systems - a system of emission bands, beginning in the blue part of the visible spectrum and extending into the region of lower refractability (i.e., towards the longer waves), and a system of absorption bands, beginning in the same region but extending in the opposite direction towards the shorter waves into the violet and ultra-violet.

E. Becquerel (1872) counted eight bright bands in the fluorescence spectrum of solid uranyl nitrate and stated that the spectra of other uranyl salts are similar, but that the bands occupy somewhat different positions for different compounds.

Morton and Bolton (1873) mapped the fluorescence and absorption spectra of 87 solid uranium compounds, including 17 double uranyl acetates. They noted the above-mentioned overlapping of the first few bands in the absorption and the fluorescence band systems (cf., Figure 3, strips 1 and 3 ) and found indications of a "fine structure" of some of the fluorescence bands (particularly in the spectra of the double chlorides, strip 2). Morton and Bolton also described changes in the uranyl spectrum which occur when anhydrous salts are hydrated or dissolved in water or other solvents.

H. Becquerel, J. Becquerel and Kamerlingh Onnes $(1909,1910)$ noted the transformation which the fluorescence and absorption spectra of solid uranyl salts underwent upon cooling to liquid air temperature $\left(-185^{\circ} \mathrm{C}\right)$ : some bands disappeared, while others split into a number of narrow, sharp components. They found that some of the sharp low temperature fluorescence bands coincide almost exactly with the (also sharp) low-temperature bands in the overlapping absorption band groups; these they designated as "revers ible" bands (we now call them "resonance bands"). A further sharpening of the bands was observed by them at the temperature of liquid nitrogen.

Nichols, Howes and co-workers carried out in 1915-1919 a very extensive study of uranyl salt spectra.

They noted that the broad absorption regions (or band groups) observed in most uranyl compounds at $+20^{\circ} \mathrm{C}$ have approximately constant 
1.

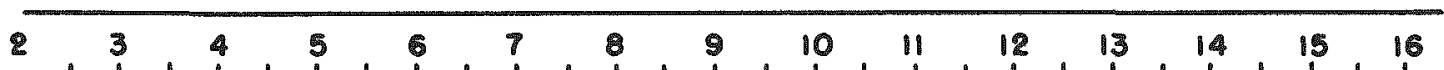

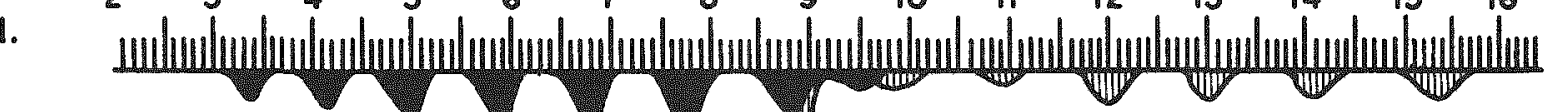

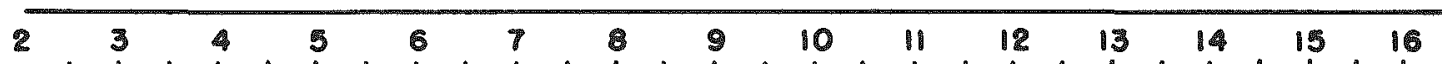

2. U.

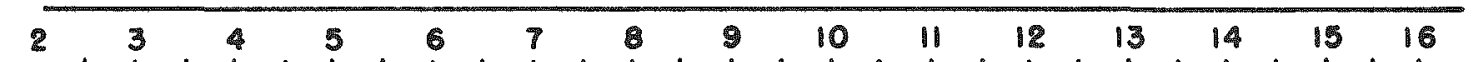

3.

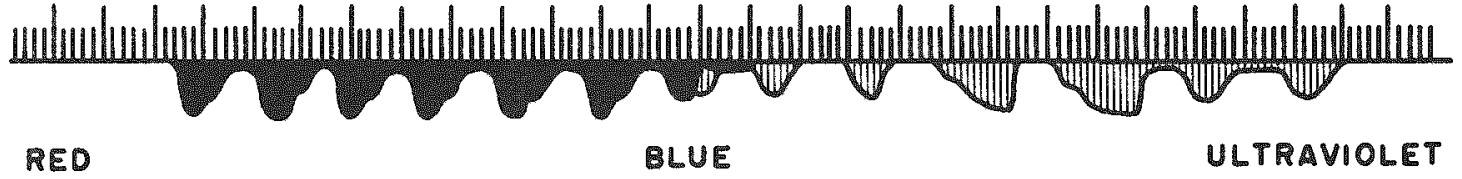

Figure 3

REPRESENTATIVE ABSORPTION AND FLUORESCENCE BAND SYSTEMS

OF SOLID URANYL SALTS (AFTER MORTON AND BOLTON, 1873)

SHOWING OVERLAPPING OF THE TWO SYSTEMS,

AND FINE STRUCTURE OF SOME BANDS

1. URANYL NITRATE

2. POTASSIUM URANYL CHLORIDE

3. CALCIUM URANYL PHOSPHATE

(FROM NICHOLS AND HOWES, 1919, p. 8)

BLACK: FLUORESCENCE BANDS

SHADED: ABSORPTION BANDS 
differences on the frequency scale. This they found to be true of both absorption and fluorescence spectrum, but the characteristic frequency intervals were different - about $820 \mathrm{~cm}^{-1}$ in the fluorescence spectrum, and about $660 \mathrm{~cm}^{-1}$ in the absorption spectrum. Nichols and Howes noticed, however, that the interval between the second and the first band on the shortwave end of the fluorescence system was that characteristic of the absorption sequence, while the interval between the last and the penultimate band on the long-wave end of the absorption system was that generally encountered in the fluorescence sequence. Table 1 shows, for example, the wave lengths of the peaks of the fluorescence and absorption bands of $\mathrm{K}_{2} \mathrm{UO}_{2}\left(\mathrm{SO}_{4}\right)_{2} \cdot 2 \mathrm{H}_{2} \mathrm{O}$ at $+20^{\circ} \mathrm{C}$; we note the (approximately) constant frequency intervals in each band system, the overlapping of three absorption and fluorescence bands, and the occurrence in the absorption system of a $\Delta \nu$-value $\left(820 \mathrm{~cm}^{-1}\right)$ characteristic of the fluorescence spectrum, and in the fluorescence system, of a $\Delta \nu$ value $\left(661 \mathrm{~cm}^{-1}\right)$ characteristic of the absorption spectrum. All the se features are understandable on the basis of Figure 1. They indicate that both systems are due to the same electronic transition $\left(20,325 \mathrm{~cm}^{-1}\right)$ coupled with acquisition of vibrational quanta of about $660 \mathrm{~cm}^{-1}$ in the excited electronic state, and of about $820 \mathrm{~cm}^{-1}$ in the ground state. The last absorption band group and the first fluorescence band group must originate in the first vibrational level of the excited and the ground state, respectively (anti-Stokes bands, dotted arrows in Figure 1). This explains why these band groups are relatively weak at room temperature and disappear at low temperature when practically no vibrating molecules exist in thermal equilibrium.

Table 1

ABSORPTION AND FLUORESCENCE BANDS OF POTASSIUM URANYL SULFATE AT $+20^{\circ} \mathrm{C}$ (AFTER NICHOLS AND HOWES, 1919)

\begin{tabular}{|c|c|c|c|c|c|}
\hline \multicolumn{3}{|c|}{ Absorption } & \multicolumn{3}{|c|}{ Fluorescence } \\
\hline$\underset{\mathrm{m} \mu}{\lambda}$ & $\left(\operatorname{cm}^{-1}\right)$ & $\Delta \nu$ & $\begin{array}{c}\lambda \\
\mathbf{m} \mu\end{array}$ & $\left(\mathrm{cm}^{\nu}\right)$ & $\Delta \nu$ \\
\hline $\begin{array}{l}435.0 \\
447.2 \\
461.4 \\
476.0 \\
492.0 \\
512.7\end{array}$ & $\begin{array}{l}22989 \\
22361 \\
21673 \\
21008 \\
20325 \\
19505\end{array}$ & $\begin{array}{l}628 \\
688 \\
665 \\
683 \\
820\end{array}$ & $\begin{array}{l}476.5 \\
492.0 \\
513.0 \\
536.0 \\
560.6 \\
588.1 \\
619.0\end{array}$ & $\begin{array}{l}20986 \\
20325 \\
19493 \\
18657 \\
17838 \\
17004 \\
16155\end{array}$ & $\begin{array}{l}661 \\
832 \\
836 \\
819 \\
834 \\
849\end{array}$ \\
\hline
\end{tabular}


Band groups which do not fade out at low temperatures are split into sharp components. Nichols and Howes noted that the narrow bands or lines which result from this splitting form identical or almost identical patterns in the several groups. (A typical pattern is shown in Figure 9.) The lines could therefore be arranged into series, each series containing one line from each group. Table 2 is a typical example of such empirical analysis. The lines belonging to a given series are separated by approximately the same frequency interval as the peaks of the broad bands at room temperature, but the constancy of the intervals is much improved at low temperature, especially if weak and uncertain components are left out. (Compare the $\Delta \nu$ values in Table 1 with those in Table 2, particularly in the stronges't series, $E, D$, and $F$.) This, too, is understandable, since the positions of the crests of the broad unresolved room temperature bands are more or less accidental, being determined by the summation of several overlapping band components.

The explanation of the origin of the band series, hundreds of which were listed by Nichols and Howes, could not be given by them. As described in Section 1, we know now that each of Nichols and Howes' series consists of bands which have in common not only the electronic transition, but also all vibrational changes other than that of the symmetric bond vibration.

Boardman (1922) plotted the fluorescence intensity of various uranyl salts as a function of the wave length of the exciting light, and obtained a curve for which the main peaks coincided with the strongest known absorption bands; this coincidence justified considering the (less prominent) excitation peaks, noticeable in the short-wave region, as indicating the location of additional absorption bands, unknown from direct observation. Several new bands in the long-wave end of the absorption spectrum could be identified in the same way. By this procedure, the absorption spectrum of the uranyl ion, previously known between $380 \mathrm{~m} \mu$ and $490 \mathrm{~m} \mu$, was extended from $320 \mathrm{~m} \mu$ to $560 \mathrm{~m} \mu$. Tables were given by Boardman for the so-identified absorption bands of cesium uranyl double chloride $\left(18120-27300 \mathrm{~cm}^{-1}\right)$, of barium uranyl double acetate $\left(18050-31480 \mathrm{~cm}^{-1}\right)$, and of uranyl acetate $\left(17880-31560 \mathrm{~cm}^{-1}\right)$.

Samojlov (1948) measured lines in the absorption and fluorescence spectra of several uranyl salts in liquid helium $\left(4.2^{\circ} \mathrm{K}\right)$. He noted that cooling from $90^{\circ} \mathrm{K}$ (liquid air) to $4.2^{\circ} \mathrm{K}$ causes further narrowing and splitting of lines and that corresponding lines shift $5-12 \mathrm{~cm}^{-1}$ towards shorter waves.

2.2 Term Analysis - The first step in the analysis of the uranyl spectrum in the light of Bohr's theory of spectra was made by Dieke and van Heel (1925). They pointed out that the different spacing of the fluorescence and absorption bands (Table 1) indicates a difference in the vibrational frequency of the UOt+ group before and after the electronic excitation. The lower frequency in the electronically excited ion $\left(600-700 \mathrm{~cm}^{-1} \mathrm{vs} .800-850 \mathrm{~cm}^{-1}\right.$ in the 
Table 2

SERIES IN THE FLUORESCENCE SPECTRUM OF URANYL NITRATE HEXAHYDRATE $\left[\mathrm{UO}_{2}\left(\mathrm{NO}_{3}\right)_{2} \cdot 6 \mathrm{H}_{2} \mathrm{O}\right]$ at $-180^{\circ} \mathrm{C}$

(AFTER NICHOLS AND HOWES, 1919)

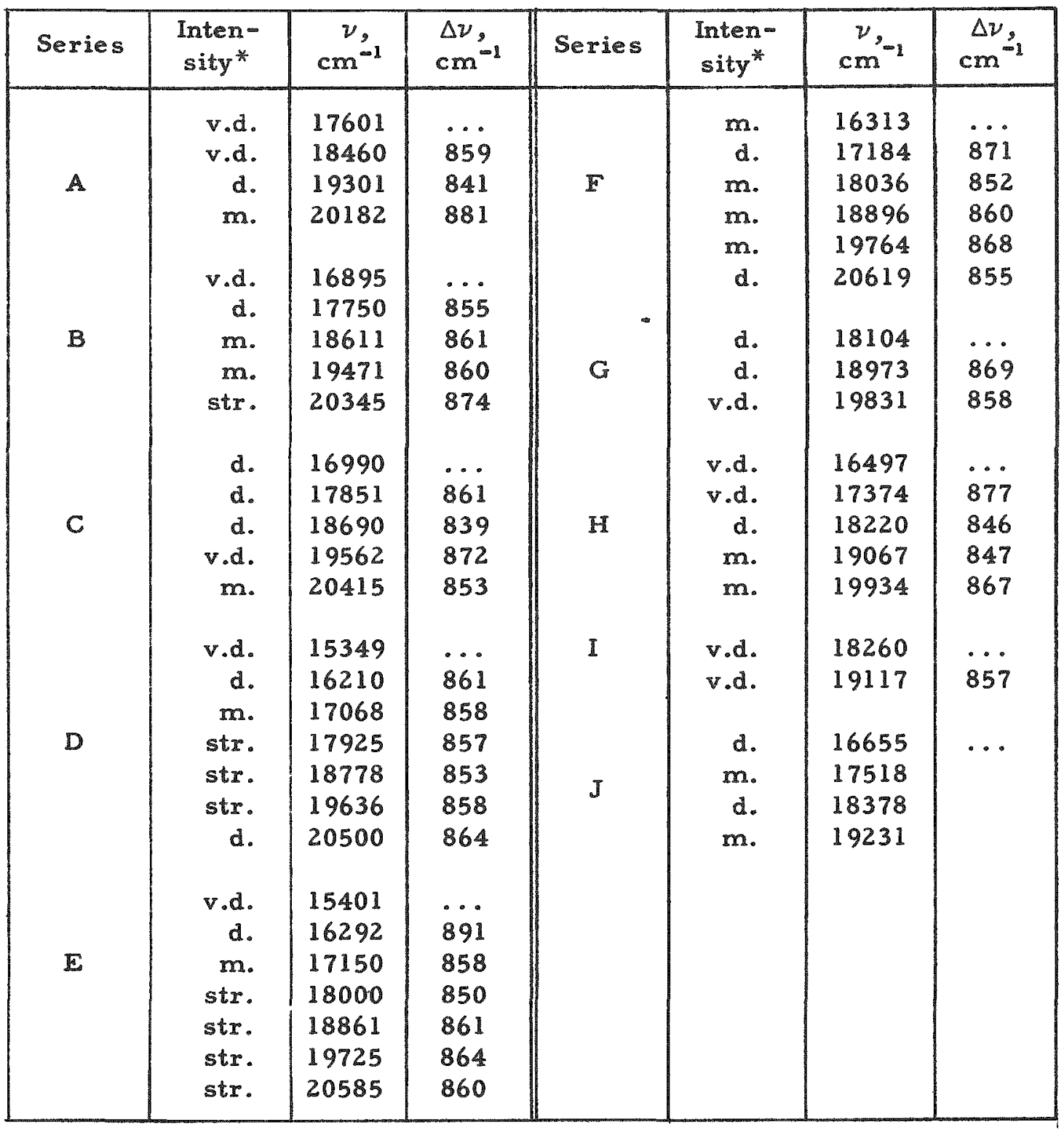

*Str., strong; m., medium; d., dim; v.d., very dim. 
non-excited ion) indicates looser binding. The approximate constancy of spacing of the several band groups indicates that the binding is almost elastic (and vibration therefore almost harmonic) in the excited as well as in the ground state.

Moerman and Kraak (1939) pointed out that the strongest absorption band of $\mathrm{UO}_{2}^{++}$corresponds to the transition from the non-vibrating ground state to the excited electronic state with one vibrational quantum and saw in this relationship a confirmation of the assumption that the $U-O$ distance is larger in the excited state. They also noted the absence of this band in fluorescence at $-180^{\circ} \mathrm{C}$, and its weak occurrence in fluorescence at room temperature; they saw in this an indication that thermal equilibrium in respect to vibrational energy is established, in the excited electronic state, before any appreciable proportion of absorbed photons has been re-emitted as fluorescence (cf., below).

Freymann, Guilmart, and Freymann $(1946,1947,1948)$ undertook a more detailed classification of the uranyl ion lines (as shown by uranyl acetate crystals at low temperatures) using, in addition to the symmetric vibration Ixequency, $860 \mathrm{~cm}^{-1}$, also two other frequencies derived from the Raman effect measurements - 930 and $210 \mathrm{~cm}^{-1} ;$ only one vibrational fre quency, $720 \mathrm{~cm}^{-1}$, was utilized in the excited electronic state. Forty-seven fluorescence lines and 40 absorption lines could be interpreted by means of these frequencies, with the additional assumption that the main vibration frequency has a satellite at a distance of $30 \mathrm{~cm}^{-1}$. This frequency was tentatively interpreted as that of a crystal vibration.

Similar analysis was also found possible in the spectra of uranyl nitrate, chloride, and fluoride.

The Raman frequency, $150 \mathrm{~cm}^{-1}$, was interpreted by Freymann, et al, not as an independent frequency, but as the difference between the frequencies 860 and $720 \mathrm{~cm}^{-1}$.

Freymann and co-workers did not know of the earlier Manhattan project work of Dieke and Duncan, first published in 1949, which had carried the term analysis of the spectrum of solid uranyl salts into much more detail. This work will be summarized in Section 4.

\subsection{Fluorescence Spectrum in Relation to Exciting Light - When}

Nichols and Howes (1919) set out to investigate the uranyl spectrum, the first question they asked was whether the fluorescence spectrun is the same whatever the exciting light. The answer was yes: excitation by light of various wave lengths always produced the same complete pattern of fluorescence bands, with approximately the same relative intensities. (The observed slight variations in the relative intensity of the resonance bands could be attributed to the re-absorption of these bands, which is more effective the deeper the exciting light penetrates into the crystal, i.e., the weaker it is absorbed.) 
Van Heel (1925) described monochromatic excitation of fluorescence in autunite (calcium uranyl phosphate) and in a potassium uranyl sulfate crystal at $-183^{\circ} \mathrm{C}$. He noted that fluorescence was strongly excited by light belonging to the absorption bands, including the "resonance frequency" (where absorption and fluorescence bands coincide), but was not excited at all by light belonging to the other fluorescence bands. This result is obvious since no fluorescence is possible without absorption.

The question whether the fluorescence spectrum of uranyl saltcrystals is independent of the wave length of the exciting light was again taken up by Levshin and Sheremetjev (1947). Spectrophotograms covering all the eight fluorescence bands of uranyl sulfate that appear at room temperature were scanned with excitation either by the mercury line $435 \mathrm{~m} \mu$ or by a group of lines in the ultraviolet $(254-366 \mathrm{~m} \mu$, mainly $>311 \mathrm{~m} \mu)$. The relative intensities of the bands, as well as the shapes of the individual bands, were found to be exactly the same in both cases. This experiment was made with identical results at the beginning of the fluorescence decay, immediately after flash excitation, and $2.7 \times 10^{-4} \mathrm{sec}$ later.

Levshin and Sheremetjev also prepared spectrophotograms of the uranyl sulfate trihydrate fluorescence at $+100^{\circ} \mathrm{C}$ and $-185^{\circ} \mathrm{C}$. At $100^{\circ} \mathrm{C}$ the spectrum was characterized (compared to its appearance at room temperature) by general broadening and slight decrease in the intensity of all bands, except for those below $490 \mathrm{~m} \mu$. There the first anti-Stokes band, present even at room temperature, was enhanced by heating, and a second and perhaps a third anti-Stokes band appeared further in the violet.

Cooling to $-185^{\circ} \mathrm{C}$ had the opposite effect - sharpening (and splitting) of the seven main bands and disappearance of the anti-Stokes band. This transformation will be described in more detail in Section 4.

All these results are easily understood. As indicated in Figure 1B, individual absorption bands lead to the excitation of a different number of vibrational quanta. However, the period of a molecular vibration (order of magnitude $10^{-13}$ to $10^{-12} \mathrm{sec}$ ) is short compared to the natural life-time of the excited electronic state (about $10^{-3} \mathrm{sec}$ for uranyl ions). In the condensed state each vibration offers a chance of exchange of kinetic energy with the medium. Therefore, the equilibration of the vibrational energy of the electronically excited molecule with the thermal agitation energy of the medium occurs long before a significant proportion of the photons had been re-emitted as fluorescence. The fluorescence spectrum therefore has an intensity distribution determined entirely by the temperature of the medium and bearing no relation to the wave length of the exciting light. 


\section{INFRARED SPECTRUM OF URANYL SALT CRYSTALS}

An important contribution to the understanding of the uranyl spectrum came from the study of infrared and Raman spectra.

Coblentz (1918) noted absorption bands at $0.92 \mu$ and $1.55 \mu$ in uranium glass. Dreisch (1927) observed the same bands and stated that they aredoublets $(0.83-0.92 \mu$ and $1.44-1.55 \mu$ respectively). However, he found them only in uranium glass; no absorption was seen in the infrared up to $2 \mu$, or in uranyl nitrate solution, in water, or in 96 per cent alcohol. Dreisch concluded that these bands do not belong to the uranyl ion but originate in some other component of uranium glass.

Conn and $W u(1938)$ studied in more detail the infrared absorption spectrum of solid uranyl salts and found a weak band at $11.6 \mathrm{~m} \mu\left(860 \mathrm{~cm}^{-1}\right)$ and an intense band at $10.8 \mathrm{~m} \mu\left(930 \mathrm{~cm}^{-1}\right)$. The presence of a band corresponding to a frequency found in Raman spectrum of concentrated uranyl salt solutions $\left(210 \mathrm{~cm}^{-1}\right)$ could not be checked because it was out of range of the instrument.

Lecomte and Freymann (1941) added to the two solid salts studied in the infrared by Conn and $W u$ eighteen others, including sulfate, double sulfates, double carbonates, nitrate, phthalate, salicylate, etc. They noted absorption bands belonging to $\mathrm{UO}_{2}^{++}$ions, as well as bands apparently belonging to the associated anions. Intense $\mathrm{UO}_{2}^{++}$absorption bands were found with peaks at $10.87 \mathrm{~m} \mu\left(920 \mathrm{~cm}^{-1}\right)$ and $11.76 \mu\left(850 \mathrm{~cm}^{-1}\right)$, and a weak band at about $1120 \mathrm{~cm}^{-1}$. The last one was not previously noted; it may represent the combination of two of the frequencies identified by Conn and $W u: 210+930=$ $1140 \mathrm{~cm}^{-1}$.

Lecomte and Freymann suggested that the $920 \mathrm{~cm}^{-1}$ band could be used for the identification of the uranyl ion in compounds in which its presence is uncertain. For example, this frequency does not appear in the absorption spectrum of uranyl trioxide. (Instead, the latter shows bands at 890,1020, and $1090 \mathrm{~cm}^{-1}$ the same frequencies, somewhat displaced, appear also in the spectrum of sodium uranate and in the product obtained from uranyl salt solution by precipitation with ammonia; the latter thus proves to be an ammonium uranate.) The $920 \mathrm{~cm}^{-1}$ frequency was present (rather unexpectedly!) in the absorption spectrum of $\mathrm{UO}_{3} \cdot 2 \mathrm{H}_{2} \mathrm{O}$ (but not in that of $\mathrm{UO}_{3} \cdot \mathrm{H}_{2} \mathrm{O}$ or of $\mathrm{UO}_{4} \cdot 2 \mathrm{H}_{2} \mathrm{O}$ ).

Sevchenko and Stepanov (1949) investigated the infrared absorption spectra of uranyl sulfate, potassium uranyl sulfate, uranyl acetate, and uranyl nitrate (fine crystal powders pressed between fluorite plates) up to $15 \mu$. Figures $4 A, B, C$, and $D$ show the transmission curves of these four salts. (The three curves in the nitrate spectrum refer to successive measurements of the 


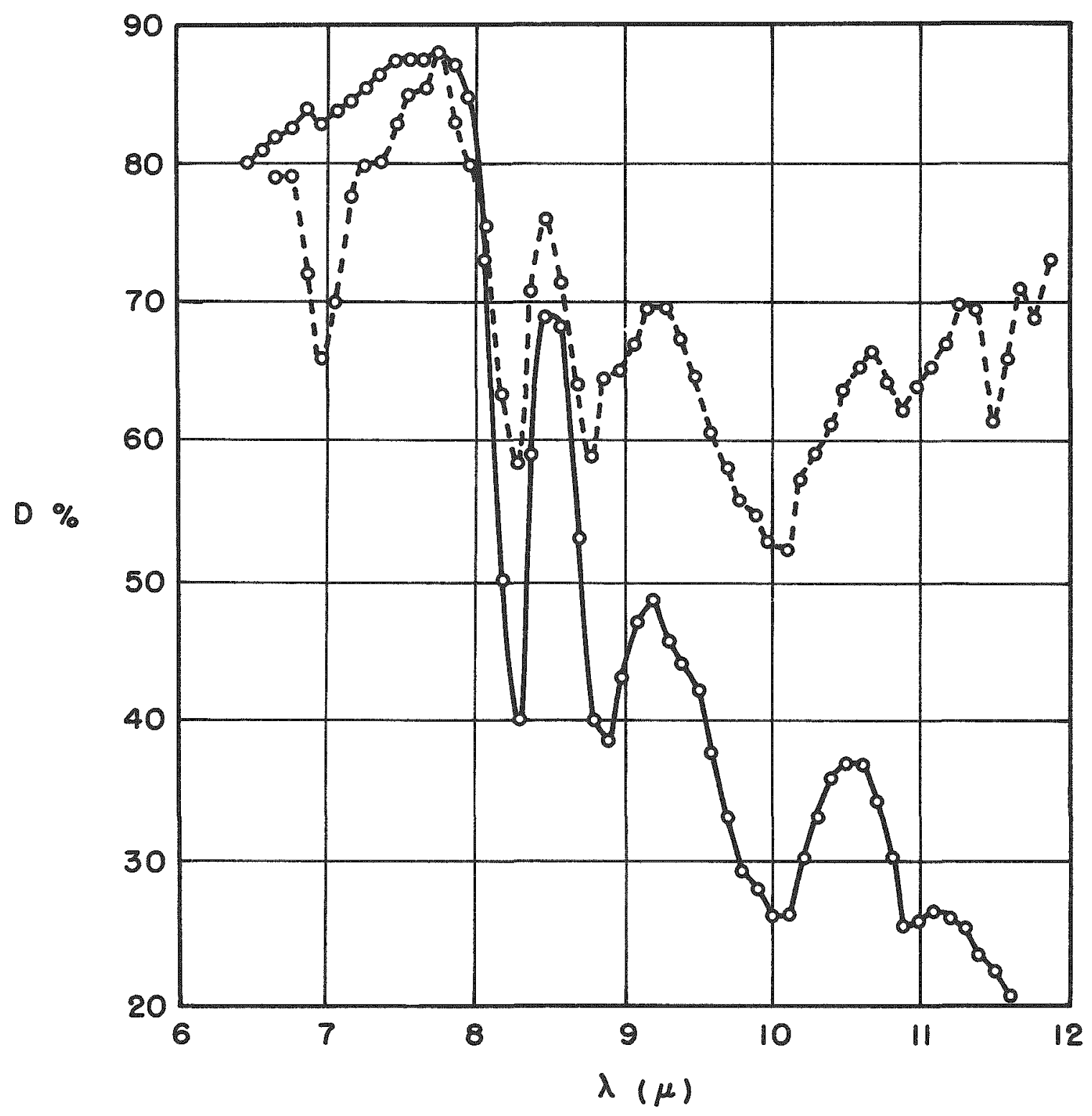

Figure 4A

INFRARED ABSORPTION SPECTRUM OF URANYL SULFATE TRIHYDRATE (AFTER SEVCHENKO AND STEPANOV, 1949) 


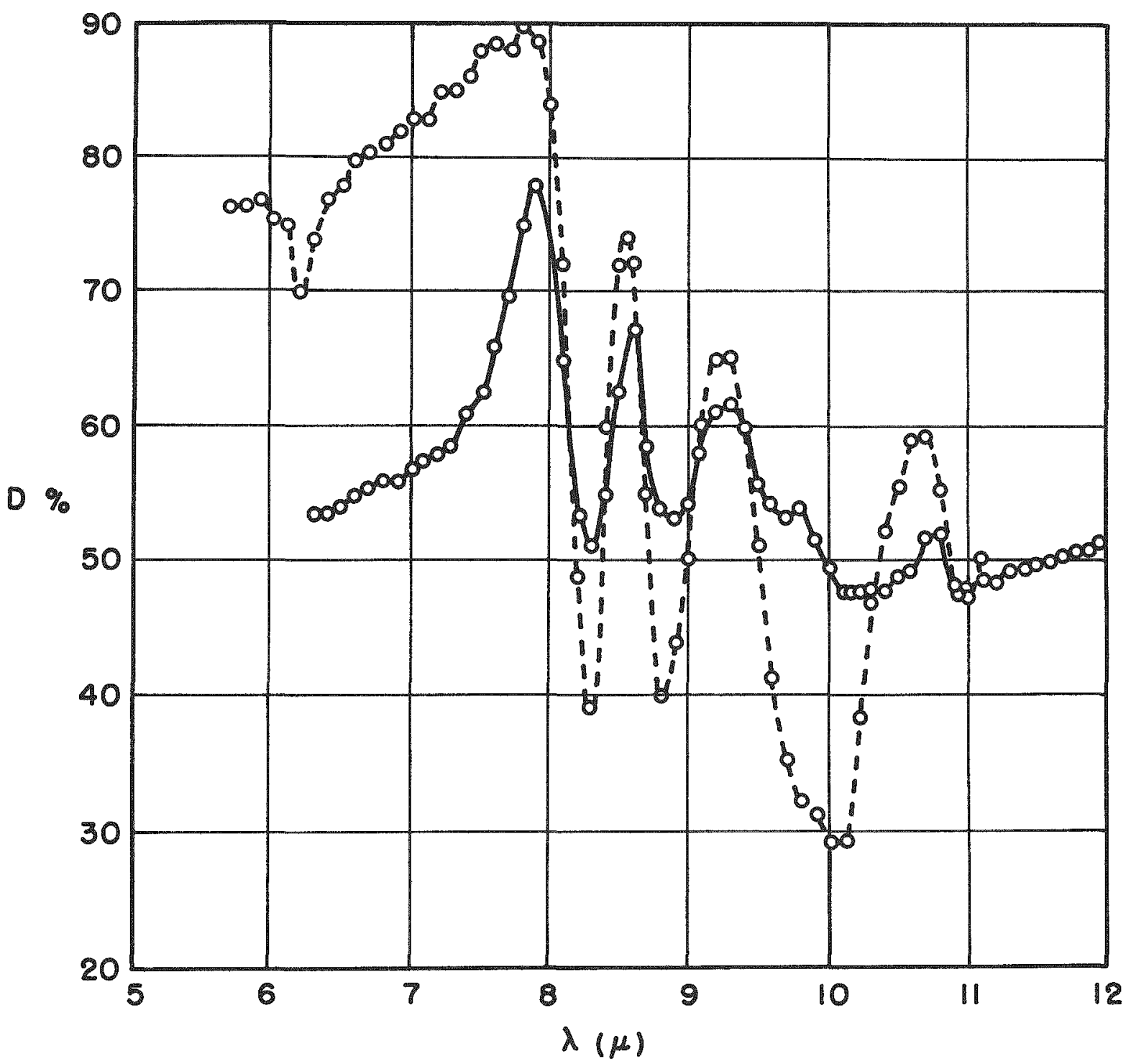

Figure $4 B$

INFRARED ABSORPTION SPECTRUM OF POTASSIUM URANYL SULFATE DIHYDRATE (AFTER SEVCHENKO AND STEPANOV, 1949) 


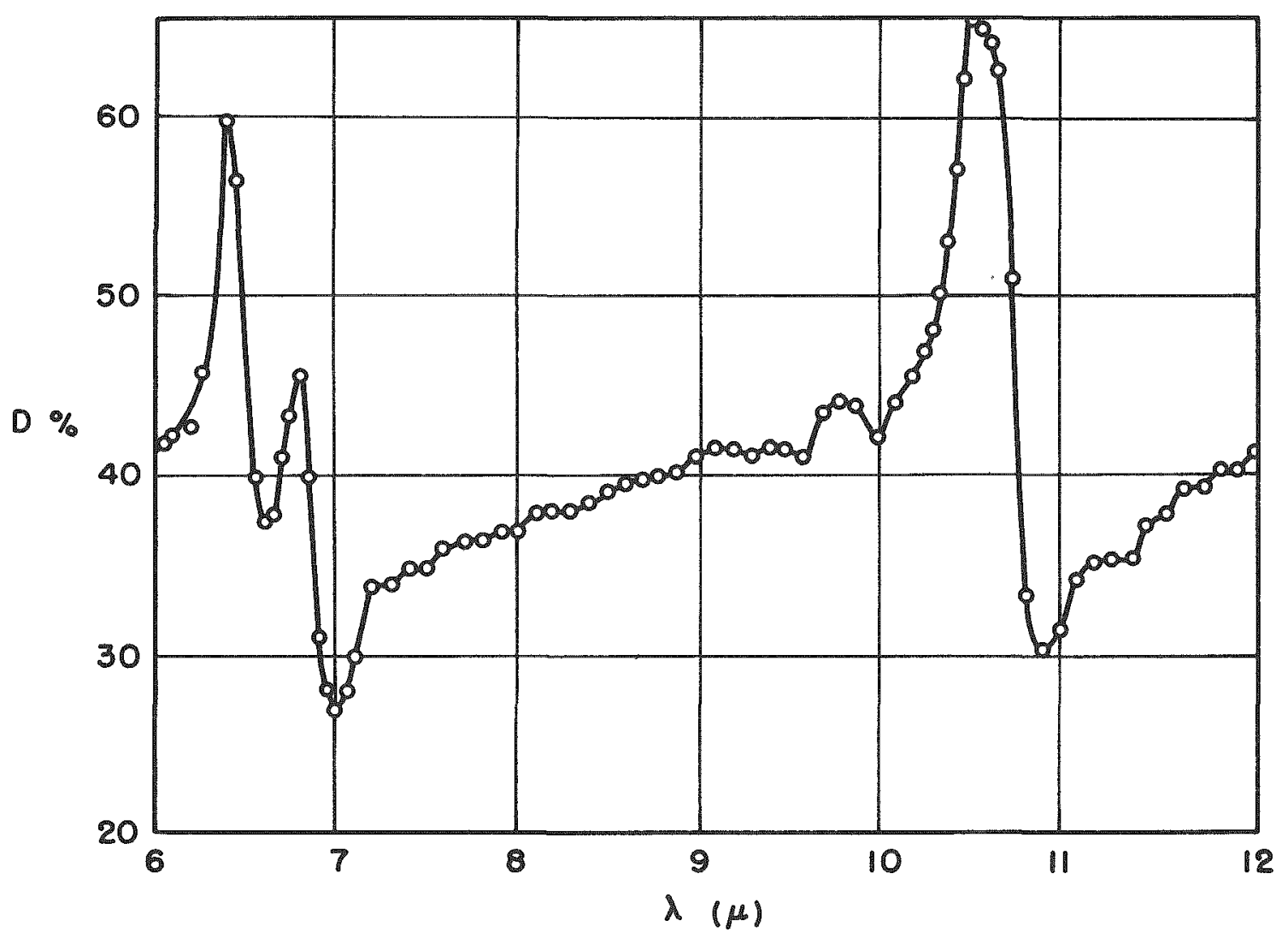

Figure $4 C$

INFRARED ABSORPTION SPECTRUM OF URANYL ACETATE HEXAHYDRATE (AFTER SEVCHENKO AND STEPANOV, 1949) 


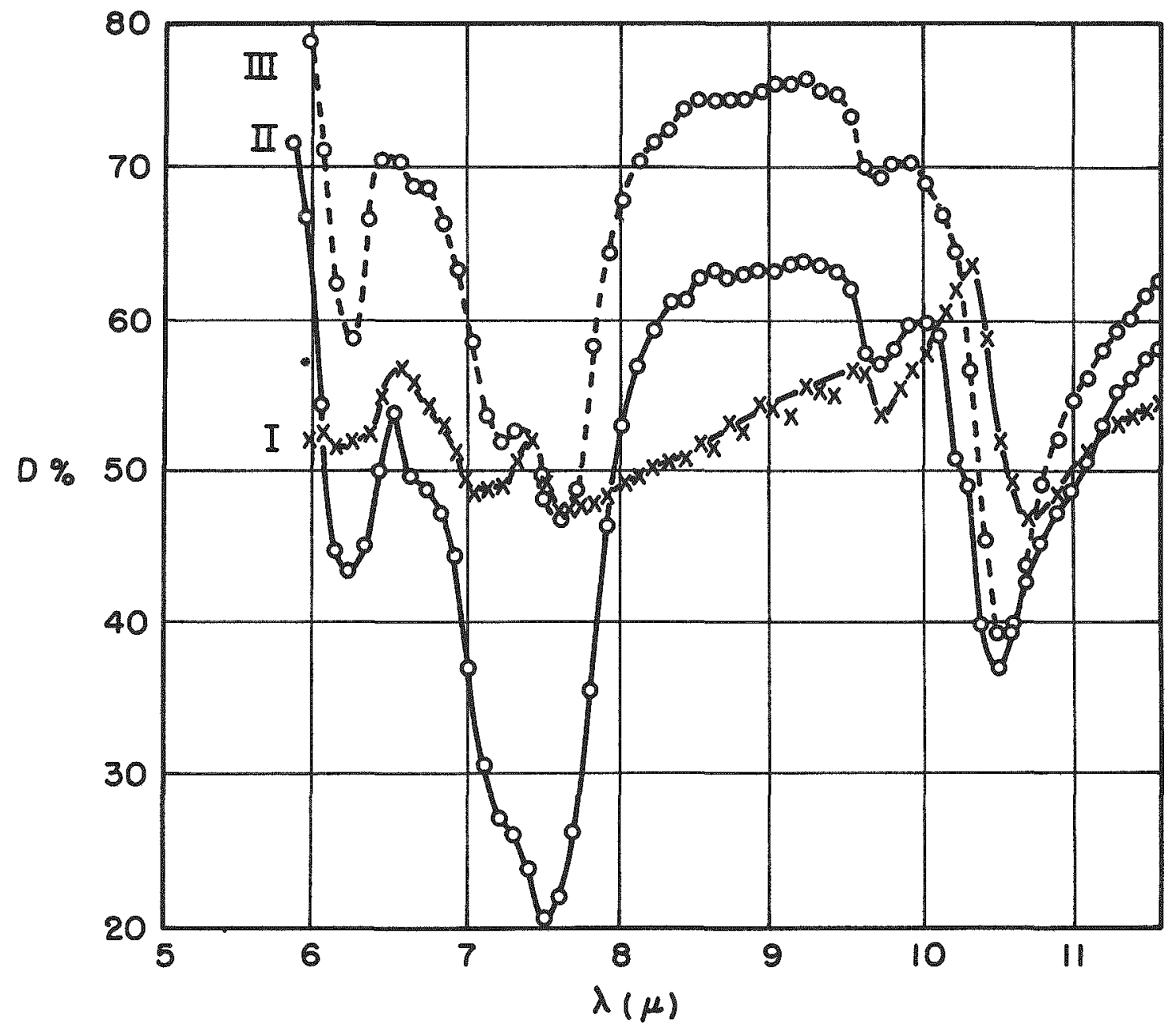

Figure 40

INFRARED ABSORPTION SPECTRUM OF URANYL NITRATE HEXAHYDRATE (AFTER SEVCHENKO AND STEPANOV, 1949) 
same preparation at one day intervals; changes may be due to adsorption of moisture on the powder.) Each salt in Figure 4 has 5 or more infrared absorption bands; none of them belongs to the anion. Table 3 gives the frequencies of those bands and their interpretation. In addition, one unclassified frequency was found in sulfate $\left(873 \mathrm{~cm}^{-1}\right)$ and in acetate $\left(877 \mathrm{~cm}^{-1}\right)$, but not in nitrate.

The frequency $990 \mathrm{~cm}^{-1}$ in sulfate is stronger than all the others, which is peculiar for a high overtone such as $5 . \nu^{\prime}$, but no other explanation of this line appears feasible.

Asterisks indicate vibrations prohibited for linear molecules. The authors interpreted their occurrence as indication that the $\mathrm{UO}_{2}^{++}$ion is bent in simple and double sulfates but almost linear in acetate and nitrate hexahydrates. (The line 1515 could be $\nu_{a}+3 \nu_{b}$, rather than $\nu_{s}+3 \nu_{b}$ cf., how ever, above p.5.).

Sevchenko and Stepanov (1949) also studied the effect of hydration on the frequency and intensity of infrared absorption bands of uranyl sulfate and uranyl nitrate. In sulfate the band at $9.65 \mu\left(\nu_{\mathrm{s}}+\nu_{\mathrm{b}}\right)_{\mathrm{s}}$ missing in the simple trihydrate (but present in complex sulfate), appears strongly in the spectrum of the dehydrated salf. The bands at 10.1,8.2 and 7.0 $\mu$ (interpreted in Table 3 as high overtones of $\nu_{b}$, strong in crystalline trihydrate (Figure 4A) and intense also in trihydrate dehydrated in vacuum at $300^{\circ} \mathrm{C}$ ) are weak or absent in the synthetic anhydrous salt.

The hydrated salts do not show the known strong $\mathrm{H}_{2} \mathrm{O}$ band at $6 \mu$, indicating that the binding of water molecules to uranyl ions is so strong as to alter deeply their structure, apparently reducing the dipole of the $6 \mu$ vibration to zero.

In nitrate, too, the overtone $7 \nu_{2}(7.2 \mu$. Figure 5) disappears upon dehydration $(n \leq 2)$. The positions of the other bands are practically independent of hydration ( $T$ able 4), showing that the force constants in the ground electronic state are not changed significantly by the removal of water molecules (however, the relative intensities of the bands vary strongly with the degree of hydration). The differences in the positions of visible absorption and fluorescence bands of the several hydrates (described in Section 5.3) must then be attributed to the effect of water molecules on the electronically excited uranyl ion. 
Table 3

INFRARED FREQUENCIES OF URANYL SALTS

(SEVCHENKO AND STEPANOV, 1949)

\begin{tabular}{|c|c|c|c|c|c|}
\hline \multirow[b]{2}{*}{ Interpretation } & \multirow{2}{*}{$\begin{array}{c}\text { Frequency } \\
\text { calc. } \\
\mathrm{cm}^{-1}\end{array}$} & \multicolumn{4}{|c|}{ Frequencies found in } \\
\hline & & $\mathrm{NO}_{2} \mathrm{SO}_{4} \cdot 3 \mathrm{H}_{2} \mathrm{O}$ & $\mathrm{K}_{3} \mathrm{UO}_{2} \mathrm{SO}_{4} \cdot 2 \mathrm{H}_{2} \mathrm{O}$ & $\mathrm{wO}_{2}\left(\mathrm{CH}_{3} \mathrm{COO}\right)_{2} \cdot 6 \mathrm{H}_{2} \mathrm{O}$ & $\mathrm{UO}_{2}\left(\mathrm{NO}_{3}\right)_{2} \cdot 6 \mathrm{H}_{2} \mathrm{O}$ \\
\hline $\begin{array}{c}\nu_{\mathrm{s}} \\
\nu_{\mathrm{b}} \\
\nu_{\mathrm{a}} \\
5 \nu_{\mathrm{b}} \\
\nu_{\mathrm{s}}+\nu_{\mathrm{b}} \\
\nu_{\mathrm{a}}+\nu_{\mathrm{b}} \\
6 \nu_{\mathrm{b}} \\
\nu_{\mathrm{s}}+2 \nu_{\mathrm{b}} \\
\nu_{\mathrm{a}}+2 \nu_{\mathrm{b}} \\
7 \nu_{\mathrm{b}} \\
\nu_{\mathrm{s}}+3 \nu_{\mathrm{b}} \\
\nu_{\mathrm{a}}+3 \nu_{\mathrm{b}} \\
?\end{array}$ & $\begin{array}{l}(830) \\
(200) \\
(920) \\
1000 \\
1030 \\
1120 \\
1200 \\
1230 \\
1320 \\
1400 \\
1430 \\
1520 \\
\ldots \ldots\end{array}$ & $\begin{array}{c}836 \\
\text { not measured } \\
913 \\
990 \\
\ldots- \\
1130 \\
1204 \\
\ldots \\
1429 \\
\ldots 73\end{array}$ & $\begin{array}{c}\text { not measured } \\
\text { not measured } \\
909 \\
990 \\
1036 \\
1130 \\
1204 \\
\ldots \\
\ldots \\
\ldots\end{array}$ & $\begin{array}{c}\text { not measured } \\
\text { not measured } \\
918 \\
1000 \\
\ldots- \\
\ldots \\
\ldots \\
\ldots \\
1429\end{array}$ & $\begin{array}{c}\text { not measured } \\
\text { not meaured } \\
935 \\
\ldots \\
1031 \\
\ldots \\
\ldots\end{array}$ \\
\hline
\end{tabular}

* Prohibited for linear model.

Table 4

INFRARED ABSORPTION BANDS OF URANYL NITRATE

(SEVCHENKO AND STEPANOV, 1949)

\begin{tabular}{|c|c|c|c|c|c|c|}
\hline \multirow{2}{*}{ Band } & \multicolumn{5}{|c|}{ Crystals, $\mathrm{nH}_{2} \mathrm{O}, \mathrm{n}=$} & \multirow{2}{*}{$\begin{array}{l}\text { Aqueous } \\
\text { Solution }\end{array}$} \\
\hline & 0 & 1 & 2 & 3 & 6 & \\
\hline$\nu_{a}$ & 10.6 & 10.6 & 10.55 & 10.6 & 10.7 & 10.6 \\
\hline$\nu_{s}+\nu_{b}$ & 9.6 & 9.7 & 9.7 & 9.7 & 9.7 & 9.7 \\
\hline$\nu_{a}+2 \nu_{b}$ & 7.8 & $7.6-7.8$ & 7.8 & 7.9 & 7.6 & 7.6 \\
\hline $7 v_{b}$ & $-\infty$ & $\ldots$ & $\infty$ & 7.2 & 7.2 & 7.2 \\
\hline$\nu_{a}+3 \nu_{b}$ & 6.7 & 6.7 & 6.6 & 6.7 & 6.6 & $\infty$ \\
\hline
\end{tabular}



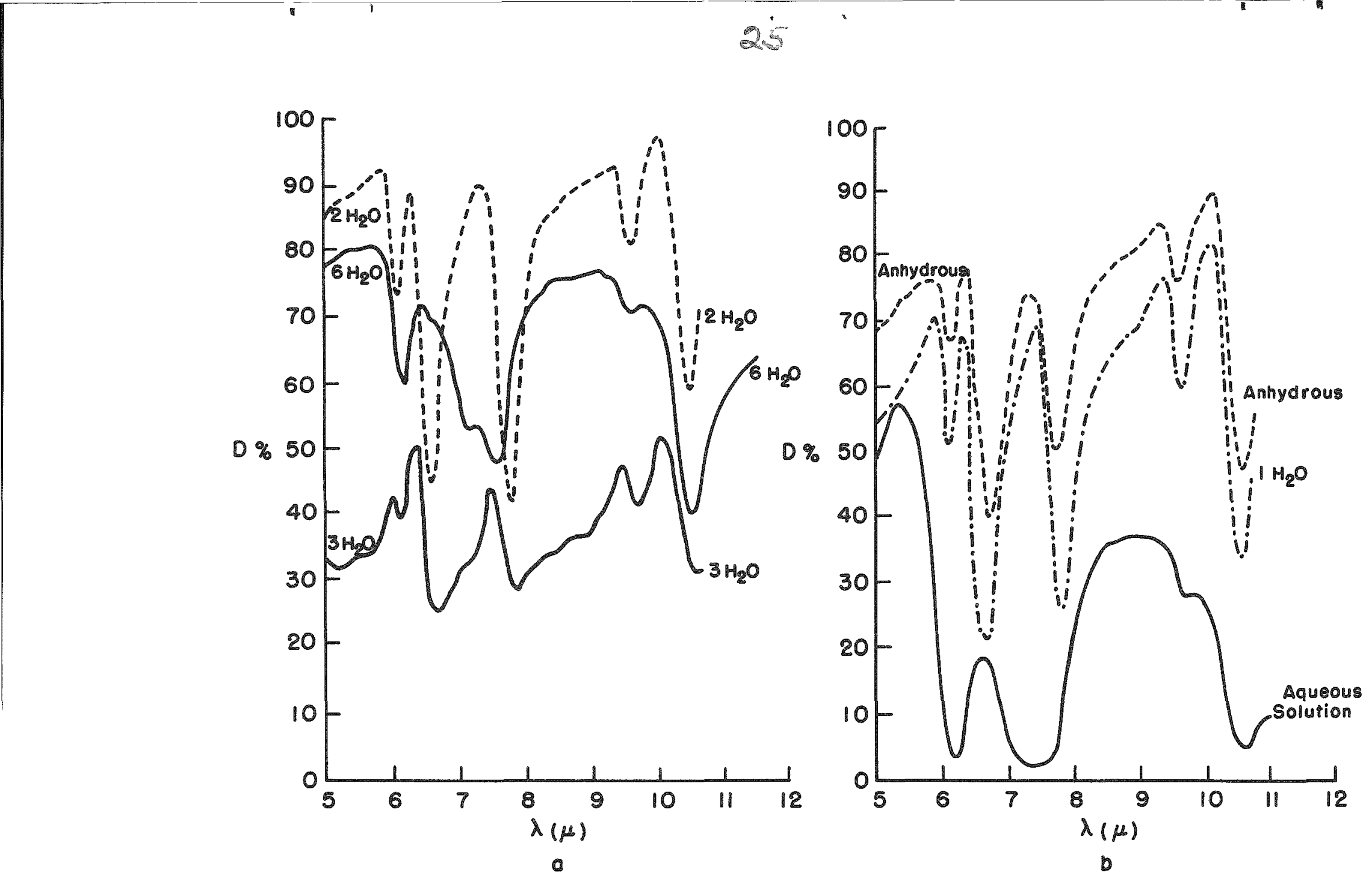

Figure 5

INFRARED ABSORPTION SPECTRA OF DIFFERENT URANYL NITRATE HYDRATES

(AFTER SEVCHENKO AND STEPANOV, 1949) 


\section{ANALYSIS OF URANYL SPECTRUM BY DIEKE AND CO-WORKERS}

As mentioned above, an investigation of the absorption and fluores cence spectra of a number of uranyl salts was undertaken in 1942-1944, first at Columbia University and later at the Johns Hopkins University under the Manhattan project. Remarkably sharp photographs and precise measurements of the fluorescence and absorption bands were obtained in this work; the intensities and the shapes of the individual bands were determined by photoelectric spectrophotometry. These investigations have been reported by Dieke and co-workers (Dieke and Duncan, 1949).

We will present here the general results of this study; some additional data on individual compounds will be given in Section 5 .

4.1 Temperature Effect - The transformation of uranyl spectra at low temperatures, discovered by the Becquerels and Kamerlingh Onnes (cf., Section 2.1) and observed on many salts by Nichols and Howes (cf.,p.14 and Figure 14) and Levshin and Sheremetjev (p.17), was studied oy Dieke and co-workers by photoelectric spectrophotometry. The results are illus trated by Figures 6 and 7. Figure 6 shows a group in the fluorescence spectrum of a crystal of cesium uranyl nitrate, $\mathrm{CsUO} 2\left(\mathrm{NO}_{3}\right)_{3}$, at five temperatures from $20^{\circ}$ to $273^{\circ} \mathrm{K}$. The three bands, A, B, and $\mathrm{C}$, appear as sharp as atomic lines at $20^{\circ} \mathrm{K}$. At $77^{\circ} \mathrm{K}$ they are considerably broadened and displaced by about $10 \mathrm{~cm}^{-1}$ towards the longer waves; at $135^{\circ} \mathrm{K}$ thev are fused into a single, three-peaked band. A new "anti-Stokes" band, C', appears at that temperature at the short wave side of band A. At $193^{\circ}$ and $273^{\circ} \mathrm{C}$ all one sees is a single broad band with two flat peaks, of which one is situated about $100 \mathrm{~cm}^{-1}$ toward the longer waves from the original line $C$ and the other about the same distance from the center of gravity of the lines $B$ and $A$. The peak $C^{\circ}$ has all but disappeared at room temperature, while increased absorption has appeared at still shorter waves.

Figure 7 shows a similar transformation of a band group in the fluorescence spectrum of a uranyl double chloride. As mentioned before on p. 11 (Figure 3) the "fine structure" is visible, in this case, even at room temperature.

The explanation of the temperature effect already was indicated in Section 1: At room temperature, fluorescence originates in various vibrational levels of the excited electronic state, including not only those of the individual ion $\mathrm{UO}_{2}^{++}$but also those of the associated anions, water molecules, and of the crystal lattice as a whole. As the temperature is lowered, the bands originating in levels involving excitation of the high-frequency fundamental vibrations, $\nu_{\mathrm{a}}$ and $\nu_{\mathrm{s}}$ (anti-Stokes bands), are the first to dis appear; at still lower temperatures the somewhat slower vibrations involving the frequency $\nu_{b}$ and the still slower lattice vibrations also are "frozen" 


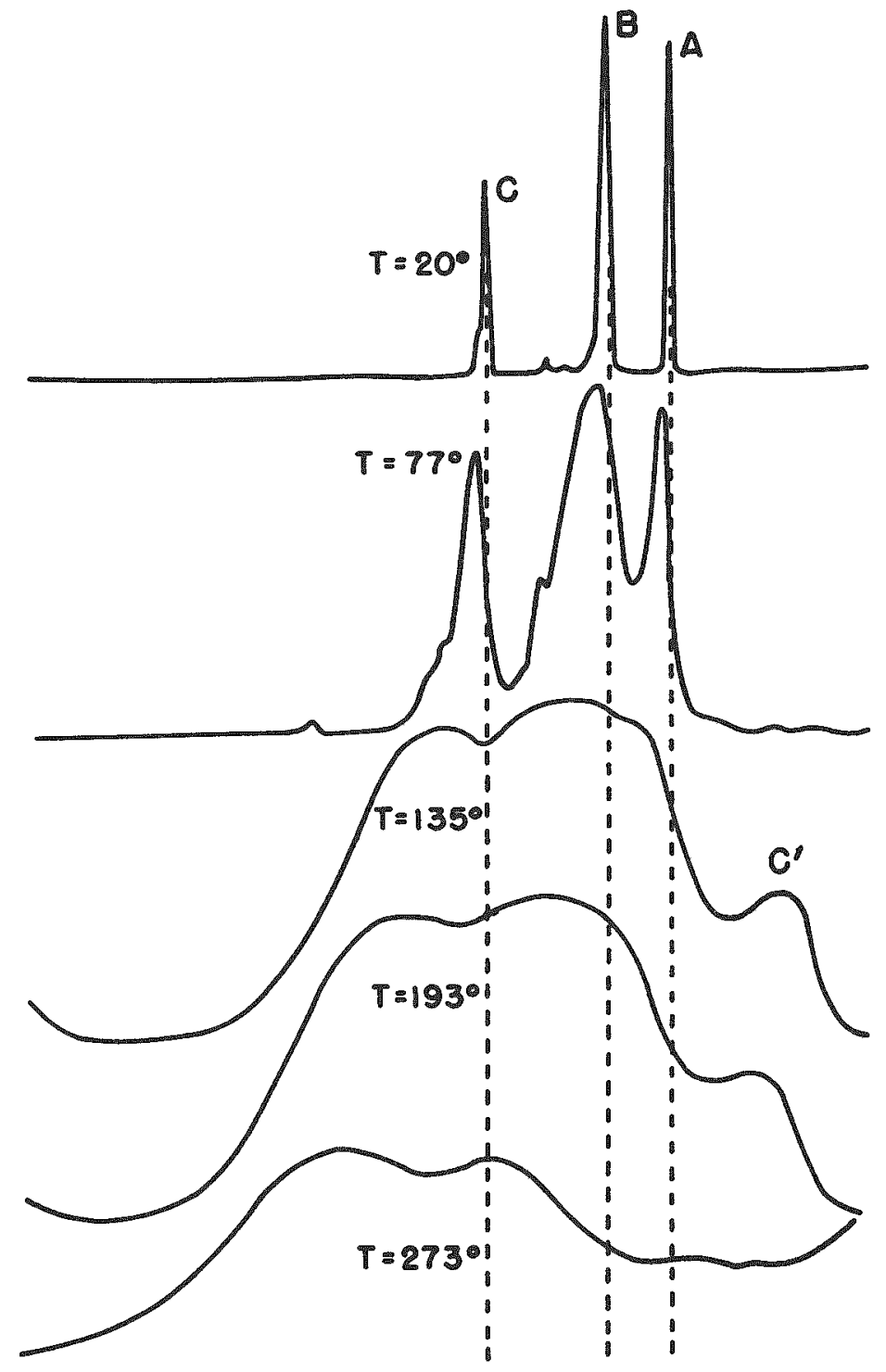

Figure 6

TEMPERATURE CHANGES IN THE STRUCTURE OF THE THIRD GROUP IN THE FLUORESCENCE SPECTRUM OF $\mathrm{CsUO}_{2}\left(\mathrm{NO}_{3}\right)_{3}$ (AFTER DIEKE, DUNCAN, ol.) 


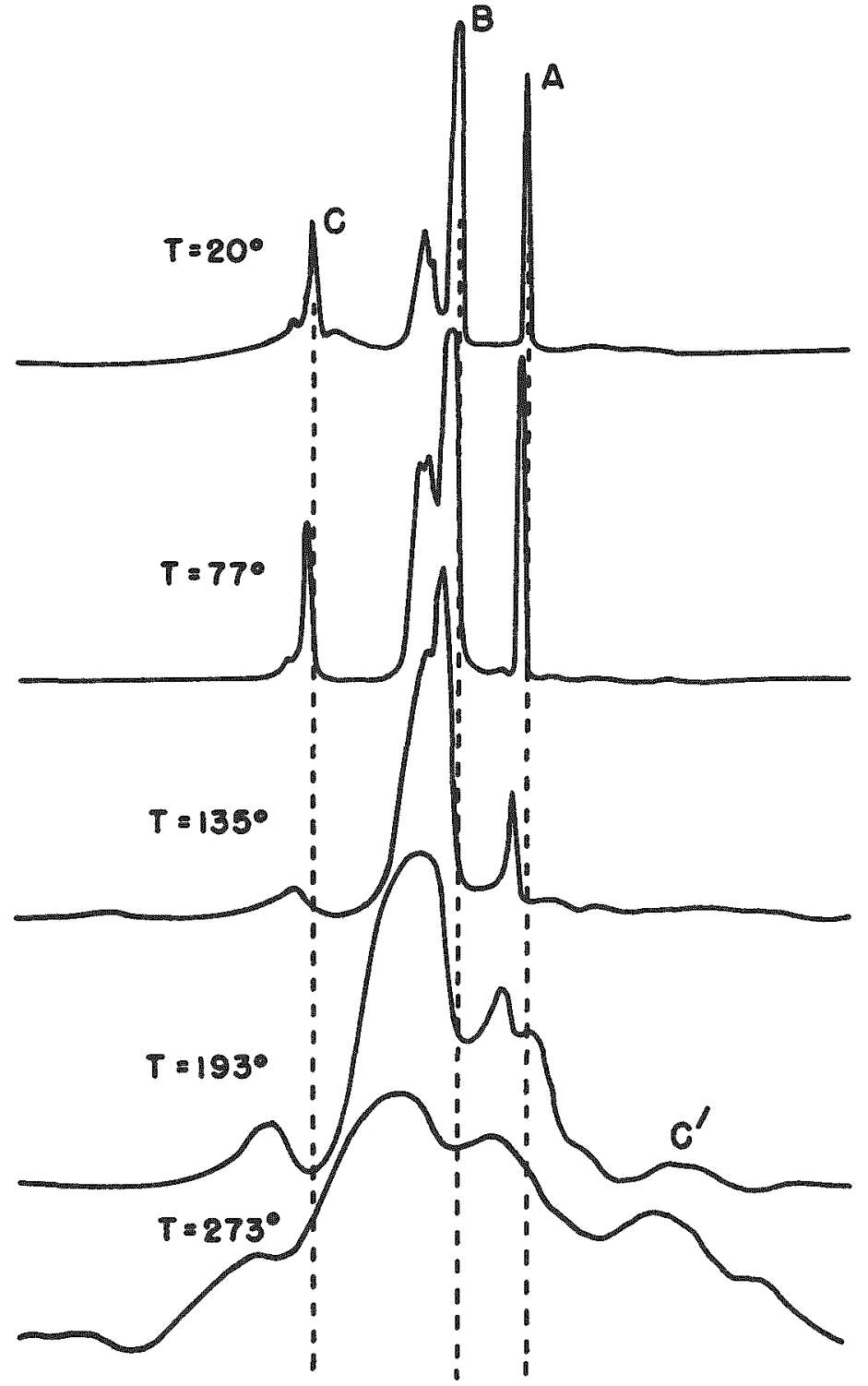

Figure 7

TEMPERATURE CHANGES IN THE STRUCTURE OF THE THIRD GROUP IN THE FLUORESCENCE SPECTRUM OF CESIUM URANYL CHLORIDE (AFTER DIEKE, DUNCAN, ol.) 
until the non-vibrating electronic state becomes the only initial level of emission; the remaining fluorescence bands are then those leading from this level to the non-vibrating ground level and to the few vibrational levels of the ground state that can combine with the vibrationless upper level according to the Franck-Condon rule.

Measurements of uranyl salt spectra at the temperature of liquid helium $\left(4.2^{\circ} \mathrm{K}\right)$ by Samojlov $(1948)$ have been described in Section 2.

4.2 Analysis of Uranyl Spectrum: Electronic States - The four last columns in Table 7 contain the frequencies corresponding to the excitation of the several upper electronic states, derived by Dieke and co-workers from the absorption spectra of uranyl salts. In Figure 8 the lower half shows schematically the arrangement of vibrational states over the ground electronic state, while the upper half indicates the arrangement of four excited electronic states; only the sequence of $\nu_{a}$ quanta and a single $\nu_{b}$ doublet is shown above the latter.

In addition to the superposition of transitions leading to several electronic states, the complexity of the absorption spectrum (as compared to the fluorescence spectrum) may be due to a non-vanishing orbital momentum of some excited states ( $\pi$ states) to stronger interaction between the excited ion and the associated anions or molecules and, possibly, to a non-linear configuration of the excited ion. Despite this complexity, Dieke and co-workers found it possible to order the most important absorption bands into a system similar to that used in the interpretation of the fluorescence spectrum, i.e., to interpret them as combinations of an electronic transition with the excitation of vibrations of the types $\nu_{5}$, $\nu_{a}$, or $\nu_{b}$. Studies of isotopic effects have helped in this identification. The influence of polar ization on absorption helps to separate bands corresponding to the several electronic transitions (since the component of a given electric dipole oscillation in a given plane in the crystal is detexmined primarily by the two electronic states, whose combination produces this oscillation).

\subsection{Analysis of Uranyl Spectrum: Dichroism, the "Yellow" and} the "White" Absorption Spectrum - Howes and co-workers (1915, 1916,1919. p. 102-131) noted that crystals of uranyl double chlorides are dichroitic. When a beam of white, linearly polarized light passes through them in appropriate crystallographic direction, they appear of different color, depending on the angle between the plane of polarization and the crystallographic axis. This means that in these crystals certain electromagnetic vibrations (or, in the language of quantum theory, oscillations of the virtual dipole associated with certain electronic transitions) occur preferentially in a definite crystallographic direction. The spectral bands which correspond to these vibrations are absorbed most strongly when the electric vector of the incident light vibrates in this direction. Inversely, the emission of the corresponding band in fluorescence will occur preferentially in the direction normal to the plane in which the corresponding oscillation occurs, and the fluorescence light will be polarized more or less strongly, depending on the direction of observation. 


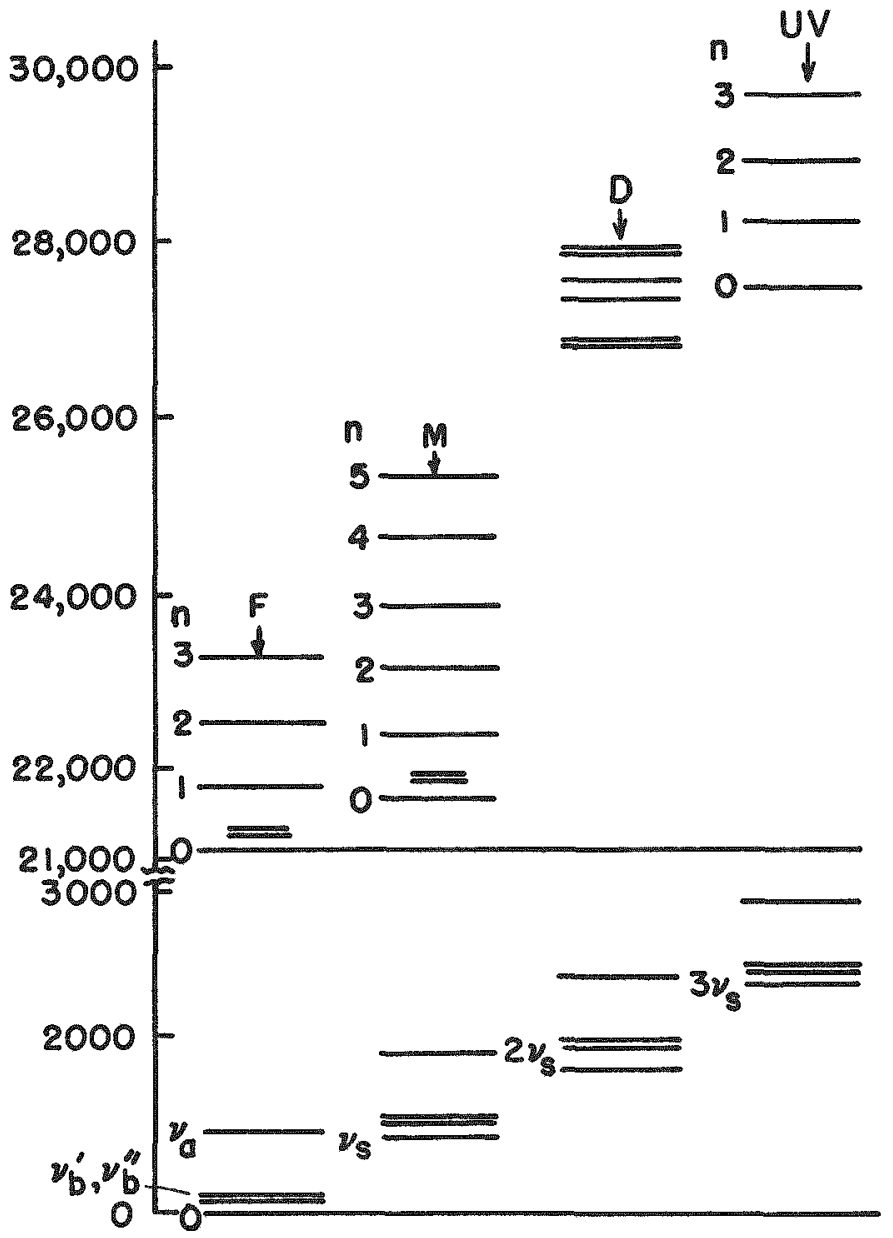

Figure 8

ENERGY LEVELS OF URANYL ION (AFTER DIEKE AND DUNCAN, 1949) 
Nichols and Howes mounted triclinic crystals of hydrated uranyl double chlorides of sodium, ammonium, or rubidium so that the light beam fell in the direction of the c-axis; in the case of the (anhydrous) cesium uranyl chloride, the light was directed parallel to the $b$-axis. Under these conditions two different absorption spectra could be obtained for light beams polarized in two mutually perpendicular planes. The crystals appeared greenish-yellow in one case ("green spectrum") and yellowishwhite in the other ("white spectrum").

Similarly, the fluorescence spectrum could be divided into two spectra ("green" and "white") depending on the polarization of its bands. The fluorescence bands of the uranyl double chlorides at $+20^{\circ} \mathrm{C}$ can often be considered as unresolved doublets (cf., p. 43 ); polarization experiments indicated that one component of the doublet often belongs to the "green" and the other to the "white" spectrum. The relation between the two types of bands in the absorption spectrum appeared less simple, but here, too, many bands proved to be doublets, consisting of one "green" and one "white" component. As the temperature was lowered to $-185^{\circ} \mathrm{C}$, the two systems changed in sharpness and relative intensity.

Similar observations were made by Dieke and co-workers. They, too, noted that in properly oriented single crystals of uranyl double chlorides or nitrates the absorption spectra were different for light beams polarized in two mutually perpendicular planes. By using a calcite rhomb between crystal and spectrograph slit, the absorption spectrum could be divided into two spectra - one for the ordinary and one for the extraordinary beam. Crystals of uranyl double chlorides or nitrates are thin plates with the axis of optical asymmetry (which probably coincides with the $\mathrm{O}-\mathrm{U}-\mathrm{O}-\mathrm{axis}$ in the $\mathrm{UO}_{2}^{++}$ion) in the plane of the plate. The two light beams fell normally on the face of the plate and were polarized perpendicular and parallel to the optical axis, respectively. Most of the absorption bands could be observed at low temperatures only in one of the two polarized beams. A few appeared in both, but with different relative intensities and with slightly different wave lengths. This strong dichroism made the crystals appear differently colored in the two transmitted beams. When the transmitted light was polarized parallel to the optical axis, little absorption occurred in the blue and the crystals appeared whitish ("white spectrum"). Blue light polarized normally to the optical axis was absorbed much more strongly than blue light polarized parallel to the axis, and in the so-polarized beam the crystal appeared yellow ("yellow spectrum," equivalent to Nichols and Howes" "green spectrum").

The differences in polarization must be taken as indicating a further multiplicity of excited electronic states in addition to that derived from the existence of the "fluorescent," "magnetic," and "ultraviolet" series (p.35). 
4.4 Analysis of Uranyl Spectrum: Vibrational Frequencies $\nu_{5}, \nu_{a}$ and $\nu_{\mathrm{b}}$ - The main reason for identifying the frequency $810-880 \mathrm{~cm}^{-1}$ with the symmetric bond frequency $\nu_{s}$ was given before (p. 5 ): it is its strong coupling with electronic transition, revealed by the excitation of several (up to 8) quanta of this vibration in electronic absorption and fluorescence bands.

Attribution of the higher frequency $\left(\nu \simeq 900 \mathrm{~cm}^{-1}\right)$ to the antisymmetric bond vibration also seems certain. It is supported by the analysis of the isotope effect and by the frequency values. According to equation 2 , the ratio $\nu_{\mathrm{s}} / \nu_{\mathrm{a}}$ should be 1.065 ; the observed ratios of the two frequencies are $\frac{956}{884}=1.081$ for cesium uranyl nitrate and $\frac{916}{836}=1.096$ for cesium uranyl chloride.

An argument against this interpretation is that symmetry considerations make simultaneous excitation of $\nu_{s}$ and $\nu_{a}$ appear impossible; but, as mentioned once before, exclusion rules of this type apply strictly to free gaseous emitters or absorbers. (For other arguments and an alternative interpretation of the $210 \mathrm{~cm}^{-1}$ frequency, see p.10.)

In some compounds such as $\mathrm{CsUO}_{2}\left(\mathrm{NO}_{3}\right)_{3}$, there is only one strong band in addition to those accounted for by $\nu_{\mathrm{s}}$ and $\nu_{\mathrm{a}}$, and its interpretation as $\nu_{s}+\nu_{b}$ appears natural. However, this band has three components, and the frequency $\nu_{b}$ must thus be triple. while theoretically one would expect only a doublet (p. 4).

The frequencies $\nu_{\mathrm{s}}, \nu_{\mathrm{a}}$, and $\nu_{\mathrm{b}}$ vary somewhat from compound to compound. Already Nichols and Howes knew that the intervals in the fluorescence band series of uranyl compounds (which we now know to be equal to the symmetric bond vibration frequency, $\nu_{s}$ ) a fe not quite constant. Fur ther examples of such variations were given by Pant (1944, 1945). The highest $\nu_{\mathrm{s}}$ frequencies (up to $888 \mathrm{~cm}^{-1}$ ). indicating the strongest $\mathrm{U}-\mathrm{O}$ bond, were observed in simple and double uranyl nitrates; lower values $\left(830-860 \mathrm{~cm}^{-1}\right)$ were found in chloride, acetate, and sulfate, and the lowest one (804-815 $\left.\mathrm{cm}^{-1}\right)$ was found in carbonate and phosphate.

Exact determinations of $\nu_{s}$ values at low temperatures for a number. of uranyl compounds were made by Dieke and co-workers. They were able to determine the antisymmetric frequencies, $\nu_{a}$, and the changes which $\nu_{\mathrm{s}}$ and $\nu_{\mathrm{a}}$ undergo with increasing intensity of vibration.

Table 6 contains the values of $\nu_{a}$ derived from the fluorescence series $\nu_{F}-\mathrm{n} \nu_{s}-\nu_{\mathrm{a}}$. The decline of the values in the vertical asymmetric vibration is the result of a growing number of quanta of the symmetric vibration.

In the second and third column of Table 7 , the vibrational frequencies $\nu_{s}$ and $\nu_{a}$ of the ground state are given for a larger variety of solid uranyl salts. 
Table 5

SYMMETRIC VIBRATION FREQUENCIES (IN $\mathrm{cm}^{-1}$ ) OF THE GROUND STATE OF THE UO ${ }_{2}^{++}$ION (AFTER DIEKE AND DUNCAN, 1949)

\begin{tabular}{|c|c|c|c|c|c|c|c|c|}
\hline \multirow{2}{*}{ Interpretation } & \multicolumn{3}{|c|}{ Double nitrates, $\mathrm{XUO}_{2}\left(\mathrm{NO}_{3}\right)_{3}$} & \multicolumn{2}{c|}{$\begin{array}{c}\text { Uranyl Nitrate, } \\
\mathrm{UO}_{2}\left(\mathrm{NO}_{3}\right)_{2}\end{array}$} & \multicolumn{2}{c|}{$\begin{array}{c}\text { Double chlorides, } \\
\mathrm{X}_{2} \mathrm{UO}_{2} \mathrm{Cl}_{4}\end{array}$} \\
\cline { 2 - 9 } & $\mathrm{Cs}$ & $\mathrm{Rb}$ & $\mathrm{K}$ & $\mathrm{NH}_{4}$ & $3 \mathrm{H}_{2} \mathrm{O}$ & $6 \mathrm{H}_{2} \mathrm{O}$ & $\mathrm{Cs}_{2}$ & $\mathrm{~K}_{2}$ \\
\hline$\nu_{\mathrm{s}}$ & 883.98 & 887.89 & 875.46 & 885.67 & 873.98 & 863.85 & 836.10 & 831.83 \\
$\left(2 \nu_{\mathrm{s}}-\nu_{\mathrm{s}}\right)$ & 879.76 & 883.12 & 871.38 & 885.01 & 870.79 & 862.58 & 832.85 & 833.41 \\
$\left(3 \nu_{\mathrm{s}}-2 \nu_{\mathrm{s}}\right)$ & 878.60 & 882.16 & 869.56 & $\ldots .-$ & $\ldots .$. & $\ldots .-$ & 830.51 & $\ldots$ \\
$\left(4 \nu_{\mathrm{s}}-3 \nu_{\mathrm{s}}\right)$ & 876.32 & 879.79 & 867.13 & $\ldots$ & $\ldots$ & $\ldots . .$. & 828.14 & $\ldots$ \\
\hline
\end{tabular}

Table 5 shows the frequencies $\nu_{\mathrm{s}}$ derived from the successive members of the fluorescence series, $\nu_{F}-n \nu_{s}$ in the fluorescence spectrum of several $\mathrm{UO}_{2}^{++}$salts. The decline of $\nu_{\mathrm{s}}$ with increasing excitation of the symmetric vibration, shown in vertical columns of Table 5 , indicates the extent of deviation of the $\mathrm{O}-\mathrm{U}=\mathrm{O}$ system from harmonic conditions.

Table 6

ASYMMETRIC BOND VIBRATION FREOUENCIES (IN $\mathrm{cm}^{-1}$ ) OF THE GROUND STA TE OF THE UO ${ }_{2}^{+{ }_{1 O N}}$ (AFTER DIEKE AND DUNCAN, 1949)

\begin{tabular}{|c|c|c|c|c|c|c|c|c|c|}
\hline \multirow{3}{*}{ Interpretation } & \multirow{2}{*}{\multicolumn{4}{|c|}{ Double nitrates, $\mathrm{XUO}_{2}\left(\mathrm{NO}_{3}\right)_{3}$}} & \multirow{2}{*}{\multicolumn{2}{|c|}{$\begin{array}{l}\text { Uranyl nitrate, } \\
\text { UO }_{2}\left(\mathrm{NO}_{3}\right)_{2}\end{array}$}} & \multicolumn{3}{|c|}{ Double chlorides, $\mathrm{X}_{2} \mathrm{UO}_{2} \mathrm{Cl}_{4}$} \\
\hline & & & & & & & \multirow[b]{2}{*}{$\mathrm{Cs}_{2}$} & \multicolumn{2}{|c|}{$\mathrm{K}_{2}$} \\
\hline & Cs & $\mathrm{Rb}$ & $\mathbf{K}$ & $\mathrm{NH}_{4}$ & $3 \mathrm{H}_{2} \mathrm{O}$ & $6 \mathrm{H}_{2} \mathrm{O}$ & & $20^{\circ} \mathrm{K}$ & $70^{\circ} \mathrm{K}$ \\
\hline$\left(\nu_{s}+\nu_{a}\right)-\nu_{s}$ & 956.20 & 962.07 & 949.91 & 959.41 & 948.12 & 940.99 & 906.26 & 903.18 & 902.89 \\
\hline$\left(2 \nu_{\mathrm{s}}+\nu_{\mathrm{a}}\right)-2 \nu_{\mathrm{s}}$ & 951.82 & 955.64 & 944.34 & 956.43 & 941.47 & 935.95 & 909.74 & 901.75 & 902.04 \\
\hline$\left(3 \nu_{\mathrm{s}}+\nu_{\mathrm{a}}\right)-3 \nu_{\mathrm{s}}$ & 948.22 & 951.91 & 940.49 & 951.56 & 936.32 & $931.38-$ & 904.82 & $\ldots$ & $\ldots$ \\
\hline$\left(4 \nu_{\mathrm{s}}+\nu_{\mathrm{a}}\right)-4 \nu_{\mathrm{s}}$ & 942.71 & 946.25 & 935.09 & $\cdots$ & 930.11 & 938.50 & 899.03 & $\cdots$ & $-\infty$ \\
\hline
\end{tabular}


Table 7

SPECTROSCOPIC CONSTANTS OF SOLID URANYL SALTS

AT $20^{\circ} \mathrm{K}$ (AFTER DIEKE AND DUNCAN, 1949)

\begin{tabular}{|c|c|c|c|c|c|c|}
\hline \multirow[b]{2}{*}{ Compound } & \multirow[b]{2}{*}{$\nu_{\mathrm{s}}$} & \multirow[b]{2}{*}{$\nu_{\mathrm{a}}$} & \multirow[b]{2}{*}{$\begin{array}{c}\text { Fluores - } \\
\text { cence } \\
\text { Series }\end{array}$} & \multicolumn{3}{|c|}{$\nu_{\mathbb{E}}$} \\
\hline & & & & $\begin{array}{l}\text { Magnetic } \\
\text { Series }\end{array}$ & $\begin{array}{c}\text { Differ } \\
\text { ence } \\
\text { Series }\end{array}$ & $\begin{array}{c}\text { U1traviolet } \\
\text { Series }\end{array}$ \\
\hline $\begin{array}{l}\mathrm{Nitrates} \\
\mathrm{UO}\left(\mathrm{NO}_{3}\right)_{2} \cdot 3 \mathrm{H}_{2} \mathrm{O} \\
\mathrm{UO}\left(\mathrm{NO}_{3}\right)_{2} \cdot 6 \mathrm{H}_{2} \mathrm{O} \\
\mathrm{CsUO}\left(\mathrm{NO}_{3}\right)_{3} \\
\text { Impurity in above } \\
\mathrm{RbUO}\left(\mathrm{NO}_{3}\right)_{3} \\
\mathrm{KUO}_{2}\left(\mathrm{NO}_{3}\right)_{3} \\
\mathrm{NH}_{4} \mathrm{UO}_{2}\left(\mathrm{NO}_{3}\right)_{3} \\
\mathrm{Rb}_{2} \mathrm{UO}_{2}\left(\mathrm{NO}_{3}\right)_{4} \\
\mathrm{~K}_{2} \mathrm{UO}_{2}\left(\mathrm{NO}_{3}\right)_{4}\end{array}$ & $\begin{array}{l}874.0 \\
863.9 \\
884.0 \\
876.0 \\
887.9 \\
875.5 \\
885.7 \\
861.3 \\
870.3\end{array}$ & $\begin{array}{l}948.1 \\
941.0 \\
956.2 \\
949.8 \\
962.1 \\
949.9 \\
959.4 \\
937.7 \\
949.5\end{array}$ & $\begin{array}{l}20,778.7 \\
20,578.3 \\
21,089.6 \\
20,947.5 \\
21,199.4 \\
21,183.0 \\
21,097.7 \\
20,817.8 \\
20,807.8\end{array}$ & $\begin{array}{l}21,480 \\
21,693.2 \\
21,796.8 \\
21,873\end{array}$ & $\begin{array}{l}23,219 \\
23,801\end{array}$ & $\begin{array}{l}27,196 \\
26,832 \\
26,959\end{array}$ \\
\hline $\begin{array}{l}\text { Chlorides } \\
\mathrm{Cs}_{2} \mathrm{UO}_{2} \mathrm{Cl} \\
\text { Impurity in above } \\
\text { Impurity in above } \\
\text { Impurity in above } \\
\mathrm{Rb}_{2} \mathrm{UO}_{2} \mathrm{Cl} \cdot 2 \mathrm{H}_{2} \mathrm{O} \\
\mathrm{K}_{2} \mathrm{UO}_{2} \mathrm{Cl}_{4} \cdot 2 \mathrm{H}_{2} \mathrm{O}\end{array}$ & $\begin{array}{l}836.1 \\
827.9 \\
827.7 \\
827.1 \\
831.8 \\
831.6\end{array}$ & $\begin{array}{l}916.3 \\
891.2 \\
904.6 \\
905.2 \\
903.2 \\
902.9\end{array}$ & $\begin{array}{l}20,096.3 \\
19,958.3 \\
19,728.2 \\
19,521.4 \\
19,961.2 \\
19,969.9\end{array}$ & $22,245.4$ & 22,975 & 26,185 \\
\hline $\begin{array}{l}\text { Sulfates } \\
\mathrm{Cs}_{2} \mathrm{UO}_{2}\left(\mathrm{SO}_{4}\right)_{2} \cdot 3 \mathrm{H}_{2} \mathrm{O} \\
\mathrm{Rb}_{2} \mathrm{UO}_{2}\left(\mathrm{SO}_{4}\right)_{2} \\
\mathrm{~K}_{2} \mathrm{UO}_{2}\left(\mathrm{SO}_{4}\right)_{2} \\
\left(\mathrm{NII}_{4}\right)_{2} \mathrm{UO}_{2}\left(\mathrm{SO}_{4}\right)_{2}\end{array}$ & $\begin{array}{l}860.5 \\
838.2 \\
827 \\
840\end{array}$ & 923.1 & $\begin{array}{l}20,593.6 \\
20,390.2 \\
20,389 \\
20,358\end{array}$ & & $\begin{array}{l}22,680 \\
22,544\end{array}$ & $\begin{array}{l}27.702 \\
27.635\end{array}$ \\
\hline $\begin{array}{l}\text { Acetates } \\
\mathrm{CsUO}_{2}\left(\mathrm{CHI}_{3} \mathrm{COO}\right)_{3} \\
\mathrm{RbUO}_{2}\left(\mathrm{CH}_{3} \mathrm{COO}\right)_{3} \\
\mathrm{NaUO}_{2}\left(\mathrm{CH}_{3} \mathrm{COO}\right)_{3} \\
\mathrm{NH}_{4} \mathrm{UO}_{2}\left(\mathrm{CH}_{3} \mathrm{COO}\right)_{3} \\
\mathrm{MgUO}_{2}\left(\mathrm{CHI}_{3} \mathrm{COO}\right)_{4} \\
\mathrm{PbUO}_{2}\left(\mathrm{CH}_{3} \mathrm{COO}\right)_{4}\end{array}$ & $\begin{array}{l}842.2 \\
852.1 \\
855.2 \\
847 \\
853\end{array}$ & $\begin{array}{l}920.0 \\
924.0 \\
927.2\end{array}$ & $\begin{array}{l}20,992.1 \\
21,049.4 \\
21.135 .0 \\
21,056 \\
20,996 \\
20.958\end{array}$ & $\begin{array}{l}21,800 \\
21,912 \\
21,811 \\
21,725\end{array}$ & $\begin{array}{l}23,820 \\
23,740 \\
23,636\end{array}$ & $\begin{array}{l}27,140 \\
26,876 \\
27,568\end{array}$ \\
\hline $\begin{array}{l}\text { Carbonate } \\
\mathrm{K}_{2} \mathrm{UO}_{2}\left(\mathrm{CO}_{3}\right)_{2}\end{array}$ & 808 & 856 & 20,943 & & & 27,775 \\
\hline
\end{tabular}


4.5 Zeeman Effect - Dieke and Duncan (1949, p. 73) could observe no Zeeman splitting in the fluorescence spectrum of solid uranyl salts. The same was true of the absorption spectrum of certain of them; a Zeeman effect appeared, however, in some of the absorption lines of others. There the lines subject to Zeeman splitting formed a separate series which was designated as "magnetic series" (symbol M). The name was used also for an analogous series of lines in compounds in which no Zeeman effect was noticeable, (cf.. Table 7). For the Zeeman effect to appear, the O-U-O direction in the crystal must be a symmetry axis; in this case, the angular momentum around this axis is quantized (quantum number $\lambda$ ), and except for the states for which $\lambda=0$ ( $\Sigma$ states), all other states $(\pi, \Delta .$.$) are doubly de-$ generate in the absence of a magnetic field (since the $\lambda$ vector can have two opposite directions). This degeneration is removed by the application of a magnetic field parallel to the axis of symmetry. The lines in which $\lambda$ is the same for both terms must remain single in the magnetic field and polarized parallel to the field. The lines for which $\Delta \lambda= \pm 1$ must split into two components which are circularly polarized but appear linearly polarized (nor mally to the field) when viewed under a right angle to the magnetic vector.

These theoretical expectations were confirmed by observations, mainly in the absorption spectrum of $\mathrm{CsUO}_{2}\left(\mathrm{NO}_{3}\right)_{3}$. The crystals of this salt have a threefold axis of symmetry parallel to the U-O direction. When a single crystal of this salt is placed in the magnetic field with the symmetry axis parallel to the field vector, many lines are split into doublets. No splitting is observed when the optical axis is normal to the field. The magnitude of the observed splitting (about $2 \mathrm{~cm}^{-1}$ in a field of $24 \mathrm{Kgauss}$ ) corresponds, within the limits of error, to the theoretical value (which is $2 \mathrm{~g}$, or $0.0935 \mathrm{~cm}^{-1}$, per Kgauss).

The fact that of the several electronic transitions involved in the absorption spectrum only one is affected by the magnetic field indicates that all the other observed series - except the $M$ series - are due to $\Sigma \rightarrow \Sigma$ transitions. (That the ground state is a $\Sigma$ state follows from the absence of per manent paramagnetism at low temperatures; the lines showing no Zeeman splitting must lead to excited states of the same type.) The upper electronic state of the magnetic series must then be a $\pi$ state.

If absorption were due to a quadrupole (rather than a weak dipole) transition (cf., p. 39), lines with $\Delta \lambda=2$ (e.g., $\Delta \rightarrow \Sigma$ transitions) could appear; these would give rise to more complex Zeeman patterns. The fact that only doublets have so far been observed in the magnetic field indicates that the uranyl spectrum contains only lines with $\Delta \lambda=0$ or 1 , and this in turn argues for the attribution of this spectrum to a weak dipole transition.

The crystals of $\mathrm{RbUO}_{2}\left(\mathrm{NO}_{3}\right)_{3}$, with a structure similar to that of the cesium uranyl double nitrate, show a similar magnetic splitting, and one may expect the same behavior from other uniaxial uranyl salts. In biaxial crystals, on the other hand, no degeneracy in respect to the $\mathrm{O}-\mathrm{U}-\mathrm{O}$ axis exists, even in states with a non-vanishing momentum around this axis, since the 
asymmetry of the internal electric field is enough to cause a separation. In agreement with this no magnetic splitting is observed in the absorption spectra of biaxial crystals, such as $\mathrm{CsUO}_{2} \mathrm{Cl}_{4}$ and $\mathrm{K}_{2} \mathrm{UO}_{2}\left(\mathrm{SO}_{4}\right)_{2}$.

4.6 Isotope Effect - The isotope effect was studied by Dieke, Duncan, and co-workers by preparing uranyl salts enriched in $U^{235}, N^{15}, O^{17}$, $\mathrm{O}^{18}$, and $\mathrm{H}^{2}$. The substitution of uranvl or oxygen isotopes affects the vibrational frequencies in the UOt ton $^{+}$itself, the substitution of nitrogen or hydrogen isotopes only vibrations involving the nitrate anion or the as sociated water molecules (in hydrated salts). The occurrence of spectral shifts caused by nitrogen and hydrogen isotope substitutions thus permits the identification of lines involving excitation of vibrations in crystal elements other than the uranyl ion itself. For a detailed discussion of these effects, we refer to the monograph of Dieke and Duncan; here we will.present only a brief summary of observations concerning the effect of the $\mathrm{U}^{235}-\mathrm{U}^{238}$ and $\mathrm{O}^{16}-\mathrm{O}^{18}$ substitution.

Assuming simple elastic force between the uranium atom and the oxygen atoms in $\mathrm{UO}_{2}^{++}$, the effect of isotopic substitutions on vibrational frequencies can be calculated theoretically (from equations 1 to 3 and the somewhat more complex equation for the asymmetric molecule $\mathrm{O}^{18} \mathrm{UO}^{16}$ ).

Table 8 show the expected ratios of frequencies for the six isotopic molecules. For the bending vibration $\left(\nu_{b}\right)$ the se ratios are expressed in terms of the parameter $c=\sqrt{2 \mathrm{~d} / \mathrm{f}}$, where d and 1 are the elastic constants of the U-O bond vibration and the bending vibration respectively (cf., $\mathrm{p} . \quad$.)

Table 8
CALCULATED OXYGEN- AND URANIUM-ISOTOPE EFFECTS $(c=\sqrt{2 d / f)}$

\begin{tabular}{|c|c|c|c|c|}
\hline \multirow{2}{*}{} & & \multicolumn{2}{|c|}{ Ratios of Analogous Frequencies } \\
\cline { 3 - 5 } & & $\mathrm{O}^{16}-\mathrm{O}^{16}$ & $\mathrm{O}^{16}-\mathrm{O}^{18}$ & $\mathrm{O}^{18}-\mathrm{O}^{18}$ \\
\hline \multirow{3}{*}{$\nu_{\mathrm{s}}$} & $\mathrm{U}^{238}$ & 1.00000 & 0.96149 & 0.94281 \\
& $\mathrm{U}^{235}$ & 1.00000 & 0.96159 & 0.94281 \\
& $\mathrm{U}_{\mathrm{a}}$ & 1.06511 & 1.04827 & 1.01160 \\
& $\mathrm{U}^{235}$ & 1.06591 & 1.04900 & 1.01245 \\
& $\mathrm{U}_{\mathrm{b}}^{238}$ & $1.06511 \mathrm{c}$ & $1.03870 \mathrm{c}$ & $1.01160 \mathrm{c}$ \\
& $\mathrm{U}^{235}$ & $1.06591 \mathrm{c}$ & $1.03953 \mathrm{c}$ & $1.01245 \mathrm{c}$ \\
\hline
\end{tabular}

For the symmetric vibration in the molecular $\mathrm{O}^{16} \mathrm{UO}^{16}$ in which the uranium atom remains at rest, the effect of the substitution of $U^{235}$ 
is nil. It becomes finite but is still very small, for the similar vibration in the asymmetric molecule, $\mathrm{O}^{18} U \mathrm{O}^{16}$. The largest uranium-isotope effect can be expected in the asymmetric vibration, $\nu_{a}$.

The effect of substituting $O^{18}$ for $O^{16}$ is considerably larger than that of the uranium substitution (cf., Tables 9 and 10).

Table 9

EXPECTED ISOTOPIC SHIETS IN $\mathrm{cm}^{-1}$ FOR SUBSTITUTION U $U^{238}-U^{235}$

\begin{tabular}{|c|c|c|c|}
\hline & $O^{16}-O^{16}$ & $O^{16}-O^{18}$ & $O^{18}-O^{18}$ \\
\hline$\nu_{s}$ & 0 & 0.09 & 0 \\
$\nu_{a}$ & 0.71 & 0.64 & 0.75 \\
$\nu_{b}$ & 0.17 & 0.17 & 0.18 \\
\hline
\end{tabular}

Table 10

EXPECTED OXYGEN ISOTOPE EFFECTS IN $\mathrm{cm}^{-1}$

\begin{tabular}{|c|c|c|c|}
\hline & $\begin{array}{c}\mathrm{O}^{16}-\mathrm{O}^{16} \\
\text { frequency }\end{array}$ & $\begin{array}{c}\mathrm{O}^{16}-\mathrm{O}^{18} \\
\text { shift }\end{array}$ & $\begin{array}{c}\mathrm{O}^{18}-\mathrm{O}^{18} \\
\text { shift }\end{array}$ \\
\hline$\nu_{\mathrm{s}}$ & 860 & 33.1 & 50.2 \\
$\nu_{\mathrm{a}}$ & 940 & 14.9 & 47.3 \\
$\nu_{\mathrm{b}}$ & 220 & 5.5 & 11.1 \\
\hline
\end{tabular}

Shifts of about $0.7 \mathrm{~cm}^{-1}$ have been observed by Dieke, et al., in many lines of the (low temperature) fluorescence spectrum of $\mathrm{CsUO}\left(\mathrm{NO}_{3}\right)_{3}$ when $U^{235}$ was substituted for $U^{238}$. These lines must involve the excitation of a quantum of the antisymmetric vibration, $\nu_{2}$. Absence of shifts of 1.4 or $2.1 \mathrm{~cm}^{-1}$ indicates that only one quantum of asymmetric vibration is excited in coupling with the electronic transition. In the fluorescence spectrum of $\mathrm{Cs}_{2} \mathrm{UO}_{2} \mathrm{Cl}_{4}$, in addition to isotopic shifts of $0.6-0.8 \mathrm{~cm}^{-1}$, shifts of $\sim 0.3 \mathrm{~cm}^{-1}$ and of $1.1-1.3 \mathrm{~cm}^{-1}$ also have been noted.

Figure $9 \mathrm{~A}$ shows a typical uranium isotope effect in the fluorescence spectrum of cesium uranyl nitrate. The " $\mathrm{U}^{2359}$ specimen was an enriched sample containing 79 per cent $\mathrm{U}^{235}$

In the absorption spectrum of $\mathrm{Cs}_{2} \mathrm{UO}_{2} \mathrm{Cl}_{4}$, the calculated shift of the $\nu_{a}^{*}$ Irequency $\left(731 \mathrm{~cm}^{-1}\right)$ is $0.6 \mathrm{~cm}^{-11}$. Experimentally, shifts up to $1.62 \mathrm{~cm}^{-1}$ 


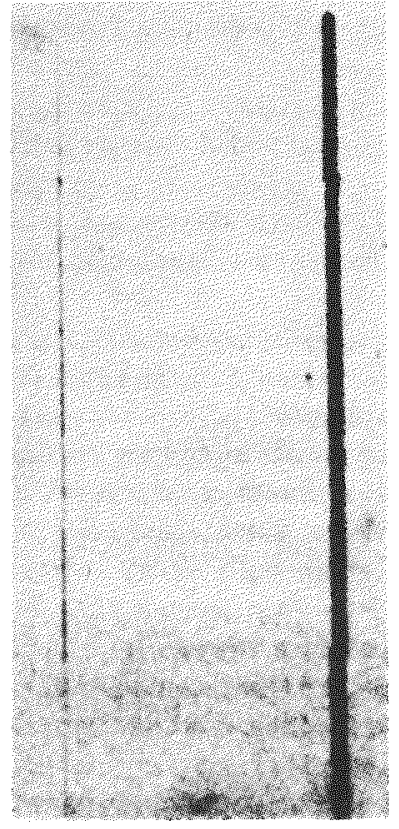

4 $3 A+B$

(a)

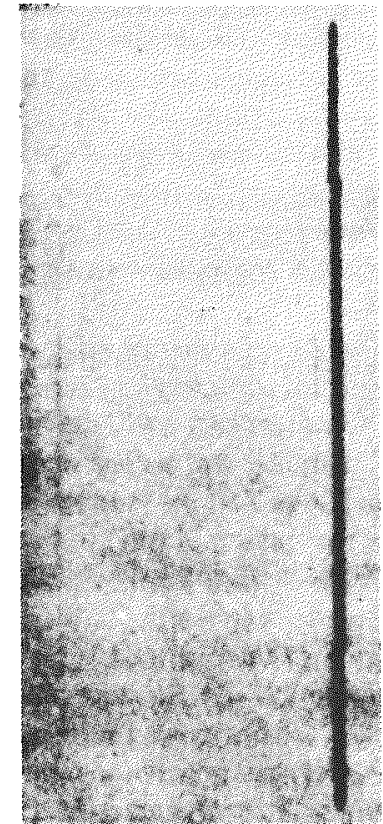

$5 A$

(b)

Figure 9A

URANIUM-ISOTOPE EFFECT IN THE FLUORESCENCE SPECTRUM OF CsUO $2\left(\mathrm{NO}_{3}\right)_{3}$ MIDDLE, ENRICHED SAMPLE; TOP AND BOTTOM, ORDINARY SAMPLE (IRON COMPARISON FAINTLY IN MIDOLE) 
have been noted. Three quanta of asymmetric vibration, $\nu_{a}^{*}$, must be acquired in lines showing this strong shift (expected shift for $3 \nu_{a}^{*}$ is $1.8 \mathrm{~cm}^{-1}$ ). Lines in which two $\nu_{\mathrm{a}}^{*}$ quanta are acquired show an isotopic shift of $1.3-1.4 \mathrm{~cm}^{-1}$ (expected, $1.2 \mathrm{~cm}^{-1}$ ). Observed shifts which are smaller than $0.6 \mathrm{~cm}^{-1}$ may be due to lines whose terms are perturbed by the proximity of terms containing $\nu_{a}^{*}$ vibrations.

Only small uranium isotope shifts, attributable to perturbation ef fects, have been observed in the absorption spectrum of $\mathrm{Cs} \mathrm{UO}_{2}\left(\mathrm{NO}_{3}\right)_{3}$, indicating that $\nu_{a}^{*}$ vibration quanta are not involved in any of the measured lines (cf., p.49).

The results of $O^{18}$ substitution $\left(1.36\right.$ per cent $\left.O^{18}\right)$ are, as expected, far more pronounced. For example, isotope shifts up to $166 \mathrm{~cm}^{-1}$ have been observed in the fluorescence spectrum of $\mathrm{CsUO}_{3}\left(\mathrm{NO}_{3}\right)_{3}$. Such a shift is to be expected, according to Table 10, for the excitation of five quanta of symmet$r$ ic vibrations, $\nu_{s}$ in the asmmetric molecule $O_{18} \mathrm{UO}_{16}$. The observed. shifts for the excitation of single vibrations are as follows:

\begin{tabular}{lcc} 
In nitrate & In chloride & $\begin{array}{c}\text { Expected } \\
\text { (Table 10) }\end{array}$ \\
\cline { 2 - 3 } 31.4 & 29.7 & $\frac{33.1 \mathrm{~cm}^{-1}}{13.7}$ \\
16.3 & $14.9 \mathrm{~cm}^{-1}$
\end{tabular}

Agreement with the simple model is as good as could reasonably be expected.

4.7 Intensity Studies: Life Time of Excited State - Absolute intensity measurements of a number of absorption bands were carried out by Dieke, et al. at $77^{\circ} \mathrm{K}$ rather than at $20^{\circ} \mathrm{K}$, because it was easier to measure the contours of broader bands. Measurements were made with a $1.5 \mathrm{~mm}$ thick crystal of $\mathrm{CsUO}_{2}\left(\mathrm{NO}_{3}\right)_{3}$.

Values of the order of $3.7 \times 10^{-8}$ (resonance band at $4740.36 \mathrm{~A}$ ): $8.2 \times 10^{-8}(4698.91 \mathrm{~A})$ and $1.36 \times 10^{-8}(4608.45 \mathrm{~A})$ were obtained for the "electronic strength," $\underline{f}_{\text {, }}$ of some of the strongest bands. A summation over all the bands belonging to the same electronic transition (e.g.. all bands of the fluorescent series) could not change the magnitude of these values by more than one unit $\left(\sum f \approx 10^{-7}\right)$. This is a value expected theoretically for guadrupole (rather than dipole) radiations. It may be, however, that we deal here with a very weak (forbidden) dipole transition: this alternative, proposed before on $p_{.} 4$, is supported by Vavilov and Levshin's interpretation of experiments on de-polarization of uranyl fluorescence.

An $\underline{f}$ number of $10^{-7}$ means that the natural lifetime of the excited electronic state is of the order of $10^{-1} \mathrm{sec}$. This value can be compared with the experimentally determined lifetime of fluorescence of uranyl salts. According to p.17. the latter is considerably shorter (about $5 \times 10^{-\frac{4}{2}} \mathrm{sec}$ ). 
Dieke saw here no contradiction, pointing out that only an upper limit for the actual duration of fluorescence is given by the natural lifetime of the excited state. However, the reduction of natural lifetime by a factor of 200 (from $10^{-1}$ to $5 \times 10^{-4} \mathrm{sec}$ ) must mean a corresponding reduction in the yield of fluorescence (from 100 per cent to 0.5 per cent) while the actual yield of uranyl fluorescence in solution was estimated - albeit by a very rough and indirect method - as close to 100 per cent! The discrepancy with Dieke's results remains to be explained. The extinction curve on non-hydrolyzed uranyl ions in solutions indicates a peak absorption coefficient of the order of 10. Assuming a band width of $100 \mathrm{m \mu}$, or about $5000 \mathrm{~cm}^{-1}$, with an average absorption coefficient of $\alpha \simeq 1$, this corresponds to a mean lifetime of the order of $10^{-4} \mathrm{sec}$ in agreement with the fluorescence measurements.

Another interesting result of the intensity measurements relates to the width of the fluorescence bands. At very low temperature, the lines belonging to impurities were often found to be sharper than those of the $\mathrm{UO}_{2}^{++}$ions themselves; among the latter the lines of the first group were generally sharper than those belonging to the second and the subsequent groups. A plausible and significant explanation of this phenomenon is that the band is broadened by electronic resonance between neighboring $\mathrm{UO}_{2}^{++}$ions (a resonance which cannot develop in the case of impurities irregularly scattered in the lattice). Excitation of the symmetric vibration, $\nu_{\mathrm{s}}$, appears to enhance this resonance. The resonance broadening implies the occurrence of excitation energy transfers between neighboring $\mathrm{UO}_{2}^{++}$ions in the lattice. A quantitative analysis leading to an estimate of the frequency of these exchanges would be of interest for the understanding of photochemical reactions and fluorescence phenomena in uranyl salts. 


\section{ADDITIONAL SPECTROSCOPIC DATA ON SOME URANYL SALTS}

5.1 Fluorides - Pant and Sakhwalkar (1944) made a study of the fluorescence spectrum of solid, hydrated uranyl fluoride at $-185^{\circ} \mathrm{C}$. They assumed that the simplest vibrational structure of any uranyl salt can be expected in fluoride. They arrived at Table 11 for the main fluorescence bands (underlining indicates intensity).

Table 11

FREQUENCIES (IN CM ${ }^{-1}$ ) OF ILUORESCENCE BANDS

OF $\mathrm{UO}_{2} \mathrm{~F}_{2} \mathrm{AT}-185^{\circ} \mathrm{C}$

\begin{tabular}{|c|c|c|c|c|c|c|}
\hline \multirow{2}{*}{ Series } & \multicolumn{5}{|c|}{ Group } & \multirow{2}{*}{$\begin{array}{l}\Delta \nu \\
\mathrm{cm}^{-1}\end{array}$} \\
\hline & 1 & 2 & 3 & 4 & 5 & \\
\hline $\mathbb{A}$ & 20234 & 19366 & 18504 & 17641 & $-\infty$ & 864 \\
\hline $\mathrm{B}$ & 20082 & 19217 & 18353 & 17492 & 16640 & 863 \\
\hline C & $\overline{--m}$ & 19150 & $18289^{\circ}$ & 17427 & 16577 & 862 \\
\hline D & --- & 19124 & 18263 & 17404 & $-\infty$ & 861 \\
\hline $\mathbf{E}$ & $=-\infty$ & 18970 & $-\infty$ & $\infty=-$ & $-\infty$ & $-\infty$ \\
\hline
\end{tabular}

Using three normal frequencies $\left(863,242\right.$, and $\left.928 \mathrm{~cm}^{-1}\right)$ for the ground state and a single frequency $\left(150 \mathrm{~cm}^{-1}\right)$ for the excited state, a term diagram could be constructed accounting for all bands in Table 11 within $\pm 10 \mathrm{~cm}^{-1}$. The $B 1$ band $\left(20082 \mathrm{~cm}^{-1}\right)$ is the resonance band. Some combinations in the table are prohibited, but as mentioned before, the exclusion rules are not strict. Excitation with short waves $\left(\nu\right.$ exc $\left.>27000 \mathrm{~cm}^{-1}\right)$ produced no lines with $\nu>20234 \mathrm{~cm}^{-1}$; this means that all vibrational quanta of the excited state, except one, are lost before the emission of fluorescence (the remaining quantum gives rise to the "anti-Stokes" band series in the first row of the table).

Dieke and Duncan (1949) reported that the sample of $\mathrm{UO}_{2} F_{2}$ they prepared showed only faint fluorescence with no resolution into lines even at $20^{\circ} \mathrm{K}$. The contrast between this finding and that of Pant may have been due to differences in water content of the sample. A table is given by Dieke and Duncan for the absorption spectrum of the double fluoride, $\mathrm{K}_{3} \mathrm{UO}_{2} \mathrm{~F}_{5}$, at $20^{\circ} \mathrm{K}$. Similarly to the $\mathrm{CsUO}_{2}\left(\mathrm{NO}_{3}\right)_{3}$ spectrum it has a double resonance line, two double lines in the $\nu_{F}+\nu_{a}$ group, three double lines in the $\nu_{F}+2 \nu_{a}$ group, etc. The reason for such a splitting, suggested in the case of nitrate (resonance with an $\mathrm{NO}_{3}^{-}$frequency), could not be valid for the fluoride; 
perhaps, in this case, there is a resonance between the frequencies $\nu_{\mathrm{g}}$ and $\nu_{\mathrm{a}}$. According to the same observers, the fluorescence spectrum of $\mathrm{Cs}_{2} \mathrm{UO}_{2} \mathrm{~F}_{4}$ shows almost no evidence of the asymmetric frequency, $\nu_{a}$.

5.2 Chlorides - According to Dieke and Duncan (1949), the fluorescence spectrum of the simple uranyl chloride, $\mathrm{UO}_{2} \mathrm{Cl}_{2}$, varies strongly with the sample used. A very pure, supposedly anhydrous, sample showed no fluorescence at all; samples containing water fluoresced more or les strongly, often with a strong continuous background.

Compared to the spectra of the double chlorides ( $\mathrm{cf}$. , below), that of $\mathrm{UO}_{2} \mathrm{Cl}_{2}$ (hydrated) is shifted towards the violet, and the asymmetric vibration, $\nu_{2}$, occurs with much lower intensity.

The fluorescence spectra of uranyl double chlorides have been studied by Nichols and Howes, as well as by Dieke and co-workers. Nichols and Howes investigated four double chlorides: $\mathrm{UO}_{2} \mathrm{Cl}_{2} \cdot 2 \mathrm{KCl} \cdot 2 \mathrm{H}_{2} \mathrm{O}, \mathrm{UO}_{2} \mathrm{Cl}_{2} \cdot 2 \mathrm{RbCl} \cdot 2 \mathrm{H}_{2} \mathrm{O}$, $\mathrm{UO}_{2} \mathrm{Cl}_{2} \cdot 2 \mathrm{NH}_{4} \mathrm{Cl} \cdot 2 \mathrm{H}_{2} \mathrm{O}$, and $\mathrm{UO}_{2} \mathrm{Cl}_{2} \cdot 2 \mathrm{CsCl}$.

All four crystallize in triclinic plates. Their fluorescence bands are partially resolved into components even at room temperature (cf., Figures 3 and 7). Five components could be distinguished at $+20^{\circ} \mathrm{C}$ in six groups and two components in the seventh ("anti-Stokes") band in the ammonium salt; an additional (eighth) band group, also consisting of five components, was discernible at the long-wave end of the spectrum.

Nichols and Howes noted that the groups as a whole were shifted towards the shorter waves with increasing atomic weight of the alkali, ammonium falling between potassium and rubidium in accordance with the general optical properties of this ion. For example, the two strongest bands of spectrum were found in position listed in Table 12.

Table 12

STRONGEST FLUORESCENCE BANDS OF DOUBLE CHLORIDES; $\mathrm{UO}_{2} \mathrm{X}_{2} \mathrm{Cl}_{4} \cdot 2 \mathrm{H}_{2} \mathrm{O}, \mathrm{AT} 20^{\circ} \mathrm{C}$

\begin{tabular}{|l|c|c|c|c|}
\hline & $\mathrm{K}$ & $\mathrm{NH}_{4}$ & $\mathbf{R b}$ & $\mathbf{C s}$ \\
\hline$\lambda$ & 503.9 & 503.1 & 502.7 & $502.4 \mathrm{~m} \mu$ \\
$\lambda$ & 525.9 & 525.0 & 524.8 & $523.4 \mathrm{~m} \mu$ \\
\hline
\end{tabular}

As the temperature was lowered from $+20^{\circ} \mathrm{C}$ to $-185^{\circ} \mathrm{C}$, the bands first split into doublets; then one component of each doublet increased in brightness while the other became indistinct or disappeared altogether. 
The bands observed at $+20^{\circ} \mathrm{C}$ often could be considered as unresolved doublets, the stronger component being the one which is comparatively weak at lower temperatures. One component of the doublet usually belonged to the "white" and one to the "green" spectrum (p.31).

The absorption spectra of the double chlorides also are better resolved at room temperature than those of most other uranyl salts. By using several large crystals in series, Howes (1918) (cf., Nichols and Howes (1919, p. 73)) was able to measure absorption bands of the ammonium salt from 18025 to $27568 \mathrm{~cm}^{-1}$ at $20^{\circ} \mathrm{C}$ and from 19459 to $26575 \mathrm{~cm}^{-1}$ at $-185^{\circ} \mathrm{C}$.

With declining temperature the absorption bands were found to shift, generally towards the violet, and split into numerous components.

Dieke and co-workers studied the fluorescence and absorption spectra of several double chlorides. Dieke and Duncan (1949) listed the lines of the spectra indicated in Table 13.

Table 13

CHLORIDE SPECTRA STUDIED BX DIEKE AND CO-WORKERS (AFTER DIEKE AND DUNCAN, 1949)

\begin{tabular}{|l|l|c|c|c|}
\hline \multicolumn{1}{|c|}{ Compound } & Spectrum & $T^{\circ}$ abs. & Region, cm & No. of lines \\
\hline $\mathrm{Cs}_{2} \mathrm{UO}_{2} \mathrm{Cl}_{4}$ & Fluorescence & $20^{\circ} \mathrm{K}$ & $20102-15057$ & 170 \\
$\mathrm{Cs}_{2} \mathrm{UO}_{2} \mathrm{Cl}_{4}$ & Absorption & $20^{\circ} \mathrm{K}$ & $20092-24837$ & 682 \\
$\mathrm{~K}_{2} \mathrm{UO}_{2} \mathrm{Cl}_{4} \cdot 2 \mathrm{H}_{2} \mathrm{O}$ & Fluorescence & $20^{\circ} \mathrm{K}$ & $19967-16568$ & 22 \\
$\mathrm{~K}_{2} \mathrm{UO}_{2} \mathrm{Cl}_{4} \cdot 2 \mathrm{H}_{2} \mathrm{O}$ & Fluorescence & $77^{\circ} \mathrm{K}$ & $20059-17376$ & 27 \\
$\mathrm{~K}_{2} \mathrm{UO}_{2} \mathrm{Cl}_{4} \cdot 2 \mathrm{H}_{2} \mathrm{O}$ & Absorption & $20^{\circ} \mathrm{K}$ & $19978-28098$ & 457 \\
$\left(\mathrm{CH}_{3}\right)_{4} \mathrm{~N}_{2} \mathrm{UO}_{2} \mathrm{Cl}$ & Fluorescence & $77^{\circ} \mathrm{K}$ & $20142-16578$ & 38 \\
$\left(\mathrm{CH}_{3}\right)_{4} \mathrm{~N}_{2} \mathrm{UO}_{2} \mathrm{Cl}_{4}$ & Absorption & $20^{\circ} \mathrm{K}$ & $20053-27413$ & 91 \\
\hline
\end{tabular}

The number of lines in the fluorescence spectrum of $\mathrm{Cs}_{2} \mathrm{UO}_{2} \mathrm{Cl}_{4}$ is considerably smaller than in the cesium uranyl nitrate spectrum, undoubtedly because of the absence of a polyatomic group such as $\mathrm{NO}_{3}^{-}$.

The electronic transitions $\nu_{F}$ and the vibrational frequencies $\nu_{\mathrm{s}}$ and $\nu_{\mathrm{a}}$, derived from the analysis of the spectra listed in Table 15, were given in Table 7 for $\mathrm{Cs}_{2} \mathrm{UO}_{2} \mathrm{Cl}_{4}, \mathrm{RbUO}_{2} \mathrm{Cl}_{4} \cdot 2 \mathrm{H}_{2} \mathrm{O}$, and $\mathrm{K}_{2} \mathrm{UO}_{2} \mathrm{Cl}_{4} \cdot 2 \mathrm{H}_{2} \mathrm{O}$. The transition $\nu_{M}$ was identified in the cesium and rubidium salts, the transitions $\nu_{D}$ and $\nu U V$ in the cesium salt only. 
The fluorescence spectra of the (triclinic) dihydrates of $\mathrm{Rb}_{2} \mathrm{UO}_{2} \mathrm{Cl}_{\frac{8}{2}}$ and $\mathrm{K}_{2} \mathrm{UO}_{2} \mathrm{Cl}_{4}$ resemble each other closer than they do the spectrum of the anhydrous (but probably also triclinic) cesium salt. The vibrational frequencies of all double chlorides are lower than those of the double nitrates. The asymmetric vibrations are strongly excited by all chlorides. In these compounds both the frequencies $\nu_{\mathrm{s}}$ and $\nu_{\mathrm{a}}$ are narow doublets, with a separation of about $2 \mathrm{~cm}^{-1}$.

The resonance line has a weak violet satellite in the rubidium and potassium double chloride (but not in the anhydrous cesium salt).

According to Dieke and Duncan (1949), the absorption spectrum of the uranyl chlorides appears at the first sight more complex than that of the nitrates (680 bands between 4975 and $4025 \mathrm{~A}$ in $\mathrm{Cs}_{2} \mathrm{UO}_{2} \mathrm{Cl}_{4}$, as against 615 bands between 4740 and $3360 \mathrm{~A}$ in $\left.\mathrm{CsUO}_{2}\left(\mathrm{NO}_{3}\right)_{3}\right)$, but its basic structure is simpler. However, only the first groups ( $4976-4483$ A) have been analyzed by Dieke. The resonance band (of the fluorescence series) occurs in the "white" spectrum only and lies at 4974.91 A. Other lines correspond to combinations of this transition with vibrational frequencies of the excited state, identified 2s $\nu_{\mathrm{b}}^{*}, \nu_{\mathrm{b}}^{*}\left(232.61,237.11 \mathrm{~cm}^{-1}\right), \nu_{\mathrm{s}}^{*}\left(713.7 \mathrm{~cm}^{-1}\right)$ and $\nu_{\mathrm{a}}^{*}$, $\nu_{\mathrm{a}}^{*}, \nu_{\mathrm{a}}^{* \prime \prime}\left(731.1,732.4,734.6 \mathrm{~cm}^{-1}\right)$. The bending vibration is thus double, and the asymmetric bond vibration, triple. In contrast to the conditions in the fluorescence spectrum, several quanta of these vibrations can be excited simultaneously with the absorption of an electronic quantum. In addition to these fairly well identified fundamental $\mathrm{UO}_{2}^{++}$vibration frequencies, the absorption spectra of the double chlorides show several other repeatedly occurring frequencies, among them 106.86, 116.30,310.19,507.89, 510.78, and $538.51 \mathrm{~cm}^{-1}$; some bands correspond to combinations of two or three of these frequencies with the electronic transition. Some of these may belong to separate electronic transitions (as indicated by differences in polar ization, described on p.31), others to vibrations of unknown nature.

Only a few bands in each absorption group are clearly identifiable with corresponding bands in the fluorescence spectrum. The numerical values of their frequencies are slightly higher in fluorescence. (This shift indicates somewhat stiffer binding in the ground state.) Their planes of polarization are the same in absorption and fluorescence.

The fluorescent series has been followed in the cesium salts down to about $4500 \mathrm{~A}$; from this region down to $3100 \mathrm{~A}$, a number of bands were identified as belonging" to the "magnetic" series (p.35): the lines of these series are wide doublets $\left(\Delta \nu=53.6 \mathrm{~cm}^{-1}\right)$ even in the absence of a magnetic field. Each of the two components is in turn a narrow doublet $\left(\Delta \nu \simeq 2 \mathrm{~cm}^{-1}\right)$. Of the two splittings, the wider one can be attributed to internal field asymmetry, while the cause of the smaller one remains unknown. (The smaller interval is of the same order of magnitude as the splitting produced in other uranyl salts by the magnetic fields used in the Zeeman effect study: if this 
interval - rather than the larger one - were caused by field asymmetry, it should have been possible to obtain a Zeeman effect in this compound, which was not the case.) In this series, too, a second group is situated at a distance of about $708 \mathrm{~cm}^{-1}$ from the first group, corresponding to the excitation of one quantum of symmetric vibration combined with the electronic excitation $\nu_{\mathbf{M}}$

In the fluorescence spectrum of tetramethyl ammonium uxanyl chloride $\left[\left(\mathrm{CH}_{3}\right)_{4} \mathrm{~N}\right]_{2} \mathrm{UO}_{2} \mathrm{Cl}_{4}$ at $77^{\circ} \mathrm{K}$, each group was found to contain six lines, twice the number found in other chlorides; however, all the lower frequency doublet components disappeared at $20^{\circ} \mathrm{K}$.

The absorption spectrum of uranyl double chlorides was studied by Diekeand co-workers in considerable detail with anhydrous $\mathrm{Cs}_{2} \mathrm{UO}_{2} \mathrm{Cl}_{4}$. The separation of this spectrum into a "yellow" and a "white" spectrum was described on p. 31. Some lines appeared in both components, but with different intensities. The "yellow" spectrum contained many more lines than the white one, particularly $<4500 \mathrm{~A}$. This biaxial crystal forms thin plates; the light beam fell normally to the large face, and the polarization of the "white" component probably corresponded to the O-U-O direction in the plane of the plate (since a similar spectrum was obtained in uniaxial, double nitrate crystals, when light was polarized in the direction of the optical axis, which is the $0-U-O$ direction).

The absorption spectrum continues into the ultraviolet; electron transitions similar to those observed in the same region in cesium uranyl nitrate contribute to this part of the spectrum.

Samojlov (1948) made measurements in liquid helium (4.2 $\mathrm{K})$ of 33 absorption lines $(44.4-486.7 \mathrm{~m} \mu)$ and 18 fluorescence lines $(486.8-540.9 \mathrm{~m} \mu)$ of $\mathrm{UO}_{2} \mathrm{Cl}_{2}$.

5.3 Uranyl Nitrate and Double Nitrates - Nichols and Howes studied the spectra of uranyl nitrate, $\mathrm{UO}_{2}\left(\mathrm{NO}_{3}\right)_{2}$, at $-180^{\circ} \mathrm{C}$, with different numbers of water molecules.

The rhombic hexahydrate (large single plates) exhibited 55 fluorescence bands, 48 of which could be arranged in ten series (cf., Table 2) with a constant difference of $860 \mathrm{~cm}^{-1}$. The absorption spectrum consisted of a number of similar series, but the constant differences $\left(731,717,703,690 \mathrm{~cm}^{-1}\right)$ varied more widely than in the fluorescence spectrum.

The triclinic trihydrate in the form of large single crystals exhibited 63 fluorescence bands, of which 55 formed 12 series with $\Delta \nu=865-875 \mathrm{~cm}^{-1}$. In the absorption spectrum of the trihydrate, 28 bands were measured, 37 of which were arranged in 9 series with $\Delta \nu=710-738 \mathrm{~cm}^{-1}$. 
The dihydrate could be obtained only as a powder (by drying the trihydrate at $100^{\circ} \mathrm{C}$ ). It showed 74 fluorescence bands, 60 of which could be ordered in 12 series with $\Delta \nu=876-883 \mathrm{~cm}^{-1}$. The absorption spectrum had to be obtained by reflection, a less satisfactory method than transmission measurement on single crystals, and only 4 series could be identified.

"Anhydrous" nitrate was obtained by reacting $\mathrm{UO}_{2}$ with $\mathrm{N}_{2} \mathrm{O}_{5}$; but the products may have contained some water, although certainly $<2 \mathrm{H}_{2} \mathrm{O}$. The spectra of such preparations were variable; if free nitric acid was left, bands remained diffuse even at $-180^{\circ} \mathrm{C}$. The fluorescence spectrum of the pure anhydrous nitrate apparently contains, at $-185^{\circ} \mathrm{C}$, only 3 sharp and strong bands.

Figure $9 \mathrm{~B}$ shows the structure of a band group in the fluorescence spectra of $\mathrm{UO}_{2}\left(\mathrm{NO}_{3}\right)_{2} \cdot 6 \mathrm{H}_{2} \mathrm{O}, 3 \mathrm{H}_{2} \mathrm{O}, 2 \mathrm{H}_{2} \mathrm{O}$ and "anhydrous" nitrate, respectively.

The $\Delta \nu$ in the fluorescence spectrum was found to increase with progressive dehydration from $860 \mathrm{~cm}^{-1}$ in hexahydrate to $868 \mathrm{~cm}^{-1}$ in trihydrate, $881 \mathrm{~cm}^{-1}$ in dihydrate, and $885 \mathrm{~cm}^{-1}$ in the "anhydrous" salt (compare Dieke's values for hexahydrate and trihydrate in Table 7). This means that the frequency of the symmetric bond vibration in the linear ion $O=U=0$ becomes higher, i.e., the bond becomes stiffer, when the number of water molecules decreases.

No similar systematic shift with hydration was noticeable in the absorption spectrum (i.e., in the vibrational quanta of the excited state of the uranyl ion).

The structure of the individual band groups changes with hydration as deeply as with a change in the anion. Nichols and Howes surmised that in both cases the main factor is different crystal symmetry rather than different chemical composition. The importance of crystal symmetry is indicated also by the spectra of double nitrates (Howes and Wilber, 1917). The bands of the two monoclinic double nitrates $\left(\mathrm{NH}_{4}\right)_{2} \mathrm{UO}_{2}\left(\mathrm{NO}_{3}\right)_{4} \cdot 2 \mathrm{H}_{2} \mathrm{O}$ and $\mathrm{K}_{2} \mathrm{UO}_{2}\left(\mathrm{NO}_{3}\right)_{4}$ had almost identical positions, while the bands of $\mathrm{NH}_{4} \mathrm{UO}_{2}\left(\mathrm{NO}_{3}\right)_{3}$ (trigonal) and $\mathrm{KUO}_{2}\left(\mathrm{NO}_{3}\right)_{3}$ (rhombic) were shifted toward higher frequencies (Figure 10).

The structure of the band groups is similar in all four double nitrates (Figure 10), but different from that in simple uranyl nitrate (Figure 9B).

Dieke, Duncan, and co-workers studied extensively both simple and double uranyl nitrates. The pure electronic transitions and the vibrational frequencies $\nu_{s}$ and $\nu_{a}$ of the ground states are shown for eight such compounds in Table 7. Dieke and Duncan's monograph (1949) contains tables of the spectra listed in Table 14. 


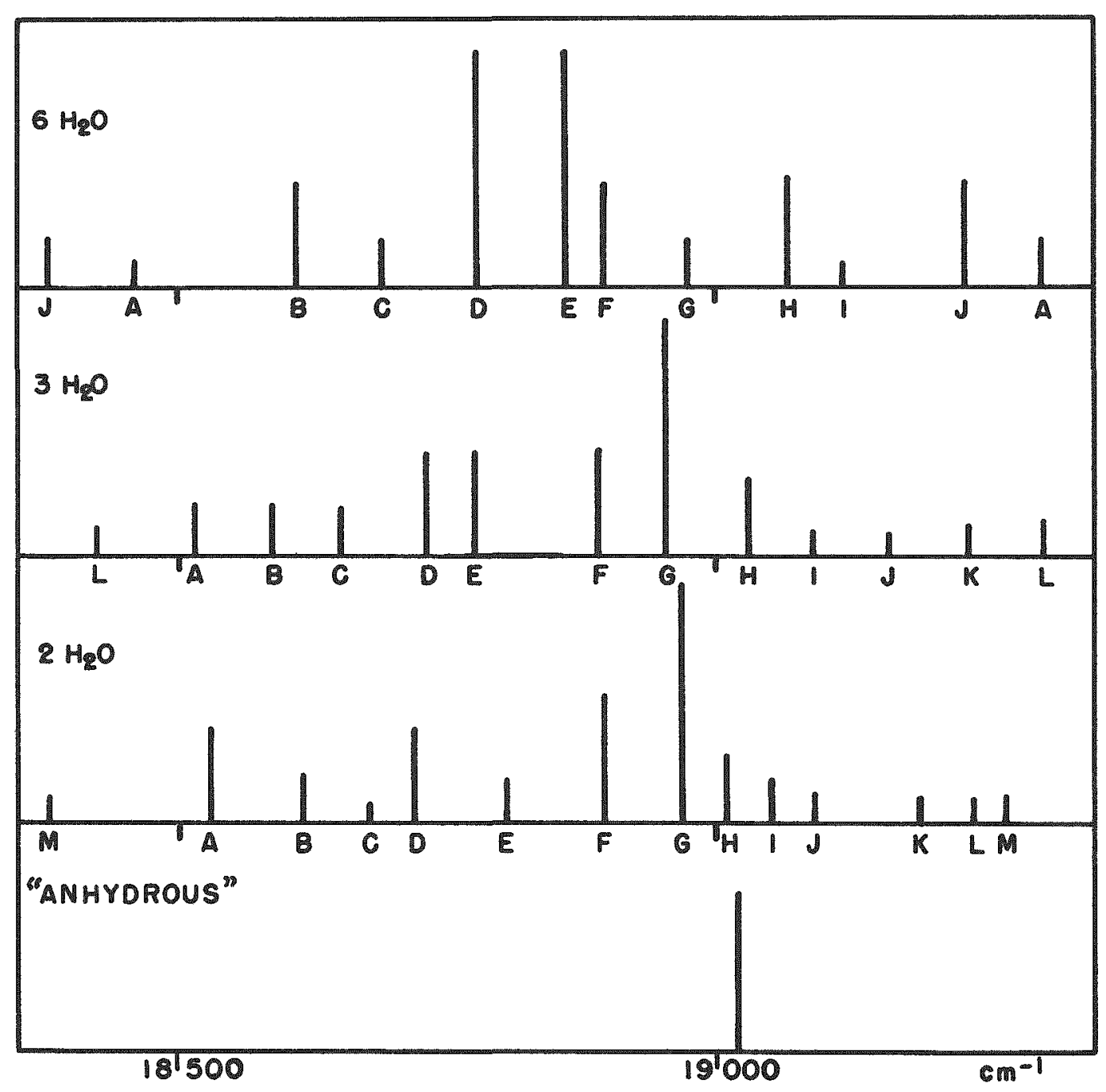

Figure 9B

COMPARISON OF A BAND GROUP IN THE LOW TEMPERATURE SPECTRA OF DIFFERENT URANYL NITRATE HYDRATES. THE SPECTRUM OF THE HEXAHYDRATE CONTAINS 7 SUCH GROUPS; THAT OF THE TRIHYDRATE, 6; THE DIHYDRATE, 5; AND. THE ANHYDROUS SALT, 3

(FROM NICHOLS AND HOWES, 1919, P. 128) 


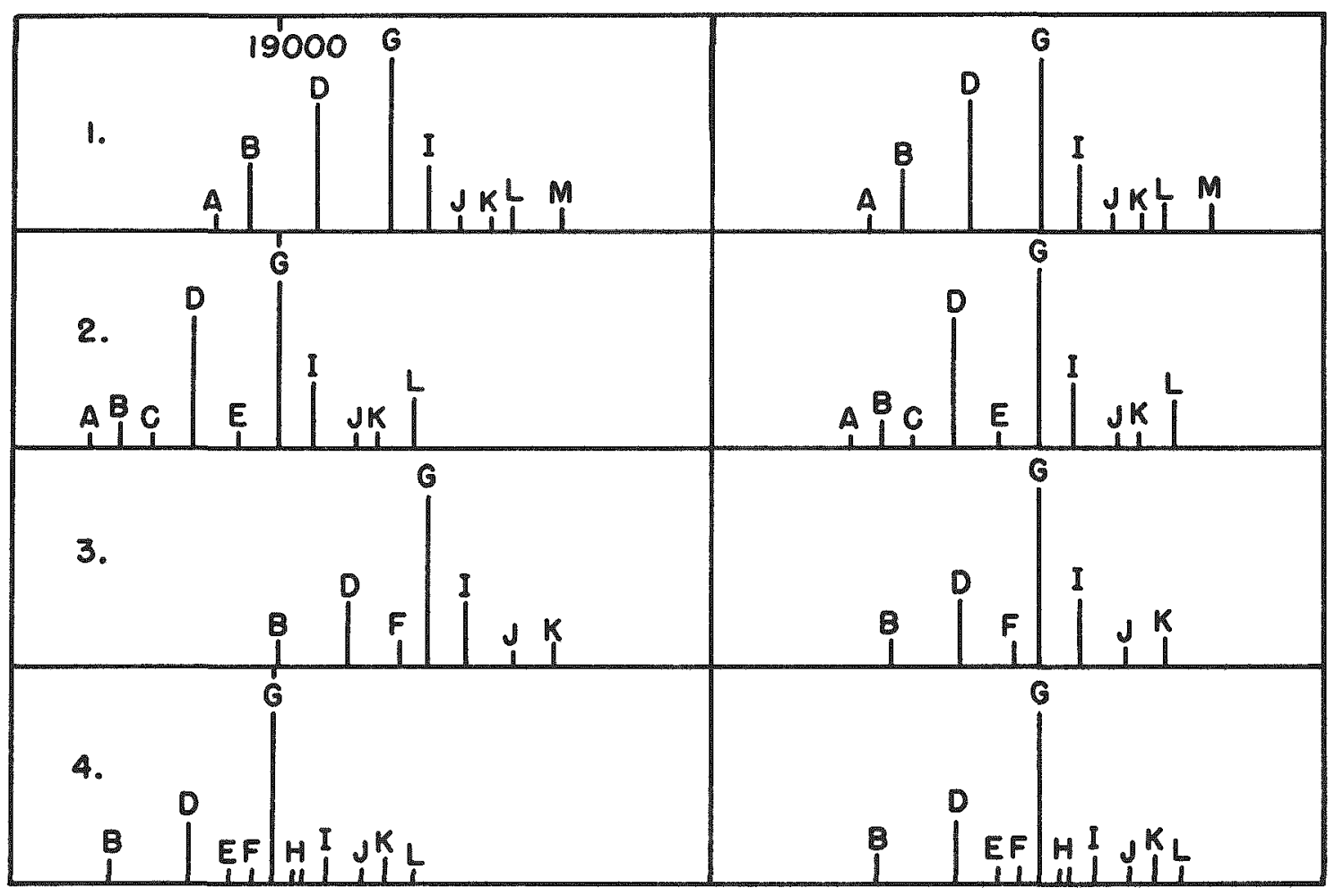

Figure 10

STRUCTURE OF A TYPICAL GROUP IN THE FLUORESCENCE SPECTRUM OF DOUBLE URANYL NITRATES AT $-180^{\circ} \mathrm{C}$

1. $\mathrm{KUO}_{2}\left(\mathrm{NO}_{3}\right)_{3}$ - TRIGONAL

2. $\mathrm{K}_{2} \mathrm{UO}_{2}\left(\mathrm{NO}_{3}\right)_{4}-$ MONOCLINIC

3. $\mathrm{NH}_{4} \mathrm{UO}_{2}\left(\mathrm{NO}_{3}\right)_{3}-\mathrm{RHOMBIC}$

4. $\left(\mathrm{NH}_{4}\right)_{2} \mathrm{UO}_{2}\left(\mathrm{NO}_{3}\right)_{4}-$ MONOCLINIC

THE BANDS OCCUPY THEIR NATURAL POSITIONS IN THE LEFT-HAND PANEL, BUT HAVE THEIR STRONGEST BANDS IN VERTICAL ALIGNMENT IN THE RIGHT-HAND PANEL. (FROM NICHOLS AND HOWES, 1919, P. 138) 
Table 14

URANYL NITRATE SPECTRA STUDIED BY DIEKE AND DUNCAN (1949)

\begin{tabular}{|l|l|l|l|c|}
\hline \multicolumn{1}{|c|}{ Compound } & $T^{\circ}$ abs. & Spectrum & Region, cm & No. of lines \\
\hline $\mathrm{CsUO}_{2}\left(\mathrm{NO}_{3}\right)_{3}$ & $20^{\circ} \mathrm{K}$ & Fluorescence & $21090-15575$ & 236 \\
$\mathrm{CsUO}_{2}\left(\mathrm{NO}_{3}\right)_{3}$ & $20^{\circ} \mathrm{K}$ & Absorption & $21090-28748$ & 617 \\
$\mathrm{RbUO}_{2}\left(\mathrm{NO}_{3}\right)_{3}$ & $20^{\circ} \mathrm{K}$ & Absorption & $21198-29049$ & 145 \\
$\mathrm{RbUO}_{2}\left(\mathrm{NO}_{3}\right)_{3}$ & $77^{\circ} \mathrm{K}$ & Absorption & $21195-27549$ & 30 \\
$\mathrm{RbUO}_{2}\left(\mathrm{NO}_{3}\right)_{3}$ & $20^{\circ} \mathrm{K}$ & Fluorescence & $21199-16728$ & 48 \\
$\mathrm{RbUO}_{2}\left(\mathrm{NO}_{3}\right)_{3}$ & $77^{\circ} \mathrm{K}$ & Fluorescence & $21192-16720$ & 39 \\
$\mathrm{KUO}_{2}\left(\mathrm{NO}_{3}\right)_{3}$ & $77^{\circ} \mathrm{K}$ & Fluorescence & $21168-18993$ & 13 \\
$\mathrm{KUO}_{2}\left(\mathrm{NO}_{3}\right)_{3}$ & $20^{\circ} \mathrm{K}$ & Absorption & $20168-23928$ & 13 \\
$\mathrm{UO}_{2}\left(\mathrm{NO}_{3}\right)_{2} \cdot 6 \mathrm{H}_{2} \mathrm{O}$ & $20^{\circ} \mathrm{K}$ & Fluorescence & $20624-16214$ & 50 \\
$\mathrm{UO}_{2}\left(\mathrm{NO}_{3}\right)_{2} \cdot 6 \mathrm{H}_{2} \mathrm{O}$ & $77^{\circ} \mathrm{K}$ & Fluorescence & $20622-16200$ & 45 \\
\hline
\end{tabular}

The $\mathrm{CsUO}_{2}\left(\mathrm{NO}_{3}\right)_{3}$ tables contain fluorescence bands between 4740 and $6419 \mathrm{~A}$. Of these, the strongest ones can be interpreted (cf., Table 15) as combinations of the resonance frequency $\nu_{F}$ with vibrational frequencies $\nu_{\mathrm{s}}, \nu_{\mathrm{a}}$, and $\nu_{\mathrm{b}}$. The remaining bands must be attributed to vibrations in which particles other than the $\mathrm{UO}_{2}^{+}$ion also take part.

In the nitrate absorption spectrum of $\mathrm{CsUO}_{2}\left(\mathrm{NO}_{3}\right)_{3}$ single crvstal, Dieke and Duncan listed 615 bands between 4740 and 3360 A. The "II spectrum" was in this case much simpler than the " $\perp$ spectrum."

In addition to the fluorescent and the magnetic series, a third "ultraviolet" series could be recognized in this spectrum. The resonance band of the fluorescent series lies at $4740.36 \mathrm{~A}$, and occurs with both polarizations: the magnetic series begins at $4608 \mathrm{~A}$. The ultraviolet series begins at $3726 \mathrm{~A}$ in the $\perp$, and at 3721 in the $\|$ spectrum.

In each series of the nitrate absorption spectrum, groups of bands are recognizable which are separated by the $\nu_{s_{1}}$ frequency; however, two such frequencies seem to be involved, $\nu_{\mathrm{s}}^{\prime}$ and $\nu_{s}^{\prime \prime}$, giving a progressively increasing number of combinations $\left(\nu_{\mathrm{s}}^{\prime}\right.$ or $\nu_{\mathrm{s}}^{\text {in }}$ in the first group, $2 \nu_{\mathrm{s}}^{\prime}, 2 \nu_{\mathrm{s}}^{\prime \prime}$ or $\nu_{\mathrm{s}}^{\prime}+\nu_{\mathrm{s}}^{\prime \prime}$ in the second group, and so on). The values of the two frequencies in the lowest state are $\nu_{s}^{\prime}=734.1$ and $\nu_{s}^{\prime \prime}=766.3 \mathrm{~cm}^{-1}$. One could ask: why not identify the second vibration with $\nu_{-m}$, an interpretation which seems supported by the numerical values? The answer is that such an interpretation is incompatible with the observed isotopic effects. The $\nu_{s}^{\prime}-\nu_{s}^{\prime \prime}$ split must be therefore attributed to resonance between the symmetric bond vibration in the $\mathrm{UO}_{2}^{++}$ion and a crystal vibration of closely similar frequency; some $\mathrm{NO}_{3}^{-}$vibrations are known to exist in this region. 
Table 15

STRONGEST FLUORESCENCE BANDS OF CSUO $\left(\mathrm{NO}_{3}\right)_{3}$ AT $20^{\circ} \mathrm{K}$ (AFTER DIEKE AND DUNCAN, 1949)* *

\begin{tabular}{|c|c|c|c|c|}
\hline \multirow{2}{*}{$\mathrm{cm}^{-1}$} & \multirow{2}{*}{$\lambda(\mathrm{A})$} & \multicolumn{2}{|c|}{$\gamma=\nu_{\mathrm{s}}-\mathrm{n} \nu_{\mathrm{s}}-\mathrm{x}$} & \multirow{2}{*}{$\begin{array}{c}\text { Intensity } \\
\langle\text { photoelectric }\end{array}$} \\
\hline & & $\mathbf{n}$ & $\mathrm{x}$ & \\
\hline $20,880.56$ & 4787.81 & 0 & $\nu_{b}^{\prime}$ & $-\infty-$ \\
\hline $20,876.41$ & 4788.76 & 0 & $\nu_{\mathrm{b}}^{\prime \prime}$ & 103 \\
\hline $20,867.49$ & 4790.81 & 0 & $\nu_{\mathrm{b}}^{\prime \prime \prime}$ & $-\infty$ \\
\hline $20,205.58$ & 4947.75 & 1 & $=--$ & 471 \\
\hline $20,133.36$ & 4965.50 & 0 & $\nu_{\mathrm{a}}$ & 902 \\
\hline $19,994.08$ & 5000.09 & 1 & $\nu_{\mathrm{b}}^{\prime}+\nu_{\mathrm{b}}^{\prime \prime}$ & 232 \\
\hline 19.983 .05 & 5002.85 & 1 & $v_{b}^{m}$ & $-\infty$ \\
\hline $19,325.92$ & 5172.96 & 2 & $-\infty$ & 355 \\
\hline $19,253.76$ & 5192.35 & 1 & $\nu_{a}$ & 1000 \\
\hline $19,112.89$ & 5230.62 & 2 & $\nu_{b}^{b}+\nu_{b}^{\prime}$ & 213 \\
\hline $18,447.32$ & 5419.34 & 3 & $-\infty$ & 123 \\
\hline $18,377.70$ & 5439.87 & 2 & $\nu_{\mathrm{a}}$ & 468 \\
\hline $18,328.67$ & 5454.42 & $?$ & $?$ & 144 \\
\hline $17,504.61$ & 5711.20 & 3 & $\nu_{a}$ & 146 \\
\hline
\end{tabular}

The changes in the uranyl nitrate spectrum with decreasing hydration also were studied by Levshin and Sheremetjev (1947) at room temperature and by Sevchenko (1949) at low temperature. They noted that with dehydration the total intensity of fluorescence decreased, frequencies and relative intensities of the lines changed. Sevchenko and co-workers (1951) prepared 6-, 3-, 2- and 1 -hydrates with water content within $0.2 \%$ of the stoichiometric values and measured their fluorescence spectra at $-185^{\circ} \mathrm{C}$; many more lines were determined than was done by Nichols and Howes (Table 16).

The lines found for hydrates with $n<3$ were quite different from those given by Nichols and Howes. The effect of deuterium substitution was strong in the higher hydrates. 
Table 16

URANYL NITRATE SPECTRA MEASUREMENTS BY SEVCHENIKO, ET AL. (1951)

\begin{tabular}{|c|c|c|}
\hline Compound & No. of lines & Range, $\mathrm{cm}^{-1}$ \\
\hline $\mathrm{UO}_{2}\left(\mathrm{NO}_{3}\right)_{2} \cdot 6 \mathrm{H}_{2} \mathrm{O}$ & 78 & $20670-15385$ \\
$\mathrm{UO}_{2}\left(\mathrm{NO}_{3}\right)_{2} \cdot 6 \mathrm{D}_{2} \mathrm{O}$ & 58 & $20684-15370$ \\
$\mathrm{UO}_{2}\left(\mathrm{NO}_{3}\right)_{2} \cdot 3 \mathrm{H}_{2} \mathrm{O}$ & 100 & $20903-15303$ \\
$\mathrm{UO}_{2}\left(\mathrm{NO}_{3}\right)_{2} \cdot 3 \mathrm{D}_{2} \mathrm{O}$ & 43 & $20777-15375$ \\
$\mathrm{UO}_{2}\left(\mathrm{NO}_{3}\right)_{2} \cdot 2 \mathrm{H}_{2} \mathrm{O}$ & 32 & $20973-16327$ \\
$\mathrm{UO}_{2}\left(\mathrm{NO}_{3}\right)_{2} \cdot 2 \mathrm{D}_{2} \mathrm{O}$ & 8 & $20775-15405$ \\
$\mathrm{UO}_{2}\left(\mathrm{NO}_{3}\right)_{2} \cdot \mathrm{H}_{2} \mathrm{O}$ & 36 & $20818-15405$ \\
$\mathrm{UO}_{2}\left(\mathrm{NO}_{3}\right)_{2} \cdot \mathrm{D}_{2} \mathrm{O}$ & 14 & $20219-16969$ \\
\hline $\mathrm{UO}_{2}\left(\mathrm{NO}_{3}\right)_{2} \cdot \ldots$ & 33 & $20805-16270$ \\
\hline
\end{tabular}

Table 17 shows the effect of $\mathrm{H}_{2} \mathrm{O}$ and $\mathrm{D}_{2} \mathrm{O}$ on the energy levels (in the first group, at $-185^{\circ} \mathrm{C}$ ). $\nu_{s}$ values decrease with increasing hydration. Two explanations are possible: The lattice forces may decrease with $n$, or the vibrating masses may increase (if one assumes that water molecules can participate in vibrations of the $\mathrm{UO}_{2}^{++}$ion).

\section{Table 17}

ELECTRONIC (E) AND VIBRATIONAL $(\nu)$ LEVELS OF $\mathrm{UO}_{2}\left(\mathrm{NO}_{3}\right)_{2} \cdot \mathrm{nH}_{2} \mathrm{O} A N D \mathrm{UO}_{2}\left(\mathrm{NO}_{3}\right)_{2} \cdot \mathrm{n}^{\prime} \mathrm{D}_{2} \mathrm{O} \mathrm{AT}-185^{\circ} \mathrm{C}$

(AFTER SEVCHENKO, ET AL. 1951)

\begin{tabular}{|c|c|c|c|c|c|c|c|c|}
\hline & anh. & $\mathrm{H}_{2} \mathrm{O}$ & $\mathrm{D}_{2} \mathrm{O}$ & $2 \mathrm{H}_{2} \mathrm{O}$ & $3 \mathrm{H}_{2} \mathrm{O}$ & $3 \mathrm{D}_{2} \mathrm{O}$ & $6 \mathrm{H}_{2} \mathrm{O}$ & $6 \mathrm{D}_{2} \mathrm{O}$ \\
\hline $\mathbf{E}$ & 20802 & 20802 & $-\infty$ & 20776 & 20776 & 20776 & 20588 & 20596 \\
\hline$v^{\prime}$ & 882 & 882 & $-\infty$ & 874 & 874 & 874 & 865 & 865 \\
\hline$\nu_{s}^{S}$ & 878 & 878 & (W eak) & 871 & 871 & 874 & 863 & 863 \\
\hline$\nu_{\mathrm{s}}^{i g}$ & 875 & 875 & $-\infty$ & 868 & 868 & 868 & 861 & 861 \\
\hline
\end{tabular}

Table 18 taken from Sevchenko and Stepanov (1951), proves the constancy of structure in groups I to IV. The multiplicity of small frequencies seems indicative of crystal vibrations rather than of vibrations in the uranyl ion. The hydration number $n$ affects $\nu_{s}$ and $\nu_{a}$ but not the third main frequency, $\nu_{b}$, supporting its interpretation as a lattice vibration rather than as a bending vibration of the uranyl ion (cf., Section 1$)$. 


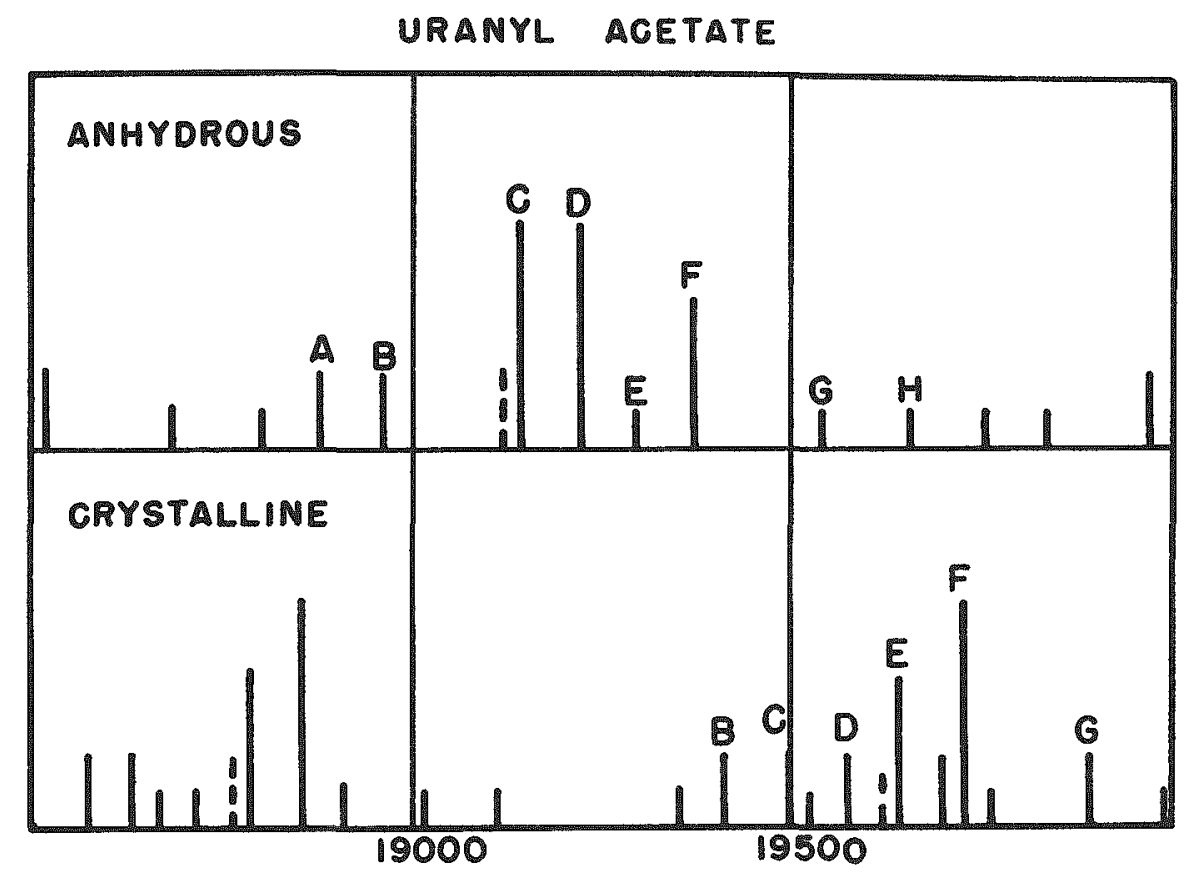

Figure 11

STRUCTURE OF BAND GROUPS IN LOW TEMPERATURE FLUORESCENCE SPECTRA OF URANYL ACETATE (ANHYDROUS) AND URANYL ACETATE DIHYDRATE (AFTER NICHOLS AND HOWES, 1919, p. 148) 


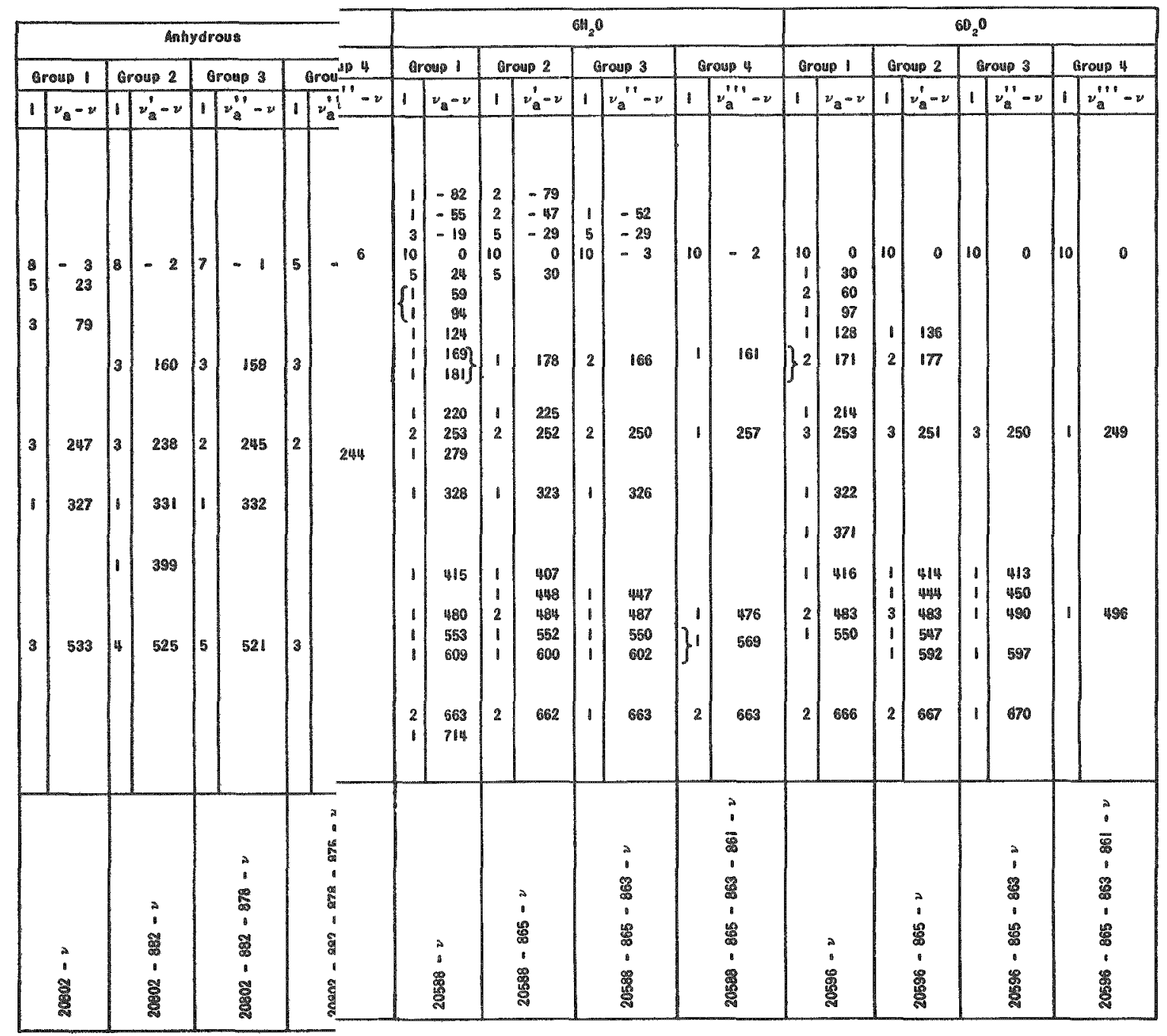




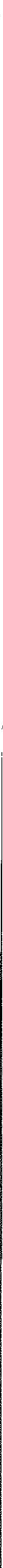


$\lim _{4}$

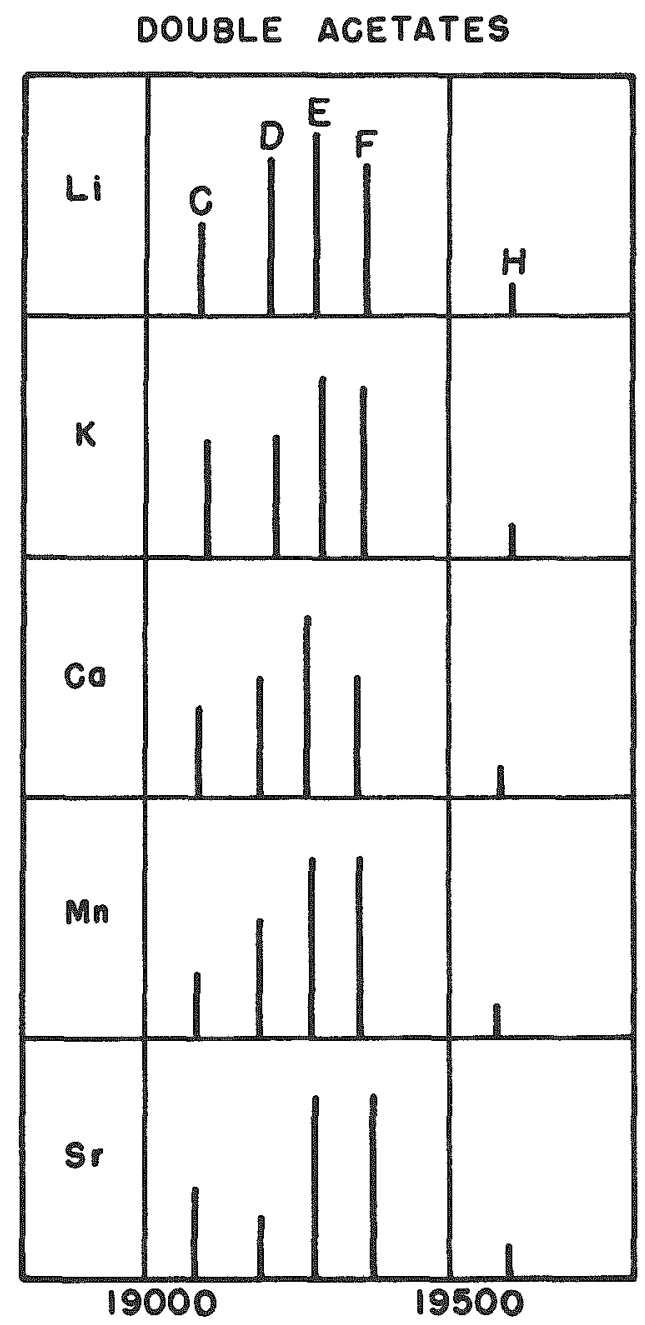

Figure 12

STRUCTURE OF BAND GROUPS IN LOW TEMPERATURE FLUORESCENCE SPECTRA OF DOUBLE ACETATES OF URANYL

(AFTER NICHOLS AND HOWES, 1919, p. 150) 
The absorption spectra of the two simple acetates and of the double acetates of magnesium, manganese, and lead overlapped the fluorescence spectrum considerably; those of the other double acetates ended at about $\nu=21800 \mathrm{~cm}^{-1}$, just where the fluorescence series began. The $\nu_{\mathrm{s}}(\mathrm{abs}$.$) ,$ similarly to $\Delta \nu_{s}$ (fluor.), was found to be higher for the simple uranyl acetate than for most double acetates (Table 19) indicating a tighter U-O bond in both the excited and the ground state.

Table 7 shows $\nu_{s}$ and $\nu_{a}$ values at $20^{\circ} \mathrm{K}$ for the six double acetates studied by Dieke and comorkers and also the electronic terms $\nu_{\mathrm{F}}, \nu_{\mathrm{M}}, \nu_{\mathrm{D}}$. and $\nu_{U}$. Tabulations are given in Dieke and Duncan's monograph of the acetate spectra listed in Table 20.

Table 20

URANYL ACETATE SPECTRA MEASURED BY DIEKE AND DUNCAN (1949)

\begin{tabular}{|l|l|l|l|c|}
\hline \multicolumn{1}{|c|}{$\mathrm{Compound}$} & Spectrum & $\mathrm{T}^{\circ} \mathrm{abs}$ & Region, cm & No. of lines \\
\hline $\mathrm{RbUO}_{2} \mathrm{Ac}_{3}$ & Fluorescence & $20^{\circ} \mathrm{K}$ & $21047-16336$ & 70 \\
$\mathrm{RbUO}_{2} \mathrm{Ac}_{3}$ & Fluorescence & $77^{\circ} \mathrm{K}$ & $21048-16751$ & 45 \\
$\mathrm{RbUO}_{2} \mathrm{Ac}_{3}$ & Absorption & $20^{\circ} \mathrm{K}$ & $20881-22860$ & 32 \\
$\mathrm{NaUO}_{2} \mathrm{Ac}_{3}$ & Fluorescence & $20^{\circ} \mathrm{K}$ & $21131-17663$ & 39 \\
$\mathrm{NaUO}_{2} \mathrm{Ac}_{3}$ & Fluorescence & $77^{\circ} \mathrm{K}$ & $21250-16378$ & 61 \\
$\mathrm{NaUO}_{2} \mathrm{Ac}_{3}$ & Absorption & $20^{\circ} \mathrm{K}$ & $21136-29388$ & 102 \\
$\mathrm{NaUO}_{2} \mathrm{Ac}_{3}$ & Absorption & $77^{\circ} \mathrm{K}$ & $21129-31008$ & 107 \\
$\mathrm{NH}_{4} \mathrm{UO}_{2} \mathrm{Ac}_{3}$ & Fluorescence & $20^{\circ} \mathrm{K}$ & $21051-16747$ & 65 \\
$\mathrm{NH}_{4} \mathrm{UO}_{2} \mathrm{Ac}_{3}$ & Fluorescence & $77^{\circ} \mathrm{K}$ & $21052-16737$ & 43 \\
$\mathrm{NH}_{4} \mathrm{UO}_{2} \mathrm{Ac}_{3}$ & Absorption & $20^{\circ} \mathrm{K}$ & $21056-27740$ & 82 \\
$\mathrm{NH}_{4} \mathrm{UO}_{2} \mathrm{Ac}_{3}$ & Absorption & $77^{\circ} \mathrm{K}$ & $21062-28570$ & 58 \\
$\mathrm{MgUO}_{2} \mathrm{Ac}_{4}$ & Absorption & $20^{\circ} \mathrm{K}$ & $20079-28300$ & 70 \\
$\mathrm{PbUO}_{2} \mathrm{Ac}_{4} \cdot 2 \mathrm{H}_{2} \mathrm{O}$ & Fluorescence & $20^{\circ} \mathrm{K}$ & $20958-16222$ & 67 \\
$\mathrm{PbUO}_{2} \mathrm{Ac}_{4} \cdot 2 \mathrm{H}_{2} \mathrm{O}$ & Fluorescence & $77^{\circ} \mathrm{K}$ & $20949-16201$ & 60 \\
\hline
\end{tabular}

In the fluorescence spectrum of all acetates, Dieke and co-workers found a conspicuous frequency of about $610 \mathrm{~cm}^{-1}$, which was represented in each group. It does not occur in any other uranyl compound and must therefore be due to a vibration of the acetate group. Asymmetric vibration 
lines are present in the spectra of all acetates, and are even stronger than the $\nu_{s}$ lines: the $\nu_{b}$ lines have a complex structure in most acetates. In $\mathrm{CsUO}_{2} \mathrm{Ac}_{3}$ the resonance line is double; the $\nu_{\mathrm{a}}$ and $\nu_{\mathrm{b}}$ lines in higher groups are double or triple. $\mathrm{NaUO}_{2} \mathrm{Ac}_{3}$ is cubic and shows no double refraction; its resonance line is single and its $\nu_{a}$ line is double in the first group, but apparently single in other groups.

The absorption spectrum of sodium uranyl acetates, too, is entirely unpolarized as expected for a cubic crystal. The fluorescence series is weak with narrow single lines; the $\nu_{2}$ frequency seems to be present. In the ammonium salt the resonance line is a narrow doublet. The fluorescence series is sharp and the magnetic series lines are very broad; because of this, no Zeeman effect could be observed.

Samojlov (1948) found, on the other hand, that the fluorescence of a single crystal of $\mathrm{NaUO}_{2} \mathrm{Ac}_{3}$ at the temperature of liquid air was circularly polarized. Polarization disappeared in crystal powder; this was ascribed to mutual compensation of $l$-and $d$-crystals. The fluorescence lines of uranyl acetate anhydrate showed linear (or a very naxrow elliptical) polarization.

In sodium uranyl acetate Samojlov noted a doubling of all fluorescence bands after cooling from $90^{\circ} \mathrm{K}$ to $4.2^{\circ} \mathrm{K}$ (liquid helium) and found from these doublets a repetition of the frequency intervals 164 and $608 \mathrm{~cm}^{-1}$.

Samojlov measured absorption and fluorescence lines of uranyl acetates on liquid helium (Table 21).

Table 21. SAMOJLOV'S MEASUREMENTS (1948) OF URANYL
ACETATE SPECTRUM AT $4.2^{\circ} \mathrm{K}$

\begin{tabular}{|l|l|c|c|}
\hline Compound & Spectrum & No. of Lines & Region, A.U. \\
\hline $\mathrm{UO}_{2} \mathrm{Ac}_{2} \cdot 2 \mathrm{H}_{2} \mathrm{O}$ & Absorption & 34 & $4556-4854$ \\
$\mathrm{UO}_{2} \mathrm{Ac}_{2} \cdot 2 \mathrm{H}_{2} \mathrm{O}$ & Fluorescence & 89 & $4854-5395$ \\
$\mathrm{UO}_{2} \mathrm{NaAc}_{3}$ & Absorption & 58 & $4296-4730$ \\
$\mathrm{UO}_{2} \mathrm{NaAc}_{3}$ & Fluorescence & 133 & $4729-5692$ \\
\hline
\end{tabular}

5.5 Sulfates - Nichols and Howes (1919) studied $\mathrm{UO}_{2} \mathrm{SO}_{4} \cdot 3 \mathrm{H}_{2} \mathrm{O}$ and several double sulfates. They found their spectra to be more complex and varied than those of nitrates or acetates. All fluorescence band groups are, however, characterized by a pair of strong bands shifted toward shorter waves with increasing molecular weight of the second cation, as 
shown in Figure 13, although less regularly than in the case of nitrates. The spectrum of the simple sulfate resembles that of the double salts more closely than in the case of nitrate or acetate.

Tables were given by Nichols and Howes for the bands, at the temperature of liquid air, of the compounds listed in Table 22 (cf., Dieke and Duncan's values of $\nu_{\mathrm{s}}$ and $\nu_{\mathrm{a}}$ at $20^{\circ} \mathrm{K}$ for $\mathrm{Cs}, \mathrm{Rb}, \mathrm{K}$, and $\mathrm{NH}_{4}$ double sulfates in Table 7).

Table 22

BANDS OF URANYL SULFATE AT $=180^{\circ} \mathrm{C}$

\begin{tabular}{|l|c|c|}
\hline & \multicolumn{2}{|c|}{$\nu_{\mathrm{s}^{\prime}} \mathrm{cm}^{-1}$} \\
\cline { 2 - 3 } & Fluorescence & Absorption \\
\hline $\mathrm{UO}_{2} \mathrm{SO}_{4} \cdot 3 \mathrm{H}_{2} \mathrm{O}$ & 852 & 696 \\
$\left(\mathrm{NH}_{4}\right)_{2} \mathrm{UO}_{2}\left(\mathrm{SO}_{4}\right)_{2} \cdot 2 \mathrm{H}_{2} \mathrm{O}$ & 837 & 703 \\
$\mathrm{Na}_{2} \mathrm{UO}_{2}\left(\mathrm{SO}_{4}\right)_{2} \cdot 3 \mathrm{H}_{2} \mathrm{O}^{*}$ & 843 & 713 \\
$\mathrm{~K}_{2} \mathrm{UO}_{2}\left(\mathrm{SO}_{4}\right)_{2} \cdot 2 \mathrm{H}_{2} \mathrm{O}$ & 830 & 703 \\
$\mathrm{Rb}_{2} \mathrm{UO}_{2}\left(\mathrm{SO}_{4}\right)_{2} \cdot 2 \mathrm{H}_{2} \mathrm{O}$ & 832 & 698 \\
$\mathrm{Cs}_{2} \mathrm{UO}_{2}\left(\mathrm{SO}_{4}\right)_{2} \cdot 3 \mathrm{H}_{2} \mathrm{O}$ & 857 & 704 \\
\hline
\end{tabular}

* Water content as given by Dieke and Duncan, 1949

Of the eight broad fluorescence bands of uranyl sulfate visible at room temperature, the 1 t and the 8 th disappear in liquid air; the others are resolved into sharp components.

Dieke and Duncan (1949) gave tables of the spectra listed in Table 23.

Table 23

URANYL SULFATE SPECTRA MEASURED BY DIEKE, ET AL. (DIEKE AND DUNCAN, 1949)

\begin{tabular}{|l|l|c|c|c|}
\hline \multicolumn{1}{|c|}{ Compound } & Spectrum & T $^{\circ}$ abs. & Region, cm & No. of lines \\
\hline $\mathrm{K}_{2} \mathrm{UO}_{2}\left(\mathrm{SO}_{4}\right)_{2} \cdot 2 \mathrm{H}_{2} \mathrm{O}$ & Fluorescence & $77^{\circ} \mathrm{K}$ & $20454-16161$ & 66 \\
$\mathrm{~K}_{2} \mathrm{UO}_{2}\left(\mathrm{SO}_{4}\right)_{2} \cdot 2 \mathrm{H}_{2} \mathrm{O}$ & Absorption & $20^{\circ} \mathrm{K}$ & $20381-23822$ & 93 \\
$\left(\mathrm{NH}_{4}\right)_{2} \mathrm{UO}_{2}\left(\mathrm{SO}_{4}\right)_{2} \cdot 2 \mathrm{H}_{2} \mathrm{O}$ & Fluorescence & $77^{\circ} \mathrm{K}$ & $20425-16100$ & 48 \\
$\left(\mathrm{NH}_{4}\right)_{2} \mathrm{UO}_{2}\left(\mathrm{SO}_{4}\right)_{2} \cdot 2 \mathrm{H}_{2} \mathrm{O}$ & Absorption & $20^{\circ} \mathrm{K}$ & $20357-27379$ & 43 \\
\hline
\end{tabular}


SULFATES

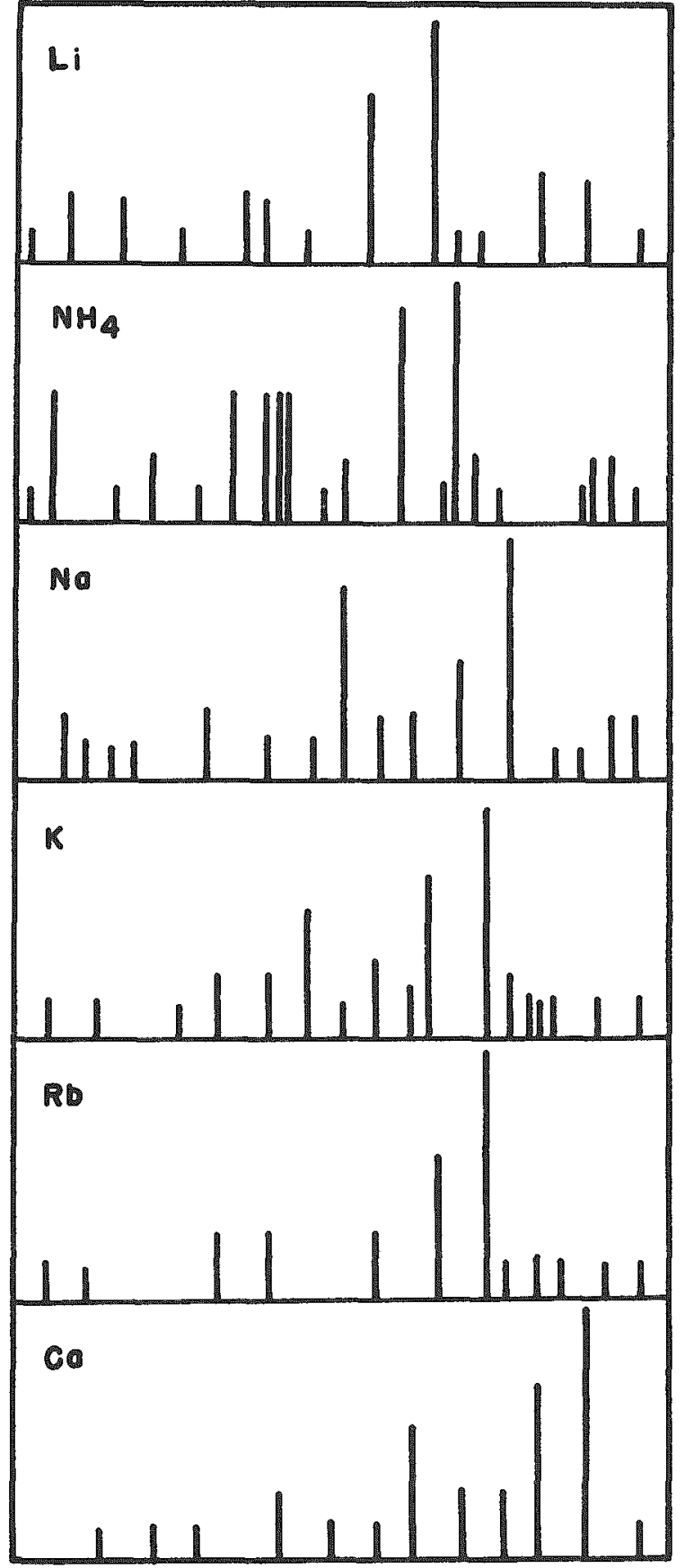

Figure 13

STRUCTURE OF LOW TEMPERATURE FLUORESCENCE BAND GROUPS OF SIMPLE AND DOUBLE URANYL SULFATES, $\mathrm{X}_{2} \mathrm{UO}_{2} \mathrm{SO}_{4} \cdot 2 \mathrm{H}_{2} \mathrm{O}$

(AFTER NICHOLS AND HOWES, 1919, p. 169) 
In rubidium double sulfate the resonance line is a narrow doublet; in the potassium salt it is triple.

Lines involving excitation of the asymmetric bond vibration, $\nu_{a}$, are relatively weak or absent in the fluorescence spectra of uranyl double sul fates of cesium, rubidium, potassium and ammonium. The $\nu_{b}$ vibration has a peculiar structure not encountered in all the other salts studied. In the rubidium salts, for example, the $\nu_{\mathrm{b}}$ group consists of eight very sharp lines, 65 to $106 \mathrm{~cm}^{-1}$ away from the resonance line. If the identification of these frequencies as belonging to the bending vibration is correct, the frequency of this vibration is here much lower than usual (about $210 \mathrm{~cm}^{-1}$ ).

$\mathrm{Tl}_{2} \mathrm{UO}_{2}\left(\mathrm{SO}_{4}\right)_{2}$ showed no fluorescence at all at $77^{\circ} \mathrm{K}$.

Levshin and Sheremetjev (1947) noted that re-crystallization of a uranyl sulfate trihydrate preparation changed the fluorescence spectrum (at room temperature); the usually observed double-peaked bands vanished and single-peaked bands, similar to those of other uranyl salts, appeared instead. The single peaks are shifted by $3-4 \mathrm{~m} \mu$ towards the violet compared to the main components and 2-5 mu towards the red of the weaker components of the doublet bands.

Photometric curves were obtained for the single and double bands in the trihydrate spectra and also for the spectra of the dihydrate and the monohydrate, obtained by dehydration of the two trihydrate preparations. The intensity of fluorescence was found to decrease strongly with dehydration in both cases but particularly in that of the doublet spectrum. Waterfree preparations of uranyl sulfate are non-fluorescent. The number and positions of the bands of the doublet spectrum remain unchanged by drying down to one water molecule (a result that contradicts the observations of Nichols and Howes); in the singlet spectrum desiccation causes the appearance of a doublet structure.

The two types of fluorescence spectra of uranyl sulfate were again studied by Gordon (1950). He observed the fluorescence spectra at $-180^{\circ} \mathrm{C}$ using crystals of uranyl sulfate obtained by slow crystallization and by rapid crystallization, respectively. The analysis indicated the presence of three molecules of water in both preparations, but the slowly-formed larger crystals (type I) lost 2.5 molecules of water by drying at $80^{\circ} \mathrm{C}$, while the rapidly-formed, smaller crystals (type II) lost only approximately 1.5 molecules. Table 24 shows the positions of the bands in the two preparations: the spectrum of a frozen uranyl sulfate solution is shown for comparison and appears to be similar to that of crystals II. The spectra of the usual laboratory preparations of uranyl sulfate correspond to the superposition of the spectra of forms I and II; at room temperature the bands are doublepeaked, one peak corresponding to the singlet bands of form I and the other to the center of gravity of the doublet bands of form II. Levshin and Sheremetjev (cf. above) must have obtained by recrystallization a preparation of Gordon's type I. 
Table 24

FLUORESCENCE BANDS OF UO $\mathrm{SO}_{4}$ AT $-180^{\circ} \mathrm{C}$ AFTER GORDON (1950)

\begin{tabular}{|l|l|l|l|l|c|}
\hline Preparation & \multicolumn{5}{|c|}{ Band Maxima, cm-1 } \\
\hline $\mathrm{UO}_{2} \mathrm{SO}_{4} \cdot 3 \mathrm{H}_{2} \mathrm{O}(\mathrm{I})$ & --- & 19675 & 18825 & 17975 & 17125 \\
$\mathrm{UO}_{2} \mathrm{SO}_{4} \cdot 3 \mathrm{H}_{2} \mathrm{O}(\mathrm{II})$ & 20340 & $19475 ; 19395$ & $18615 ; 18530$ & $17750 ; 17665$ & -5 \\
$\mathrm{UO}_{2} \mathrm{SO}_{4}(3 \mathrm{M})$ & 20310 & 19460 & 18610 & 17750 & 16900 \\
frozen & & & & & \\
\hline
\end{tabular}

The absorption spectrum of $\mathrm{K}_{2} \mathrm{UO}_{2}\left(\mathrm{SO}_{4}\right)_{2} \cdot 2 \mathrm{H}_{2} \mathrm{O}$ was measured by Dieke, et $a l_{.}$in polarized light at $20^{\circ} \mathrm{K}$. The resonance line is double with a weaker violet component with both polarizations. Throughout the spectrum the lines are slightly shifted in the $\|$ spectrum in respect to those in the $\perp$ spectrum. The $M$ series is diffuse, if at all present; the $D$ series dominates the middle of the spectrum, beginning at $4335 \mathrm{~A}$. There is a series of sharp lines in the ultraviolet, but the structure there is highly complex. Continuous absorption begins at $3450 \mathrm{~A}$.

\subsection{Carbonates - Dieke and Duncan (1949) tabulated the spectra} summarized in Table 25. By a microscopic method the absorption spectra of potassium and of guanidonium uranyl carbonate were obtained with small crystals. In both materials the $M$ series appeared between the second and the third group of the $F$ series. An intricate structure was found in the $M$ series of both salts and in the $F$ series of the guanidonium salt. It was also noted in the fluorescence spectrum of the potassium salt.

Table 25

URANYL CARBONATE SPECTRA TABULATED BY DIEKE AND DUNCAN (1949)

\begin{tabular}{|l|l|c|c|c|}
\hline \multicolumn{1}{|c|}{ Compound } & Spectrum & Ta abs. $^{\circ}$ & Region, $\mathrm{cm}^{-1}$ & No. of lines \\
\hline $\mathrm{K}_{2} \mathrm{UO}_{2}\left(\mathrm{CO}_{3}\right)_{2}$ & Fluorescence & $20^{\circ} \mathrm{K}$ & $20921-16605$ & 65 \\
$\mathrm{~K}_{2} \mathrm{UO}_{2}\left(\mathrm{CO}_{3}\right)_{2}$ & Fluorescence & $77^{\circ} \mathrm{K}$ & $20933-17393$ & 57 \\
$\mathrm{~K}_{2} \mathrm{UO}_{2}\left(\mathrm{CO}_{3}\right)_{2}$ & Absorption & $77^{\circ} \mathrm{K}$ & $20943-28483$ & 55 \\
$\left(\mathrm{CN}_{3} \mathrm{H}_{6}\right)_{2} \mathrm{UO}_{2} \mathrm{CO}_{3} \cdot \mathrm{xH}_{2} \mathrm{O}^{*}$ & Absorption & $77^{\circ} \mathrm{K}$ & $20757-27699$ & 75 \\
\hline
\end{tabular}

* Guanidonium uranyl carbonate 
Table 26.

Samojlov (1948) made wavelength measurements summarized in

Table 26

URANYL SULFATE SPECTRUM MEASUREMENTS

AT $4.2^{\circ} \mathrm{K}$ (SAMOJLOV, 1948)

\begin{tabular}{|l|l|c|c|}
\hline \multicolumn{1}{|c|}{ Compound } & Spectrun & Region, A.U. & No. of lines \\
\hline $\mathrm{UO}_{2} \mathrm{SO}_{4} \cdot 3 \mathrm{H}_{2} \mathrm{O}$ & Absorption & $4597-4917$ & 46 \\
$\mathrm{UO}_{2} \mathrm{SO}_{4} \cdot 3 \mathrm{H}_{2} \mathrm{O}$ & Fluorescence & $4918-5453$ & 36 \\
$\mathrm{UO}_{2} \mathrm{R}_{2}\left(\mathrm{SO}_{4}\right)_{2} \cdot 2 \mathrm{H}_{2} \mathrm{O}$ & Fluorescence & $4943-5603$ & 38 \\
\hline
\end{tabular}

5.7 Phosphates - Only diffuse bands were found by Nichols and Howes in the fluorescence spectrum of glassy uranyl phosphate containing excess phosphoric acid even at liquid air temperatures, while sharp bands could be observed with crystalline double phosphates (Figure 14).

The three crystalline preparations free of phosphoric acid exhibited, at $-180^{\circ} \mathrm{C}$, identical systems of narrow fluorescence bands with $\Delta \nu=804-815 \mathrm{~cm}^{-1}$ (a lower vibration frequency than found in all other uranyl salts). Prepara tions 4 and 5 showed both narrow and diffuse bands, the latter with $\Delta \nu=825 \mathrm{~cm}^{-1}$; preparations 6 and 7 had only diffuse bands with $\Delta \nu=851$ and $870 \mathrm{~cm}^{-1}$, respectively.

Howes and Wilber (1916) concluded from these experiments that the occurrence of sharp spectral bands at liquid air temperature depends on crystalline structure. We understand now why this must be so, since the spectrum of ions in crystals is the result of broadening and splitting of the bands of free ions in the electric field of the adjoining ions (or dipoles). In a crystalline structure the field is the same for all ions of a given type, and this produces splitting into more or less sharp components; in the glassy, i.e., undercooled, liquid state, on the other hand, random distribution and orientation of ions and molecules lead to variations in the strength and direction of electric forces, and this results in diffuse broadening of the spectral lines rather than in their splitting into well-definied components.

5.8 Frozen Uranyl Salt Solutions - Nichols and Howes also studied the absorption and fluorescence spectra of frozen UOt salt solutions in water and alcohol. The results are, as one could expect, rather confusing, since the spectra are produced by a variety of crystal hydrates. What hy drate (or hydrates) will be present in any given case will depend not only on temperature but also on the rate of cooling (or heating). The spectrum of each solvate, as well as that of the free ion $\mathrm{UO}_{2}^{+}$, changes with temperature 


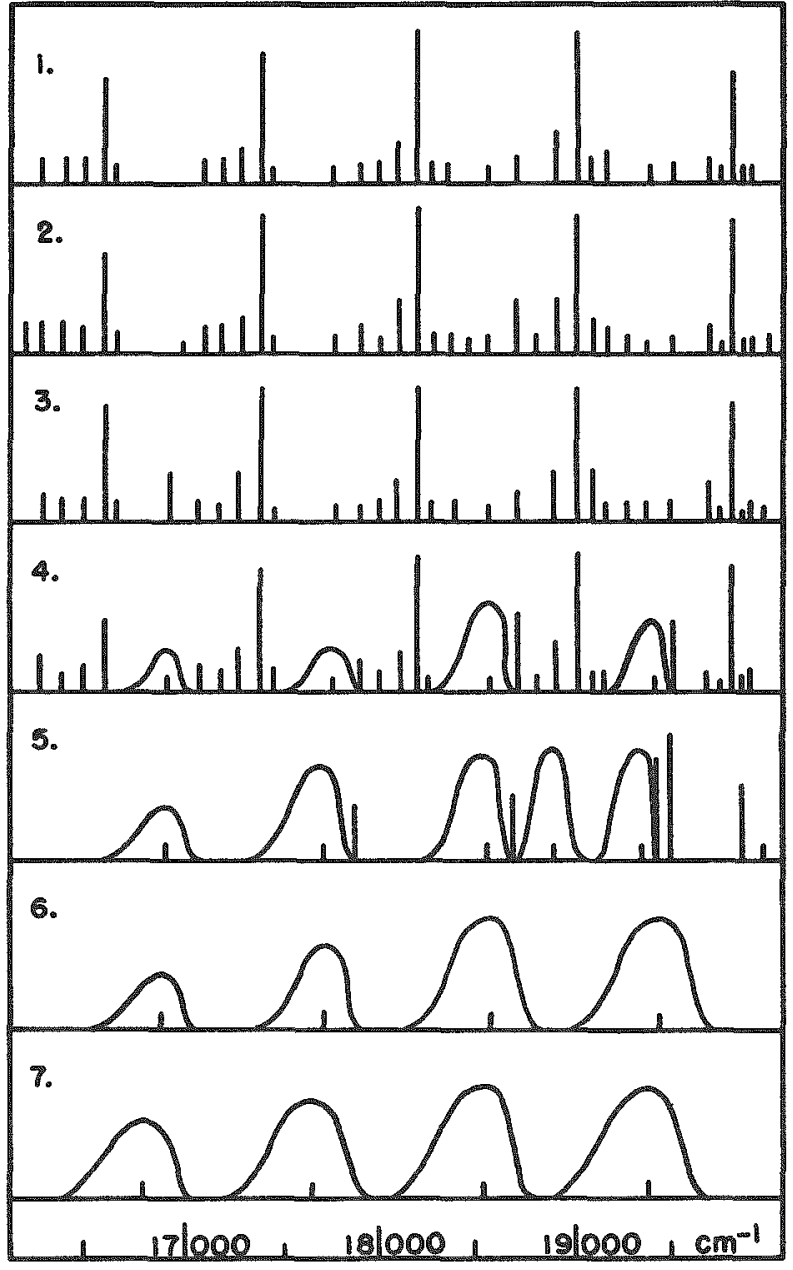

Figure 14

FLUORESCENCE BANDS OF URANYL PHOSPHATE AT $180^{\circ} \mathrm{C} .1,2,3,-$ WITHOUT EXCESS $\mathrm{H}_{3} \mathrm{PO}_{4} 4^{\circ}, 5,6,7-$ WITH INCREASING PROPORTION OF FREE $\mathrm{H}_{3}$ PO (AFTER NICHOLS AND HOWES)

1. $4 \mathrm{NO}_{2} \mathrm{HPO}_{4} \cdot 3 \frac{1}{2} \mathrm{H}_{2} \mathrm{O}+1 \mathrm{Na}_{2} \mathrm{HPO}_{4}$

$22 \mathrm{NO}_{2} \mathrm{HPO}_{4} \cdot 3 \frac{1}{2} \mathrm{H}_{2} \mathrm{O}+1 \mathrm{Na}_{2} \mathrm{HPO}_{4}$

3. $1 \mathrm{UO}_{2} \mathrm{HPO}_{4} \cdot 3 \frac{1}{2} \mathrm{H}_{2} \mathrm{O}+1 \mathrm{Na}_{2} \mathrm{HPO}_{4}$

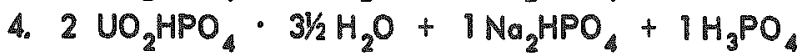

5. $\mathrm{UO}_{2} \mathrm{HPO}_{4} \cdot 3 / 2 \mathrm{H}_{2} \mathrm{O}+2 \mathrm{No}_{2} \mathrm{HPO}_{4}+1 \mathrm{H}_{3} \mathrm{PO}_{4}{ }^{*}$

6. $\mathrm{UO}_{2} \mathrm{HPO}_{4} \cdot 3 \mathrm{~K}_{2} \mathrm{H}_{2} \mathrm{O}+1 \mathrm{No}_{2} \mathrm{HPO}_{4}+2 \mathrm{H}_{3} \mathrm{PO}_{4}^{* *}$

7. $\mathrm{UO}_{2} \mathrm{HPO}_{4} \cdot 3 \frac{1}{2} \mathrm{H}_{2} \mathrm{O}+$ excess $\mathrm{H}_{3} \mathrm{PO}_{4}^{* * *}$

"much Irae sodium phosphare

* syrupy af $20^{\circ}$; vitreous ot $-180^{\circ}$

* * vitreous at oll tmperatures 
in its own characteristic way as described above for crystalline salts. Despite this complexity spectros copicobstiations could perhaps be used to identify different crystalline solvates of uranyl salts and to determine the limits of their stability and the rates of their transformation. Therefore, a brief summary of the findings of Nichols and co-workers is given here.

Nichols and Merritt (1914) and Howes (1915) first investigated the spectra of uranyl salt solutions of different concentrations (from $1 \mathrm{M}$ to $1 \times 10^{-3} \mathrm{M}$ ) as a function of temperature (cf. also Nichols and Howes, 1919 , pp. 180-205). The solutions were frozen and cooled to the desired temperature by inserting test tubes into a massive copper block (cooled with liquid air) with openings provided for the incident and the fluorescent light.

The investigated systems included $\mathrm{UO}_{2} \mathrm{SO}_{4}$ in water or sulfuric acid; $\mathrm{UO}_{2} \mathrm{~K}_{2}\left(\mathrm{SO}_{4}\right)$ in water or sulfuric acid; $\mathrm{UO}_{2} \mathrm{Cl}_{2}$ in water; and $\mathrm{UO}_{2}\left(\mathrm{NO}_{3}\right)_{2}$ in water, nitric acid, or alcohol.

Upon cooling, a general increase in the intensity of the whole fluorescence spectrum was noted; two or more bands, not visible at room tem perature, became visible at low temperature. The band peaks were shifted gradually, over a total range of the order of $1 \mathrm{~m} \mu$. Usually, the shift was towards the shorter waves; sometimes it was first towards the shorter and then back towards the longer waves.

Bands became narrower as the temperature decreased; often they were resolved into two or more components. The spectra were sometimes quite different, depending on whether the cooling was sudden or gradual (Figure 15).

The observed changes must have been due to two superimposed phenomena: (1) decrease in thermal vibrations in the ions and in the medium surrounding the ions, and (2) crystallization and re-crystallization. Cessation of thermal agitation would affect the spectrum even if the uranyl ions (and their balancing anions) remained scattered at random in the ice mass, as they may be upon sudden freezing. The arrangement of solvent molecules around each frozen-in uranyl cation may undergo discontinuous changes as the temperature is lowered. In addition to structures which are disorderly in respect to cations and anions but more or less orderly in respect to the immediate surroundings of each ion, phases containing cations, anions, and solvent molecules in true crystalline arrangement will arise if the rate of freezing is not fast compared to the rate of crystalliza tion. The more dilute the solutions, the smaller the chance of the ions being assembled into a crystal before their diffusion is stopped by solidification of the medium and the greater the likelihood of the spectrum retaining the broad-banded structure characteristic of an undercooled solution. 


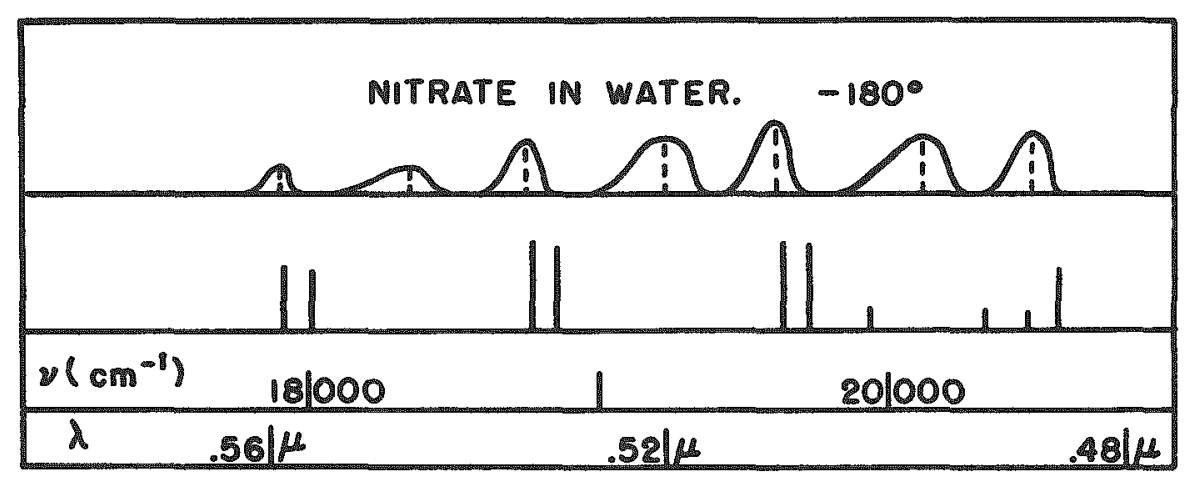

Figure 15

URANYL NITRATE SOLUTION (IM). FLUORESCENCE SPECTRUM AT - $180^{\circ} \mathrm{C}$ AFTER SNAP FREEZING AND AFTER SLOW COOLING TO SAME TEMPERATURE

(FROM NICHOLS AND HOWES, 1919, FIGURE 96) 
As an example we reproduce Nichols and Howes' results obtained with uranyl nitrate. Figure 16 shows schematically the changes in the fluorescence spectrum of $1 \mathrm{M} \mathrm{UO} \mathrm{UO}_{2}\left(\mathrm{NO}_{3}\right)_{2}$ solution upon cooling: First, the number of diffuse fluorescence bands is increased from two at $+20^{\circ}$ to four at $0^{\circ}$ and $-18^{\circ} \mathrm{C}$; then, between $-18^{\circ}$ and $-25^{\circ} \mathrm{C}$, a transformation occurs which leads to the appearance of three new diffuse double bands. At still lower temperatures, the longer wave components of these double bands split into sharp doublets, while the shorter-wave components become weaker and remain diffuse. By very slow cooling, the diffuse components can be made to disappear altogether, while snap-freezing to $-180^{\circ} \mathrm{C}$ leads to a spectrum with both sets of bands still diffuse and about equal in intensity (Figure 15).

Upon heating, the spectral transformations which had occurred in slow cooling between $-60^{\circ}$ and $-180^{\circ} \mathrm{C}$ were reversed, but above $-60^{\circ} \mathrm{C}$ the change back to the broad double bands failed to occur; at $-18^{\circ} \mathrm{C}$ (the cryohydrate point) the spectrum of the unfrozen solution reappeared.

As anticipated above, the changes were less sharp in $0.1 \mathrm{M}$ and $0.01 \mathrm{M}$ than in $1 \mathrm{M}$ solution.

The fluorescence bands which failed to become dissolved into sharp lines at $-180^{\circ} \mathrm{C}$ in neutral aqueous solution did so in the presence of a small excess of nitrate ions (Figure 17). In the presence of a large excess of nitrate ions, on the other hand, all bands remained diffuse even at $-180^{\circ} \mathrm{C}$ (Figure 18).

In $50 \%$ aqueous alcohol the low-temperature fluorescence spectra were quite different from those of aqueous solutions (Figure 19). Some spectra obtained under these conditions (e.g.., that of $0.1 \mathrm{M}$ uranyl nitrate in $50 \%$ ethanol at $-185^{\circ} \mathrm{C}$ ) indicated co-existence of two sets of bands, one sharp and one diffuse. These may correspond to hydrated and ethanolated uranyl ions, respectively.

Germann (1922) inquired whether the five different fluorescence spectra of frozen uranyl nitrate solution, observed by Nichols and Howes, could all belong to the same crystal hydrate. Systematic density measure ments and thermal analysis convinced him that, in addition to the hexahy drate, another hydrate, $\mathrm{UO}_{2}\left(\mathrm{NO}_{3}\right)_{2} \cdot 24 \mathrm{H}_{2} \mathrm{O}$, stable between $-35^{\circ}$ and $-20^{\circ} \mathrm{C}$, occurred in these systems. He interpreted Nichols and Howes' spectra as belonging to various mixtures of the hexahydrate with this "ikositetrahydrate."

Gordon (1950) measured the position of fluorescence bands in a frozen solution of $\mathrm{UO}_{2} \mathrm{SO}_{4}$ and found them to be identical with those of crystals of $\mathrm{UO}_{2} \mathrm{SO}_{4} \cdot 3 \mathrm{H}_{2} \mathrm{O}$ (type II) obtained by fast crystallization. 


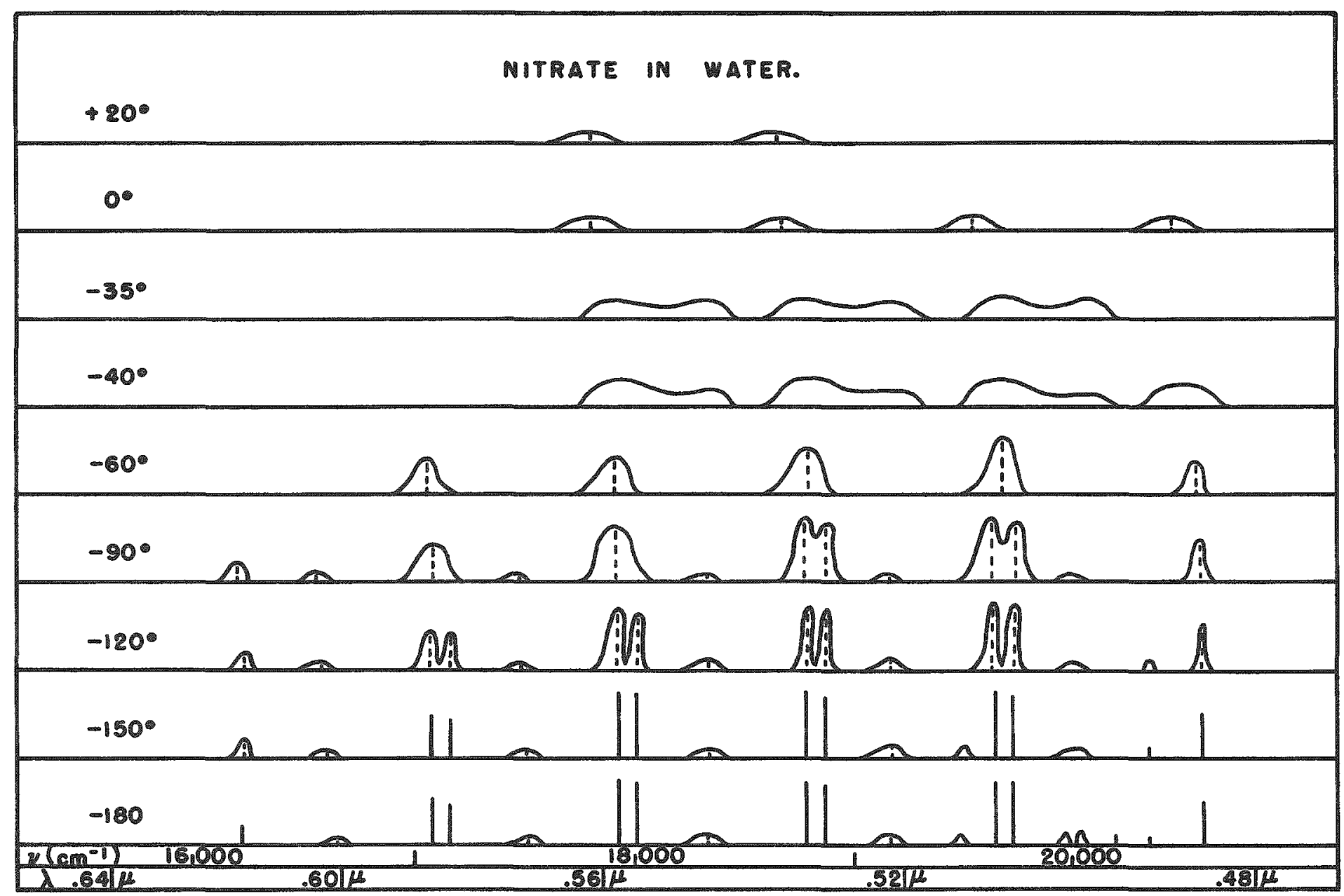

Figure 16

URANYL NITRATE SOLUTION (IM). CHANGES IN FLUORESCENCE SPECTRUM UPON COOLING (FROM NICHOLS AND HOWES, 1919, FIGURE 97) 


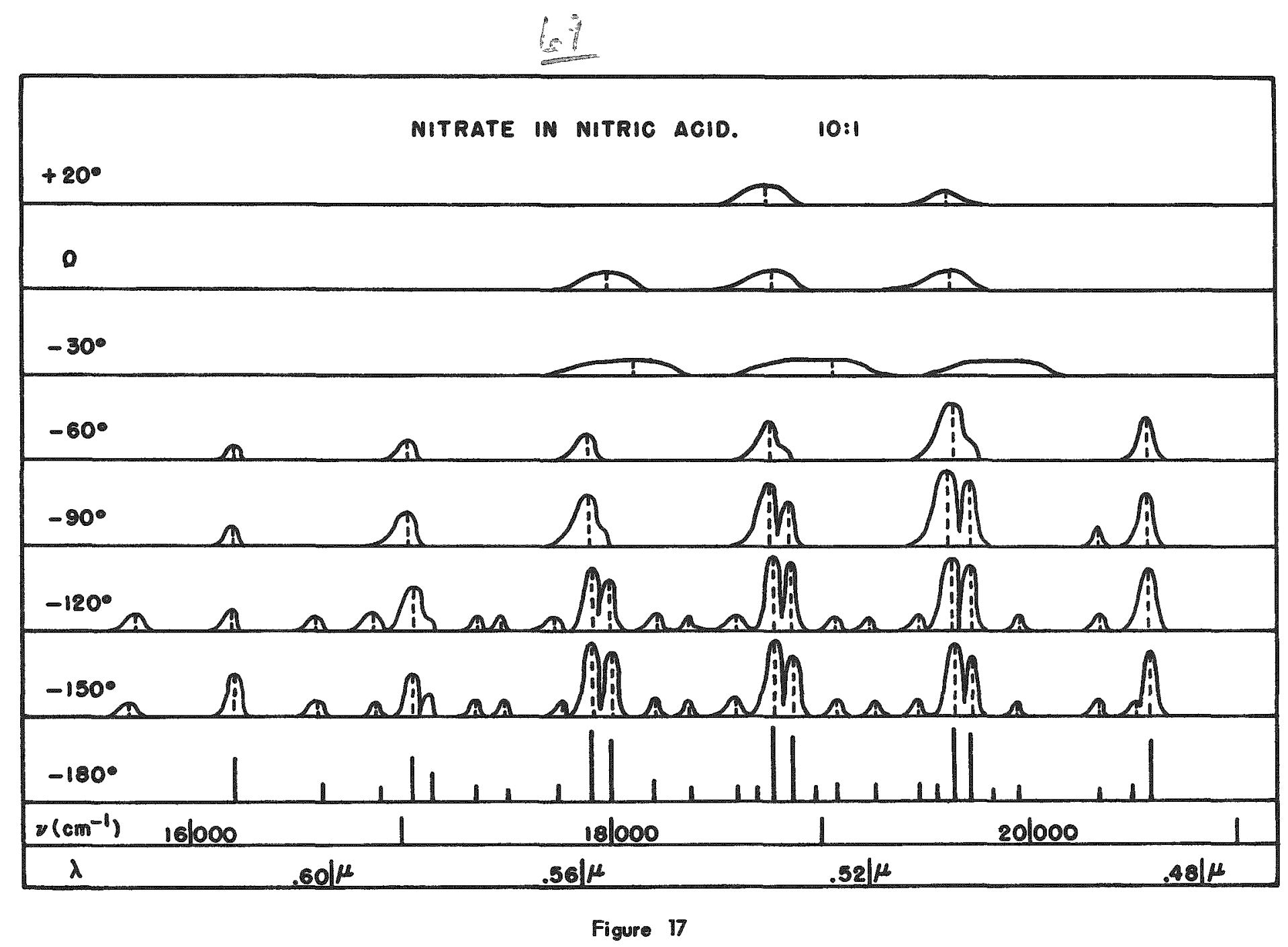

URANYL NITRATE SOLUTION (IM). FLUORESCENCE SPECTRUM

IN PRESENCE OF EXCESS NITRIC ACID

(FROM NICHOLS AND HOWES, 1919, FIGURE 101) 


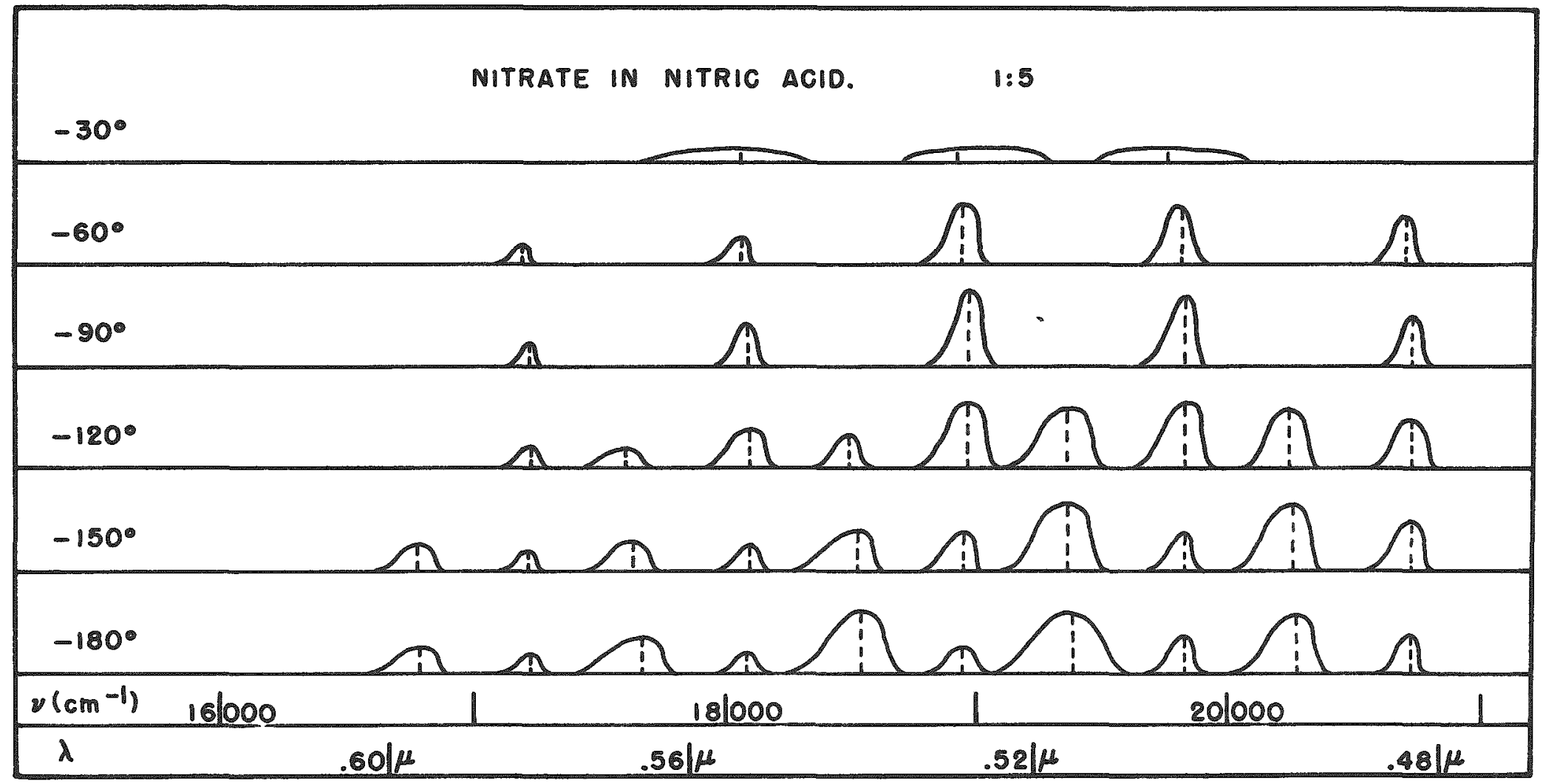

Figure 18

URANYL NITRATE SOLUTION (IM). FLUORESCENCE SPECTRUM

IN LARGE EXCESS OF NITRIC ACID

(FROM NICHOLS AND HOWES, 1919, FICURE 104) 
7

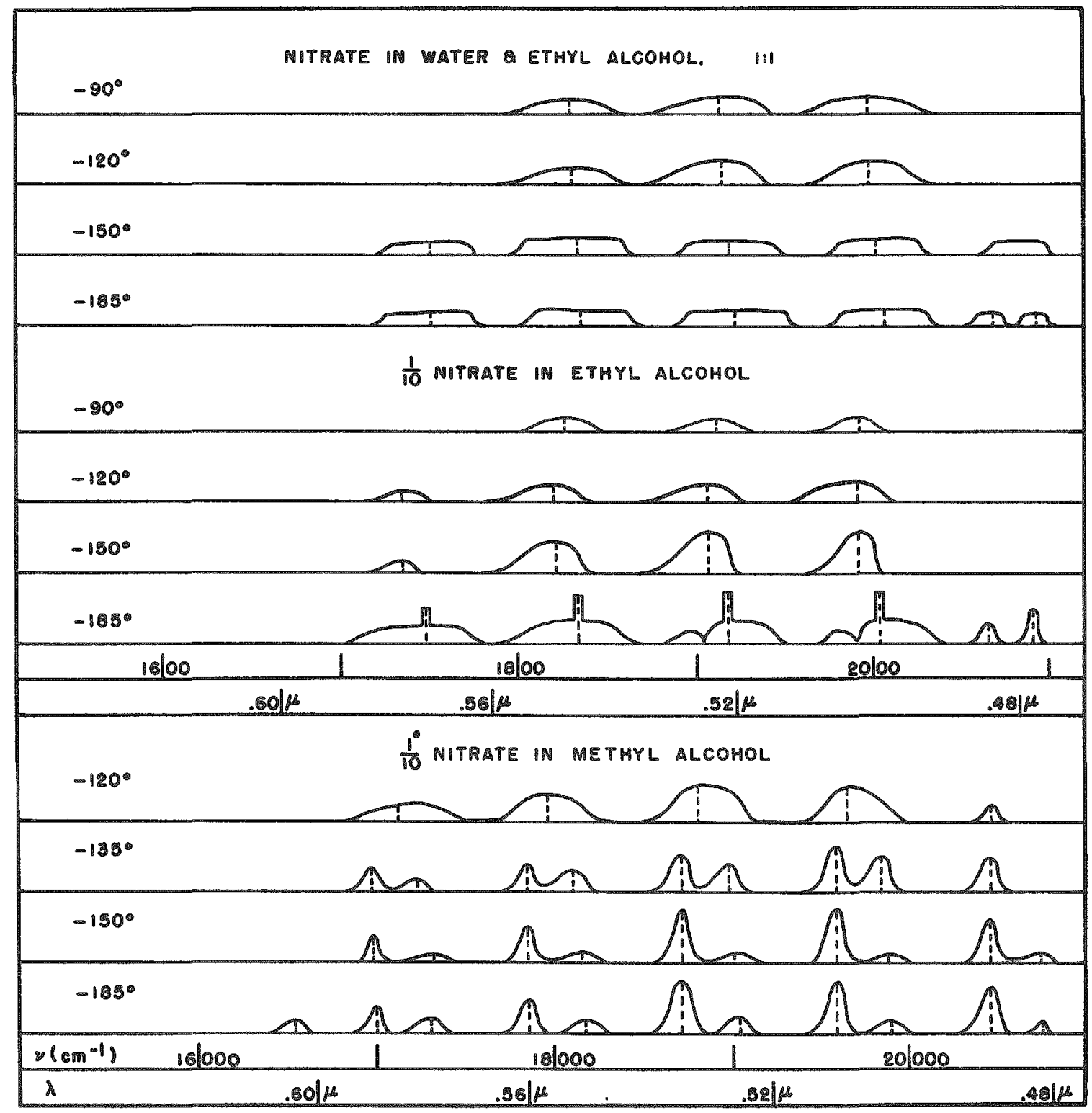

Figure 19

URANYL NITRATE SOLUTION (IM). FLUORESCENCE SPECTRUM IN WATER AND ALCOHOL (AFTER NICHOLS AND HOWES, 1919, FIGURE 106) 


\section{2}

5.9 Miscellaneous Observations - Ephraim and Mezener (1933) wanted to know whether a rule, discovered by Ephraim in the spectra of rare earth salts, that the cation bands are shifted towards the shorter waves with in creasing polarizing action of the anion, applies also to uranium. They noted that the data of Nichols and Howes in fact show a shift of uranyl bands in double salts towards shorter waves with increased polarizability - of the alkali ion. This shift is particularly clearly recognizable in fluorescence spectra.

Ephraim and Mezener's own measurements of reflection spectra of certain uranyl halides, such as $\mathrm{UO}_{2} \mathrm{Br}_{2} \cdot 7 \mathrm{H}_{2} \mathrm{O}, \mathrm{UO}_{2} \mathrm{~F}_{2} \cdot 3 \mathrm{KF}, \mathrm{UO}_{2} \mathrm{Br}_{2} \cdot 2 \mathrm{KBr} \cdot 2 \mathrm{H}_{2} \mathrm{O}$, and $\mathrm{UO}_{2} \mathrm{Br}_{2} \cdot 2 \mathrm{NH}_{3} \mathrm{Br}$, at the temperature of liquid air, gave results in general agreement with the rule. Double nitrates were found to be unsuitable for comparison because of differences in the crystal system and consequent variations in the spectrum. Uranyl nitrate crystals with $0,2,3$, and 6 molecules of water also had very different spectra (cf. Section 5.6), but the intervals between bands in a given series showed a systematic decrease with increasing number of water molecules. $\mathrm{n}$ (from $885 \mathrm{~cm}^{-1}$ at $\underline{n}=0$ to $860 \mathrm{~cm}^{-1}$ at $\underline{n}=6$ ). Double sulfates exhibited shifts similar to those in double halides.

Ephraim and Mezener used these results (as well as similar obser = vations with $U($ IV) and $U($ III) salts) to argue in favor of considering uranium as a "rare earth" rather than as a homologue of titanium and wolfram - a point of view which has later received support from the work on transuranium elements. 


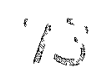

\section{REFERENCES}

1833 D. Brewster, Trans. Roy. Soc. Edinburgh, 12.

1852 G. G. Stokes, Phil. Trans., 142;517.

1853 G. G. Stokes, Phil. Trans., 143: 385.

1872 E. Becquerel, Compt. rend., 75: 296.

1873 H. Morton and H. C. Bolton, Chem. News, 28: 47, 113, 164, 233, 244, $257,268$.

1909 H. Becquerel, J. Becquerel, and H. Kamerlingh Onnes, Verslag Akad. Wetenschap. Amsterdam 17: 1045.

1910 H. Becquerel, J. Becquerel, and H. Kamerlingh Onnes, Compt. rend., 150: 647: Ann. chim. phys. 8, 20: 145.

1914 E. L. Nichols and E. Merritt, Phys.Rev., 3:457.

1915 H. L. Howes, Phys. Rev., 6: 193.

1916 H. L. Howes and D. T. Wilber, Phys. Rev., 7: 394.

1917 H. L. Howes and D. T. Wilber, Phys. Rev., 10:348.

1918 W. W. Coblentz, Nat. Bur. Standards, (U.S.), Sci. Paper No. 325.

1918 H. L. Howes, Phys. Rev., 11:66

1919 E. L. Nichols and H. L. Howes, "Fluorescence of the Uranyl Salts," Carnegie Inst. Wash. Pub., 298.

1919 E. I. Nichols, H. L. Howes and F. G. Wick, Phys. Rev., 14: 201-221.

1922 L. J. Boardman, Phys, Rev., 20: 552.

1922 F. E. E. Germann, J. Am. Chem. Soc., 44: 1468.

1925 G. H. Dieke and A. C. S. van Heel, Verslag Akad. Wetenschap. Amsterdam, 34: 652; Proc. Acad. Sci. Amsterdam, 28: 953; Communs. Kamerlingh Onnes Lab. Univ. Leiden, Supp1. 55a.

1925 A. C. S. van Heel, Verslag Akad. Wetenschap. Amsterdam, 34: 654; Proc. Acad. Sci. Amsterdam, 28: 955.

1927 T. Dreisch, Z. Physik., 40:714.

1933 F. Ephraim and M. Mezener, Helv. Chim. Acta, 16:1257.

1938 G. K. T. Conn and C. K. Wu, Trans. Faraday Soc., 34: 1483-1492.

1939 N. F. Moerman and H. H. Kraak, Rec. trav. chim., 58: 34.

1941 J. Lecomte and R. Freymann, Bull. soc. chim., 8: 622.

1944 D. D. Pant and N. D. Sakhwalkar, Proc. Indian Acad. Sci., A19:135.

1945 D. D. Pant, Proc. Indian Acad. Sci., A22: 95, 110. 
1946 M. Freymann, T. Guilmart and R. Freymann, Compt. rend., 223: 545, 573.

1947 M. Freymann, Compt. rend., 225: 529.

1947 V. L. Levshin and G. D. Sheremetjev, Zhur. Eksptl. T eoret. Fiz., 17: 209.

1948 M. Freymann, Compt. rend., 226: 332; M. Freymann and R. Freymann, Compt. rend., 227: 1096.

1948 B. N. Samojlov, Zhur. Ekspt1. Teoret. Fiz., 18: 1030.

1949 G. H. Dieke and A. B. F. Duncan, "Spectroscopic Properties of Uranium Compounds," National Nuclear Inergy Series, Division III, Volume 2, McGraw-Hill Book Company, Inc., New York.

1949 A. N. Sevchenko, Bull. acad. Sci. U.R. S. S., Ser.phys., 13: 188.

1949 A. N. Sevchenko and B. I. Stepanov, Zhur. Eksptl. Teoret. Fiz., 19: 1113.

1950 B. E. Gordon, Doklady Akad. Nauk. S. S. S. R., 74: 913.

1951 A. N. Sevchenko and B. I. Stepanov, Zhur. Ekspt1. Teoret. Fiz., 21: 212.

1951 A. N. Sevchenko, V. M. Vdovenko and T. V. Kovaleva, Zhur. Ekspt1. Teoret. Fiz., 21: 204. 